NISTIR 6866

\title{
Comparison of CFAST and FDS for Fire Simulation with the HDR T51 and T52 Tests
}

Jason E. Floyd 


\section{Comparison of CFAST and FDS for Fire Simulation with the HDR T51 and T52 Tests}

Jason E. Floyd

Fire Research Division

Building and Fire Research Laboratory

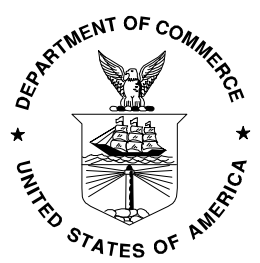

U.S. Department of Commerce Donald L. Evans, Secretary

Technology Administration Phillip J. Bond, Under Secretary for Technology 


\title{
COMPARISON OF CFAST AND FDS FOR FIRE SIMULATION WITH THE HDR T51 AND T52 TESTS
}

\begin{abstract}
This work uses three methods: hand calculations, a zone model code (CFAST), and a computational fluid dynamics code (FDS), to examine two fire tests from the HDR facility, a decommissioned reactor containment building in Germany. The two tests, T51.23 and T52.14, used different fuels, propane gas and a hydrocarbon solvent, and occurred in two quite different locations, low in the containment and just below the containment operating deck, respectively.

The two tests pose different challenges for analysis. The T51.23 test contains a simple fuel, propane gas premixed with air, but a fairly complex geometry for the fire compartment with restricted ventilation. The T52.14 test uses a more complex fuel, a hydrocarbon solvent that burned in an underventilated manner, with a somewhat simpler geometry for the fire compartment. However, the T52.14 test contained a large atria-like space in close proximity to the fire room which poses an additional challenge. Together these two tests examine the suitability of computational methods for calculating fires in structures containing multiple levels with complex compartment interconnections.
\end{abstract}




\section{TABLE OF CONTENTS}

LIST OF TABLES $\ldots \ldots \ldots \ldots \ldots \ldots \ldots \ldots \ldots \ldots \ldots \ldots \ldots \ldots \ldots \ldots \ldots$

LIST OF FIGURES $\ldots \ldots \ldots \ldots \ldots \ldots \ldots \ldots \ldots \ldots \ldots \ldots \ldots \ldots \ldots \ldots$ vii

$1.0 \quad$ INTRODUCTION $\ldots \ldots \ldots \ldots \ldots \ldots \ldots \ldots \ldots \ldots \ldots \ldots \ldots \ldots \ldots \ldots \ldots \ldots$

2.0 OPEN ISSUES IN FIRE MODELING $\ldots \ldots \ldots \ldots \ldots \ldots \ldots \ldots \ldots \ldots \ldots$

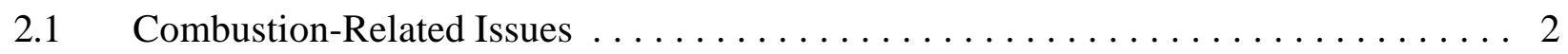

2.2 Mass Flow and Heat Transfer Issues $\ldots \ldots \ldots \ldots \ldots \ldots \ldots \ldots \ldots \ldots \ldots$

2.3 Issues Regarding Human Factors in Computer Code Applications . . . . . . . . . . . . 4

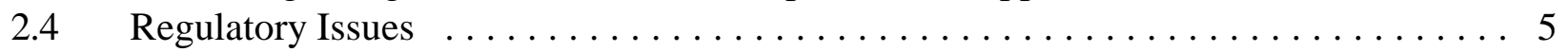

3.0 OVER VIEW OF CALCULATIONAL METHODS $\ldots \ldots \ldots \ldots \ldots \ldots \ldots \ldots$

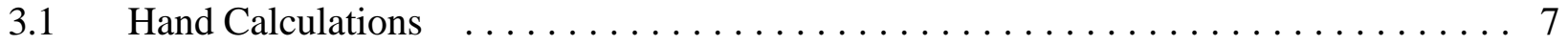

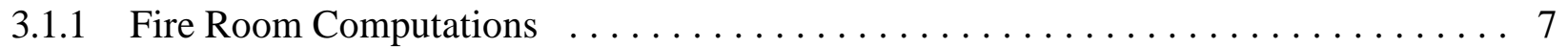

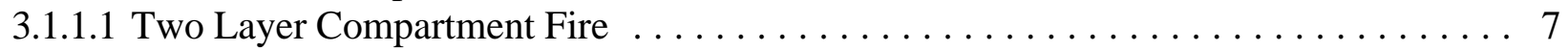

3.1.1.2 Single Layer Compartment Fire $\ldots \ldots \ldots \ldots \ldots \ldots \ldots \ldots \ldots \ldots$

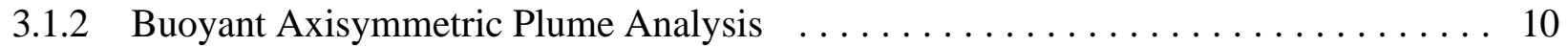

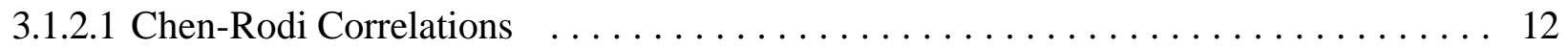

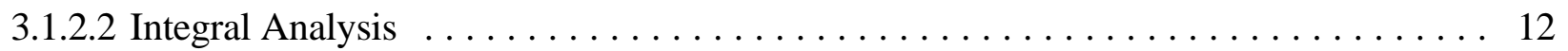

$3.2 \quad$ Fire Dynamics Simulator $\ldots \ldots \ldots \ldots \ldots \ldots \ldots \ldots \ldots \ldots \ldots \ldots \ldots \ldots$

3.2 .1 Code Description and History $\ldots \ldots \ldots \ldots \ldots \ldots \ldots \ldots \ldots \ldots \ldots \ldots$

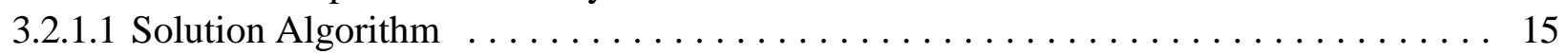

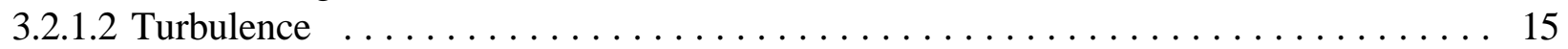

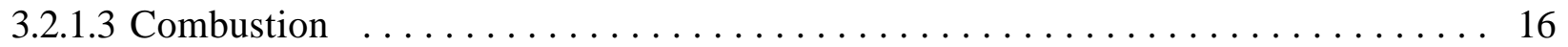

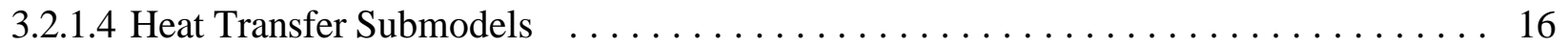

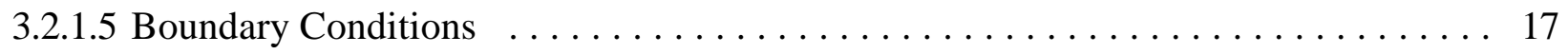

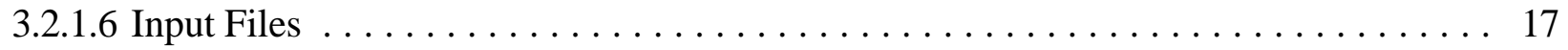

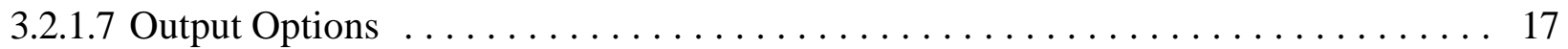

3.2 .2 Summary of NIST Validation Efforts $\ldots \ldots \ldots \ldots \ldots \ldots \ldots \ldots \ldots \ldots \ldots$

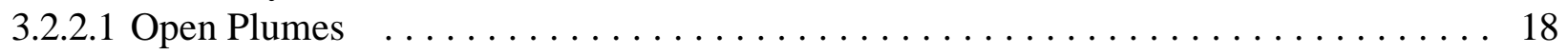

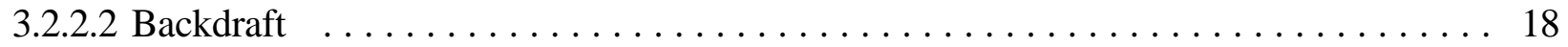

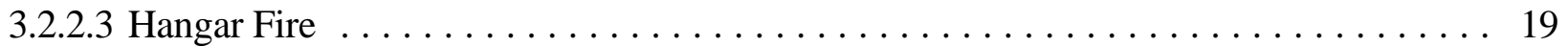

3.2.2.4 Flashover ... . . . . . . . . . . . . . . . . . . . . . . . 19

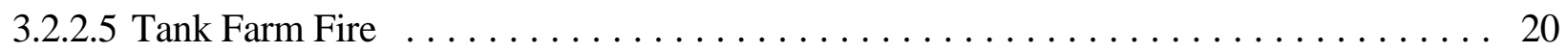

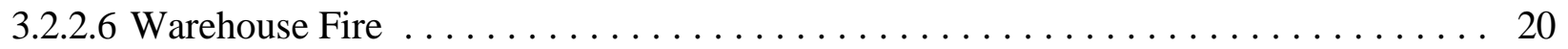

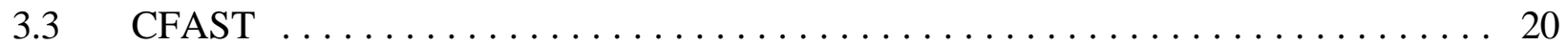

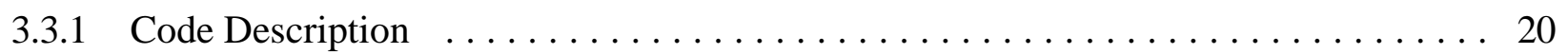

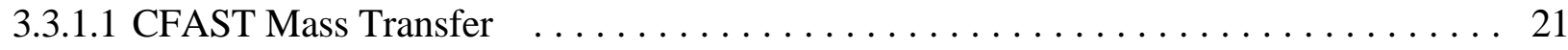

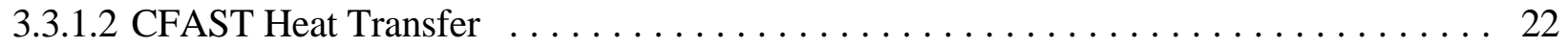

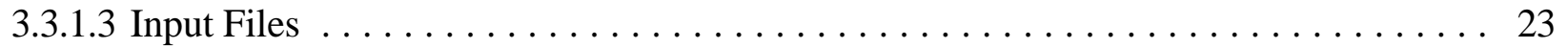

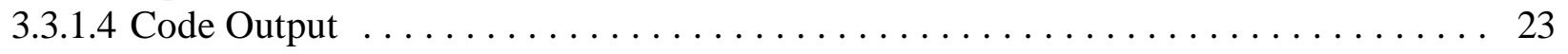




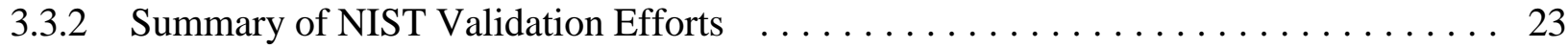

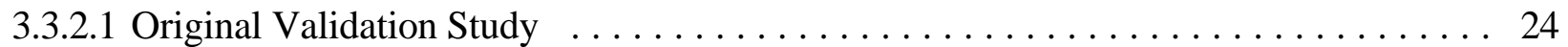

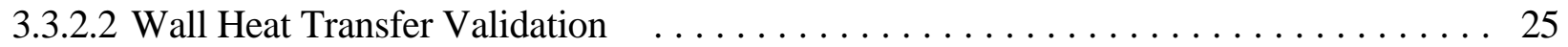

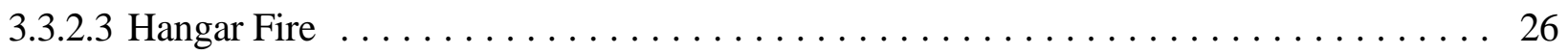

3.3.2.4 Smoke Layer Development $\ldots \ldots \ldots \ldots \ldots \ldots \ldots \ldots \ldots \ldots \ldots \ldots \ldots \ldots$

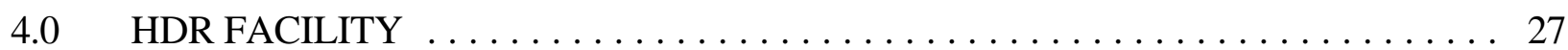

4.1 SUMMARY OF Facility AND FIRE TEST SERIES $\ldots \ldots \ldots \ldots \ldots \ldots \ldots \ldots 27$

4.2 T51 GAS FIRE TEST DESCRIPTION $\ldots \ldots \ldots \ldots \ldots \ldots \ldots \ldots \ldots \ldots \ldots . \ldots \ldots 28$

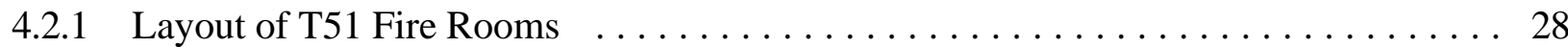

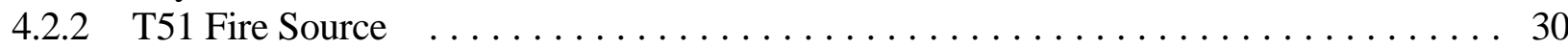

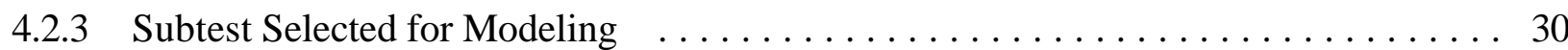

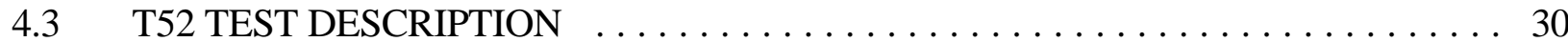

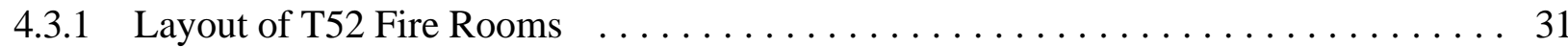

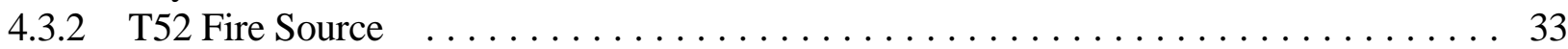

4.3.3 Subtest Selected for Modeling $\ldots \ldots \ldots \ldots \ldots \ldots \ldots \ldots \ldots \ldots \ldots \ldots \ldots \ldots \ldots \ldots \ldots \ldots \ldots$

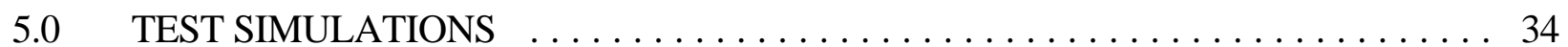

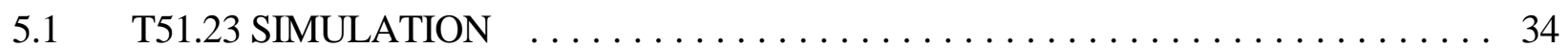

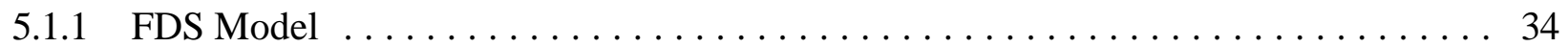

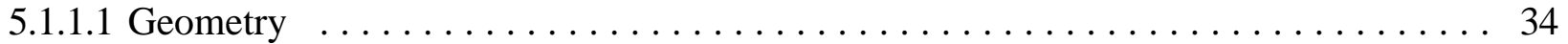

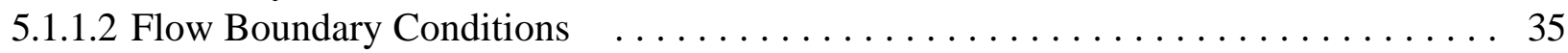

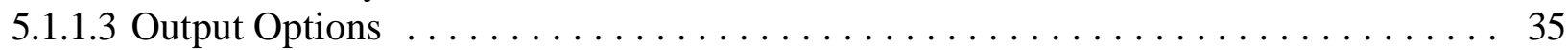

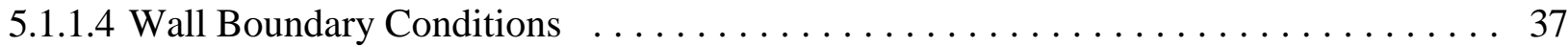

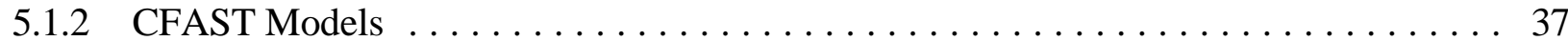

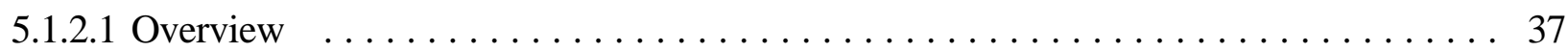

5.1.2.2 Compartment Specifications and Compartment Interconnections $\ldots . \ldots \ldots \ldots . \ldots 39$

5.1 .3 Hand Calculations .................................... 34

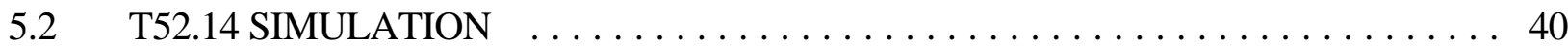

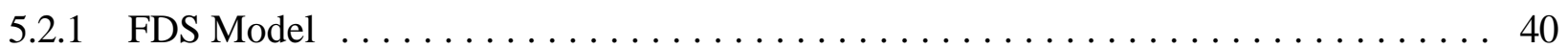

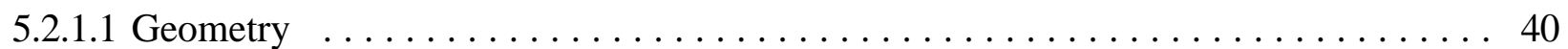

5.2 .1 .2 Flow Boundary Conditions $\ldots \ldots \ldots \ldots \ldots \ldots \ldots \ldots \ldots \ldots \ldots \ldots, \ldots \ldots \ldots$

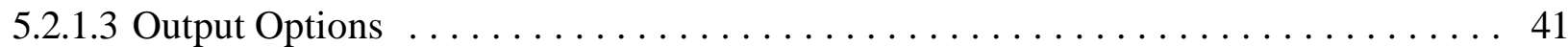

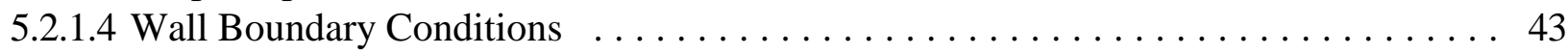

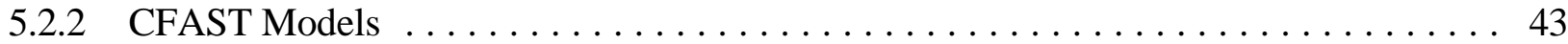

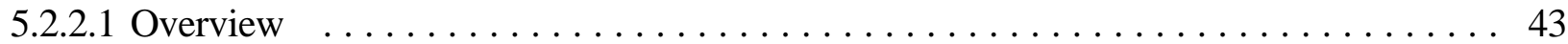

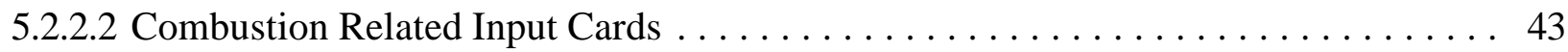

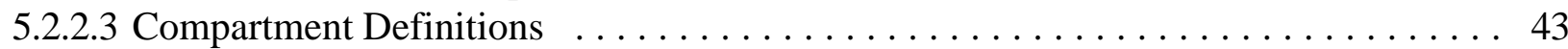

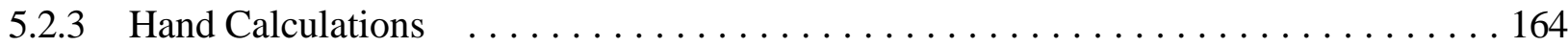




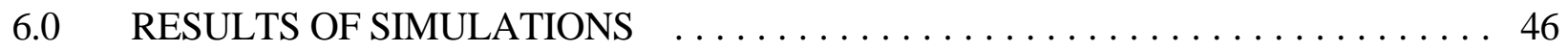

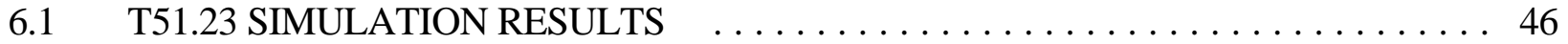

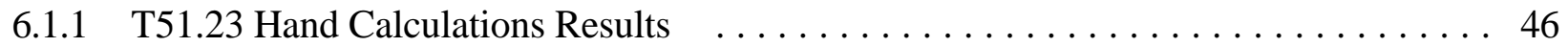

6.1 .2 T51.23 CFAST Results $\ldots \ldots \ldots \ldots \ldots \ldots \ldots \ldots \ldots \ldots \ldots \ldots \ldots \ldots$

6.1.2.1 T51.23 CFAST Temperature Predictions $\ldots \ldots \ldots \ldots \ldots \ldots \ldots \ldots \ldots \ldots$

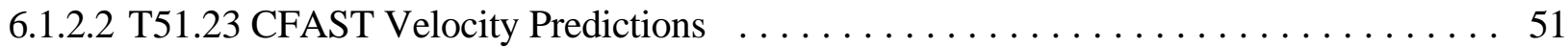

6.1.2.3 T51.23 CFAST Gas Concentration Predictions $\ldots \ldots \ldots \ldots \ldots \ldots \ldots \ldots$

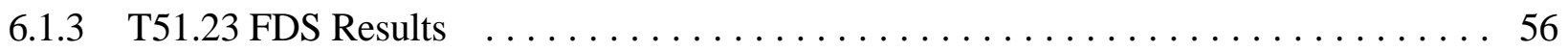

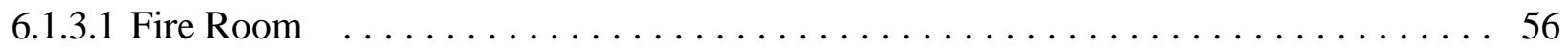

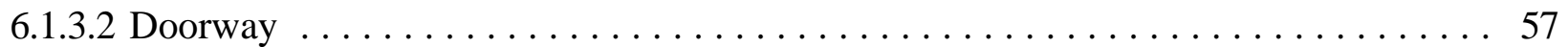

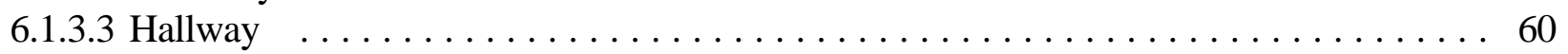

6.1 .4 Intercomparison of All Analysis Methods $\ldots \ldots \ldots \ldots \ldots \ldots \ldots \ldots \ldots \ldots \ldots$

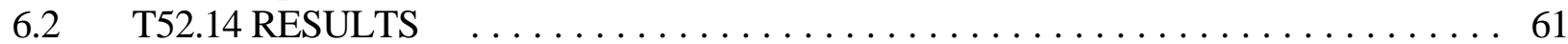

6.2 .1 T52.14 Hand Calculations Results $\ldots \ldots \ldots \ldots \ldots \ldots \ldots \ldots \ldots \ldots \ldots \ldots$

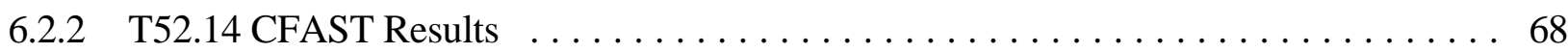

6.2 .2 .1 T52.14 CFAST Temperature Results $\ldots \ldots \ldots \ldots \ldots \ldots \ldots \ldots \ldots \ldots \ldots$

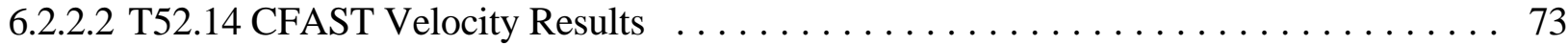

6.2.2.3 T52.14 CFAST Gas Concentration Results . . . . . . . . . . . . . . . . . . . . 74

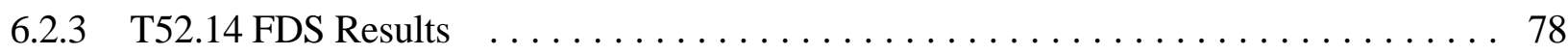

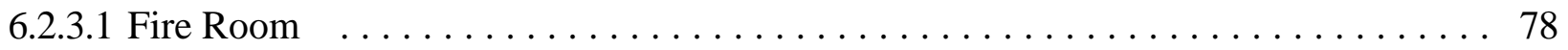

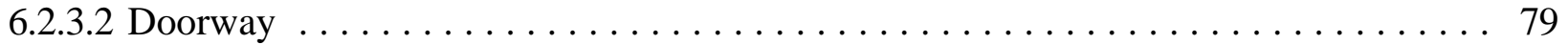

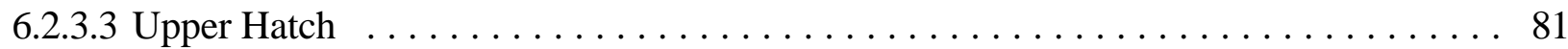

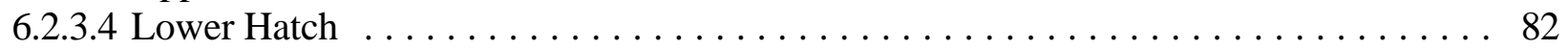

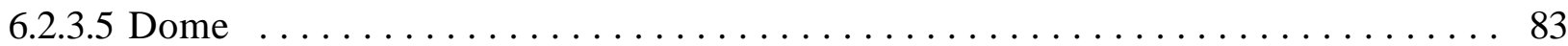

6.2.4 Intercomparison of All Analysis Methods $\ldots \ldots \ldots \ldots \ldots \ldots \ldots \ldots$

7.0 SUMMARY OF PERFORMANCES AND USABILITY $\ldots \ldots \ldots \ldots \ldots \ldots$

7.1 SUMMARY OF T51.23 RESULTS $\ldots \ldots \ldots \ldots \ldots \ldots \ldots \ldots \ldots \ldots \ldots$

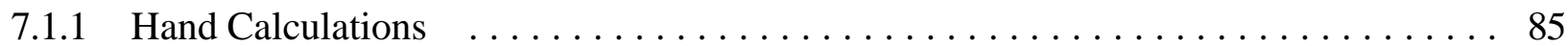

7.1 .2 CFAST Calculations $\ldots \ldots \ldots \ldots \ldots \ldots \ldots \ldots \ldots \ldots \ldots \ldots \ldots \ldots$

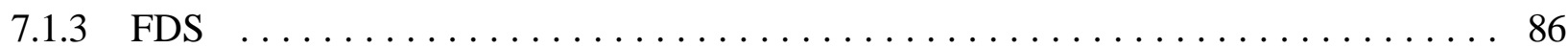

$7.2 \quad$ SUMMARY OF T52.14 RESULTS $\ldots \ldots \ldots \ldots \ldots \ldots \ldots \ldots \ldots \ldots$

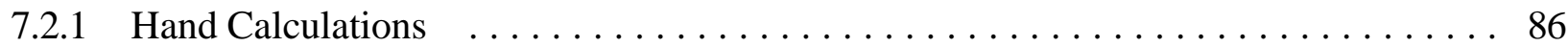

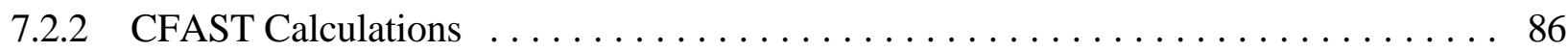

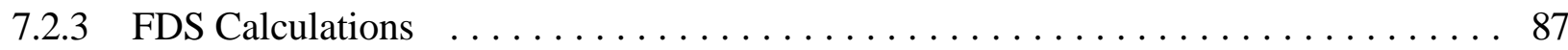

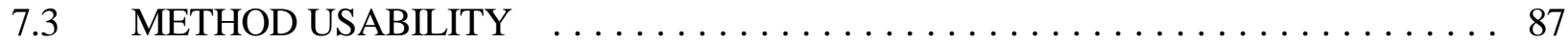

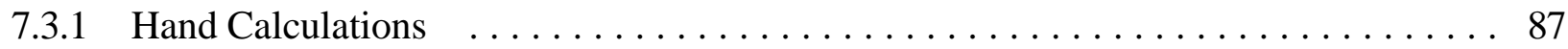

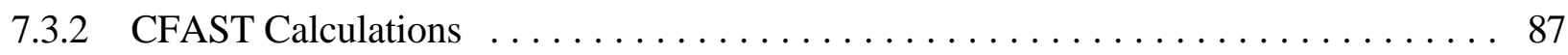

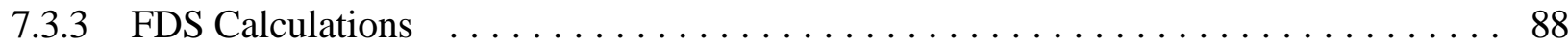

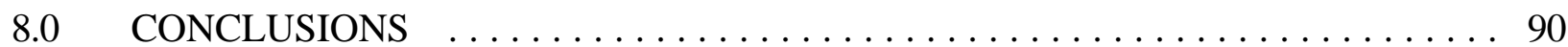

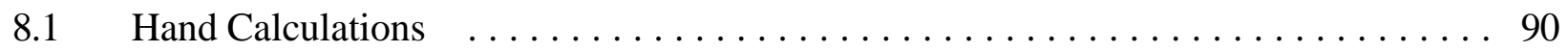

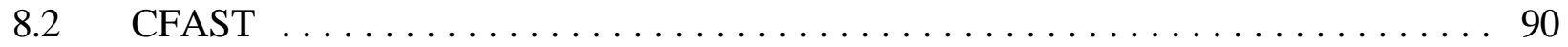

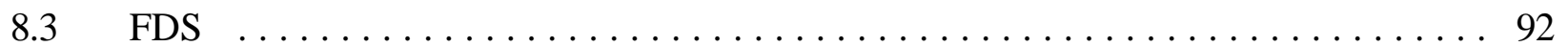


9.0 WORKS CITED

10.0 ADDITIONAL REFERENCES 


\section{LIST OF TABLES}

Table 2.1: Fire Simulation Accuracy Criteria $\quad \ldots \ldots \ldots \ldots \ldots \ldots \ldots \ldots \ldots \ldots \ldots \ldots \ldots \ldots \ldots$

Table 3.1: CFAST Validation Results for Upper Layer Peak Temperature . . . . . . . . . 24

Table 3.2: CFAST Validation Results for $\mathrm{O}_{2}$ and $\mathrm{CO}_{2}$ Concentrations $\ldots \ldots \ldots \ldots \ldots$

Table 3.3: CFAST Validation Results for Mass Flow Rates. . . . . . . . . . . . . . . . 25

Table 4.1: T51 Fire Compartment Dimensions . . . . . . . . . . . . . . . . . . 29

Table 4.2: T52 Fire Compartment Dimensions $\ldots \ldots \ldots \ldots \ldots \ldots \ldots \ldots \ldots \ldots \ldots \ldots \ldots$

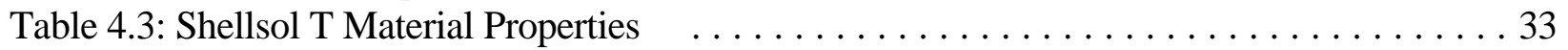

Table 6.1: T51.23 Hand Calculation Results vs. Measured Data . . . . . . . . . . . . 46

Table 6.2: Steady State Fire Room Predictions for All T51.23 Analyses Compared to Data . . 61

Table 6.3: T51.23 Hand Calculation Results vs. Measured Data . . . . . . . . . . . . . 62

Table 6.4: T52.14 Measure Fire Room Doorway Average Temperatures $\ldots \ldots \ldots \ldots$. . . 63

Table 6.5: T52.14 Measure Fire Room Doorway Average Velocities $\ldots \ldots \ldots \ldots$. . . . . 63

Table 6.6: T52.14 Plume Hand Calculation Results $\ldots \ldots \ldots \ldots \ldots \ldots \ldots$. . . . . . . . 64

Table 6.7: T52.14 Mass Flow Rates at Key Locations $\ldots \ldots \ldots \ldots \ldots \ldots \ldots$. . . . . . . . 67

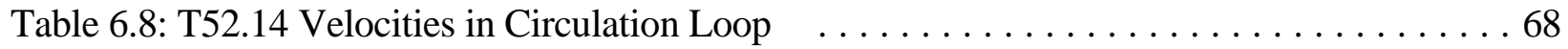

Table 6.9: T52.14 FDS Results for the Fire Room During Fire Peak . . . . . . . . . . . . . 79

Table 6.10: T52.14 FDS Results for the Doorway During Fire Peak $\ldots \ldots \ldots \ldots . \ldots . . . . .81$

Table 6.11: T52.14 FDS Results for the Upper Hatch During Fire Peak $\ldots \ldots \ldots . \ldots . . . .82$

Table 6.12: T52.14 FDS Results for the Lower Hatch During Fire Peak . . . . . . . . . . 82

Table 6.13: T52.14 FDS Results for the Upper Sensor Grid During Fire Peak $\ldots . . . . .84$

Table 6.14: Steady State Fire Room Predictions for All T52.14 Analyses vs. Data . . . . . 84 


\section{LIST OF FIGURES}

Figure 3.1: Compartment Fire with Two Layers (Distinct Thermocline) $\ldots \ldots \ldots \ldots \ldots$

Figure 3.2: Compartment Fire with a Single Layers (No Distinct Thermocline) $\quad \ldots \ldots \ldots \ldots$

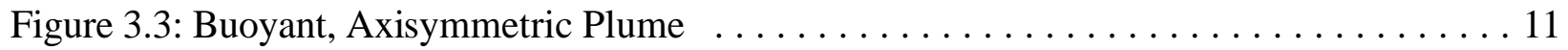

Figure 4.1: HDR Facility and Fire Test Locations $\ldots \ldots \ldots \ldots \ldots \ldots \ldots \ldots \ldots \ldots \ldots$

Figure 4.2: T51 Fire Floor $(1.400$ Level $) \quad \ldots \ldots \ldots \ldots \ldots \ldots \ldots \ldots \ldots \ldots \ldots \ldots$

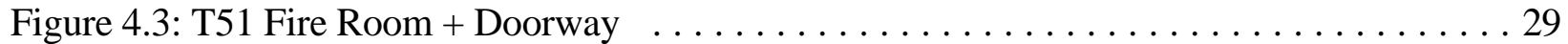

Figure 4.4: T52 Fire Floor $(1.900$ Level $) \quad \ldots \ldots \ldots \ldots \ldots \ldots \ldots \ldots \ldots \ldots \ldots \ldots \ldots \ldots$

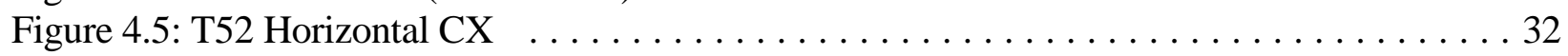

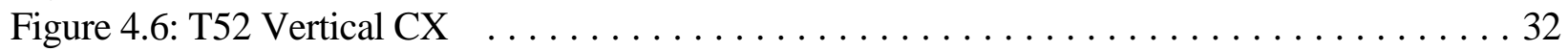

Figure 4.7: T52.14 Burning Rate and Test Phase Definitions $\quad \ldots \ldots \ldots \ldots \ldots \ldots \ldots \ldots$

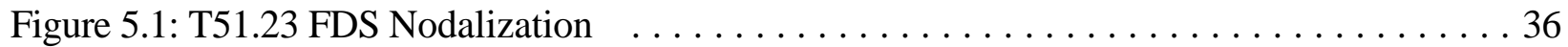

Figure 5.2: CFAST Model D Compartment Layout $\ldots \ldots \ldots \ldots \ldots \ldots$

Figure 5.3: T52.14 FDS Nodalization for Fire Level+Dome Input Geometry with

Cutaway to Show Hatch Connection to Dome . . . . . . . . . . . . . . . 42

Figure 5.4: CFAST Compartment Layout for T52.14 Model C . . . . . . . . . . . . . 44

Figure 6.1: T51.23 Fire Room Upper Layer Temperatures, Measured vs. CFAST . . . . . . 48

Figure 6.2: T51.23 Fire Room Lower Layer Temperatures, Measured vs. CFAST . . . . . . 48

Figure 6.3: T51.23 Hallway Upper Layer Temperatures, Measured vs. CFAST . . . . . . . 49

Figure 6.4: T51.23 Hallway Lower Layer Temperatures, Measured vs. CFAST . . . . . . . 49

Figure 6.5: T51.23 Level 1.600 Main Staircase Temperatures, Measured vs. CFAST . . . . . 50

Figure 6.6: T51.23 Dome Temperatures, Measured vs. CFAST $\ldots \ldots \ldots \ldots \ldots \ldots \ldots$

Figure 6.7: T51.23 Level 1.600 Spiral Staircase Temperatures, Measured vs. CFAST . . . . 51

Figure 6.8: T51.23 Doorway Velocities, Measured vs. CFAST $\ldots \ldots \ldots \ldots \ldots \ldots \ldots \ldots$

Figure 6.9: T51.23 Upper Hallway Velocity, Measured vs. CFAST . . . . . . . . . . . . . 52

Figure 6.10: T51.23 Lower Hallway Velocity, Measured vs. CFAST . . . . . . . . . . . . 53

Figure 6.11: T51.23 Velocity in Main Staircase 1.600/1.700 Hatch, Measured vs. CFAST . 53

Figure 6.12: T51.23 Oxygen Concentration in the Upper Doorway, Measured vs. CFAST . . 54

Figure 6.13: T51.23 Carbon Dioxide Concentration in the Doorway, Measured vs. 55

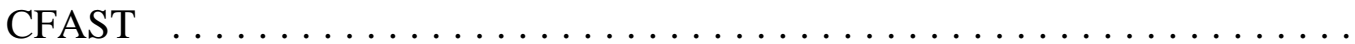

Figure 6.14: T51.23 Carbon Dioxide Concentration in the Hallway, Measured vs. CFAST . . 55

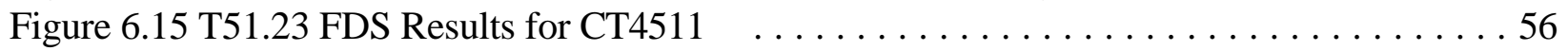

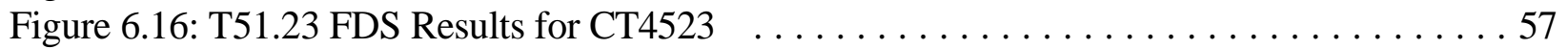

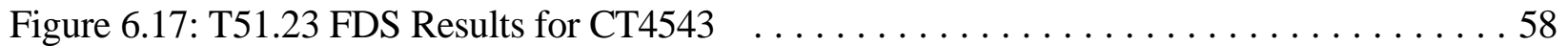

Figure 6.18: T51.23 FDS Doorway Temperature Profile $\ldots \ldots \ldots \ldots \ldots \ldots \ldots \ldots$

Figure 6.19: T51.23 Doorway Time Averaged Velocity Contours for FDS v1.0 . . . . . . . 59

Figure 6.20: T51.23 Doorway Time Averaged Velocity Contours for FDS v2.0 $\alpha$. . . . . . 59

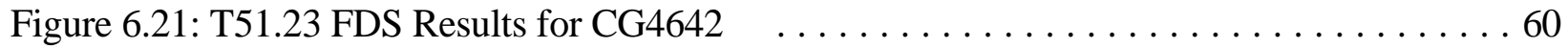

Figure 6.22: T51.23 FDS Hallway Temperature Profiles $\ldots \ldots \ldots \ldots \ldots \ldots \ldots \ldots$

Figure 6.23: T52.14 +31 m Sensor Grid Average Temperatures $\ldots \ldots \ldots \ldots \ldots \ldots . \ldots \ldots 6$

Figure 6.24: T52.14 +39 m Sensor Grid Average Temperatures $\ldots \ldots \ldots \ldots \ldots$

Figure 6.25: T52.14 +31 m Sensor Grid Average Velocities $\ldots \ldots \ldots \ldots \ldots \ldots \ldots$

Figure 6.26: T52.14 T52.14 +39 m Sensor Grid Average Velocities $\quad \ldots \ldots \ldots \ldots \ldots \ldots . \ldots 66$ 
Figure 6.27: T52.14 Fire Room Temperatures, Measured vs. CFAST . . . . . . . . . . . . 69

Figure 6.28: T52.14 CFAST Predicted Layer Heights $\ldots \ldots \ldots \ldots \ldots \ldots \ldots \ldots \ldots$

Figure 6.29: T52.14 Fire Level Hatch Upper Layer Temperatures, Measured vs. CFAST . . 71

Figure 6.30: T52.14 Upper Sensor Grid Temperatures, Measured vs. CFAST . . . . . . . . 72

Figure 6.31: T52.14 Level 1.600 Temps Near Spiral Staircase, Measured vs. CFAST . . . . . 72

Figure 6.32: T52.14 Doorway Layer Velocities, Measured vs. CFAST . . . . . . . . . . 73

Figure 6.33: T52.14 Fire Level to Dome Velocities, Measured vs. CFAST . . . . . . . . . 74

Figure 6.34: T52.14 Dome to Level 1.900 by Main Staircase Velocities, Measured vs.

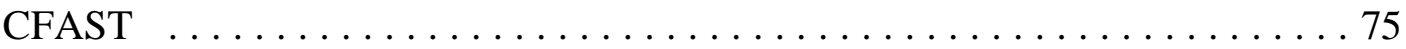

Figure 6.35: T52.14 Doorway Upper Layer $\mathrm{O}_{2}, \mathrm{CO}_{2}$, and $\mathrm{CO}$, Measured vs. CFAST $\ldots \ldots 75$

Figure 6.36: T52.14 $\mathrm{CO}_{2}$ Concentration at the Dome Hemispherical Head Over the Fire

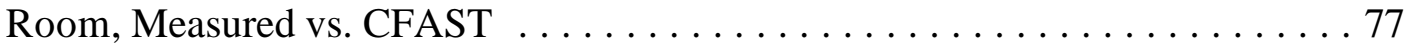

Figure 6.37: T52.14 $\mathrm{CO}_{2}$, in Upward Flow Path 1.700 Level, Measured vs. CFAST . . . . . 77

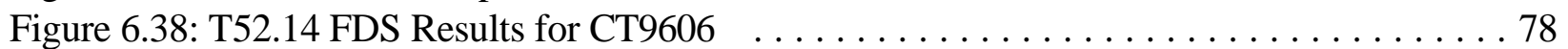

Figure 6.39: T52.14 FDS Results for Doorway Temperature Profile $\ldots \ldots \ldots \ldots$. . . . . . 80

Figure 6.40: T52.14 FDS Results for Doorway Velocity Profile $\ldots \ldots \ldots \ldots \ldots \ldots$ 


\section{$1.0 \quad$ INTRODUCTION}

This work examines the predictive capabilities of three methods ${ }^{*}$ : hand calculations ${ }^{1,2}$; CFAST, the Consolidated model of Fire growth And Smoke Transport ${ }^{3}$; and FDS, the Fire Dynamics Simulator $^{4}$. A brief description of each of the methods will be given. Then the simulation results will be compared against test data from two fire experiments performed in the HDR test facility $^{5}$ (Nowlen, 1995), the containment building from a decommissioned German nuclear reactor. The first experiment is the T51.23 gas fire experiment which involved a $1 \mathrm{MW}$ propane gas fire low in the containment building. The second experiment is the T52.14 oil pool fire experiment which was a $3 \mathrm{MW}$ oil fire high in the containment building.

The following is a brief discussion of the contents of the remainder this report:

Chapter 2 provides background information on some of the open issues with regards to fire modeling.

Chapter 3 gives a brief overview of the three methods used in this report.

Chapter 4 gives a brief description of the HDR facility and the fire experiments followed by an overview of the T51.23 and T52.14 tests.

Chapter 5 presents the development of the input files for the two HDR tests for the CFAST and FDS simulations as well as the approach taken for of the hand calculations.

Chapter 6 compares the results of the hand calculations and the CFAST and FDS simulations with the HDR measured data.

Chapter 7 summarizes the performance of the calculational results and the author's perception of the usability of the different methods.

Chapter 8 draws conclusions of the observed performance of each of the three computational methods with recommendations for future work.

*Certain commercial products are mentioned in this report in order to specify adequately the equipment used. Such identification does not imply recommendation or endorsement by the National Institute of Standards and Technology, nor does it imply that the equipment or products are necessarily the best available for the purpose. 


\subsection{OPEN ISSUES IN FIRE MODELING}

Current fire simulation tools have a number of open issues involving modeling assumptions and approximations that should be considered before they are accepted for risk prediction. Some of these open issues are identified in this subsection.

\subsection{Combustion-Related Issues}

When simulating the effects of a fire on a structure and/or its inhabitants, it should be obvious that the success of such a simulation is highly dependent on the successful specification of the fire source. Fires are a very complex phenomena. For many real-life fire sources, such as furniture or spilled organic fluids, the evolution of a fire is a result of a complex feedback interaction between the condensed phase and the gas phase of the fuel.

Fire codes are currently unable to perform more than simple, correlation-based computations for fire growth ${ }^{6}$. Rather than actually calculate the growth of the fire, it is typically left to the user to specify the time-dependent fire source explicitly in an input file. For many common items of furniture and for some common organic liquid fuels researchers have performed experiments to measure the burning rate of these items. However, given that the feedback between a fire and its fuel source is greatly dependent on the compartment in which the fire is located, these predetermined fire growth curves are not always applicable.

Another aspect of defining the fire source, is defining how the source combusts. Depending on available oxygen, fuel composition, fuel type, and temperatures reached, the resulting combustion products can differ widely from one fire to another both in terms of the numbers of chemical species produced and in the relative amounts. Unfortunately, for those who wish to calculate combustion product formation, the chemical reactions that take place during a fire are very complex and numerous. For example, to completely model methane combustion requires a score of reaction equations ${ }^{7}$. Solving such a large system of equations is not feasible to do for large structures, so simplifications must be made. Again, many fire codes make very simplistic assumptions regarding combustion products that tend to fail during highly underventilated combustion. This is especially unfortunate as it is during underventilated combustion that large quantities of lethal carbon monoxide are produced and transported throughout a structure. It is these products that are responsible for most, $76 \%$, of the deaths due to fire 8 .

\subsection{Mass Flow and Heat Transfer Issues}

There are essentially two classes of software tools used to model fires: control volume codes and field models. Control volume codes create a control volume for each room or subset of rooms in a structure. Field models create many nodes to explicitly represent a structure or subset of a structure with a finite-differenced computational grid. In this work, one computer code of each class has been used. CFAST and hand computations are the first type, and FDS is the second type. Both classes of models have a number of generic open issues, some of which are discussed herein. 
In a control volume code, the flow field is not explicitly solved for. Rather, correlations and basic fluid dynamics principles, such as Bernoilli's Equation, are used to generate the mass flow between compartments. Correlations are developed by a combination of experimental results and analysis of a particular type of mass transfer from first principles. As such, very complex flow fields tend not to be covered by correlations.

One such subset of flow geometries is large, area aspect ratio compartments which include hallways, vertical shafts, and atria. In a hallway, the long transport times for species to move from one end to another result in large changes in conditions along the length of a hall which is contrary to a control volume approach which assumes uniform conditions throughout a compartment. Vertical flows in control volume codes are mostly handled by some form of plume correlation which attempts to calculate the entrainment caused by the flow. However, these plume correlations are developed from either free plumes or wall/corner plumes. In a long vertical shaft a plume can assume a variety of flow conditions which are not handled by traditional correlations 9 . A plume can either act like a free plume, hug one wall of the shaft with a descending plume on the other side, rotate around the shaft in a random manner along with a descending plume, or completely fill the shaft. Furthermore, if the plume continues to support combustion a buoyancy enhancement effect will arise. While integral models have been developed to handle free plumes with combustion ${ }^{10}$, this author has been unable to locate any such models for confined plumes.

A second generic problem area for control volume codes is underventilated combustion. The very nature of a control volume approach homogenizes the spatially dependent gas concentrations in a compartment. As such only simplistic models of combustion are possible which will not accurately capture the true behavior which depends on local concentrations and temperatures. In a control volume code, the effects of a burning gas layer will be averaged over its control volume when in fact some of the effects would be localized. This affects combustion product formation, convective heat transfer due to high local temperatures in the prototype versus lower average temperatures in the model, and radiation heat transfer due to an intense local source in the prototype versus a more diffuse, global source of radiation in the model.

Lastly, heat transfer to surfaces is often difficult for a control volume code to properly account for. Since the flow field in a compartment is not being calculated, convective heat transfer to the walls can only be determined by the use of simple correlations using heat transfer coefficients. These correlations tend to be based on natural convention correlations for flat horizontal plates and flat vertical plates, e.g. ceilings/floors and walls. As such, significant errors can exist due to surface orientations and the actual compartment flow field so that either too much or too little heat transfer occurs to surfaces. Radiation heat transfer in control volume codes can only be handled by simple calculations as a control volume approach removes geometric information about the relative orientations of a compartment's surfaces. Since most rooms tend to be rectangular parallelepipeds, this can typically be accounted for. However, in oddly shaped rooms or for the radiant heat flux on a particular object or objects in a room, simple correlations based on rectangular rooms will not accurately calculate the heat transfer. 
Field models have their own generic issues. As with control volume models, the complex chemistry of a fire means that combustion models tend to be simple and in underventilated conditions may not function correctly. Since field models actually calculate the flow field, simulations of smoke propagation in hallways and vertical shafts, in theory, should not pose a problem. However, depending on the codes ability to resolve the eddy structures in fire driven flow, the entrainment into a hallway or shaft flow may not be correctly calculated. Furthermore, depending on the resolution of the noding, correlations for wall heat transfer may still be required. Lastly, since field models preserve geometric information, radiation heat transfer can be calculated from first principles using methods such as ray tracing. However, these methods are computationally expensive and tend to be simplified to avoid lengthy calculation times. As such, interactions such as absorption/radiation by soot or wall-to-wall and wall-to-gas interactions may be simplified or omitted altogether. Radiation calculations are also hindered by the ability to correctly determine the local soot concentrations due to simplifications in the combustion model. For small fires this may not be an issue, but for large fires that reach flashover, radiation heat transfer becomes a critical phenomena.

\subsection{Issues Regarding Human Factors in Computer Code Applications}

From the author's experience, a software program will only become a useful tool to the typical user if the user comprehends the software, its inputs, and its outputs. If a potential user does not understand the software it will not be used at all, or worse, it will be used in an incorrect manner giving false or misleading results.

The first step to using a computational tool for safety analysis is to understand the tool itself. The user must obtain an understanding of the underlying assumptions used in developing the tool. The user must also gain an understanding of the tool's limitations. Without this understanding, a user may unknowingly apply the tool to a scenario beyond its capabilities. A well-written user's manual that discusses the theories, assumptions, and algorithms related to the code's development and execution as well as a discussion of known limitations of the code can alleviate the problem of misapplying the tool (Bukowski, 1995). However, a well documented discussion of the tool's theory and limitations will only be useful if the user has the educational background and/or practical experience with which to comprehend the theory.

Once the user understands the tool and has determined its suitability for the problem at hand, the user must then apply the tool to the problem. Fires in structures are complex. There are many things that must be defined by the user such as the fuel source, the geometric layout, and heat transfer surfaces. This process can be aided by well written documentation. A well written input manual containing detailed examples for a variety of fires and structures is an immense aid to a user. These examples should describe in detail what is being modeled and how the real-life prototype is transformed into a computer model. An input preprocessor, preferably a graphical one, is also a valuable tool, especially if it is capable of flagging potential errors in the user's input. Finally, the user must be able to easily use the results given by the model. This may seem to be a simple matter, but again, the software's authors can make this easy or very difficult. In general, the more portable the output format, the easier it will be to make comparisons to measured data or to predictions made by other methods of analysis. This can be done by either 
having a user friendly post-processor that can extract data from an output file and convert it to a portable form, or to have the output file in a common data format such as comma-delimited ASCII text, PLOT3D (C) format, or Microsoft Excel (c) format.

Both CFAST and FDS have postprocessors for viewing output data. However, in their current incarnations extracting specific subsets of the output data for use with other data analysis tools can be a difficult task.

\section{$2.4 \quad$ Validation Issues}

The purpose of using a computational fire model is to make some determination about the effect a fire will have on a structure and its inhabitants. In the structure design process one wishes to make this determination in order to assess aspects of the fire safety of the structure. If the analysis is to be used to demonstrate to a regulator or to the public that the structure has some level of safety, then the tool used will require some form of approval for use ${ }^{11}$. That is, by some method it must be accepted by the users of the tool, the regulators, and the general public that the particular analysis method is well suited to the problem for its results to be meaningful in terms of a risk analysis.

To gain approval, some form of benchmarking will be needed. The analysis method will need to be evaluated through a series of blind predictions ${ }^{6}$. That is, a set of standard problems will need to be defined by either a regulatory organization or a standards setting body such as ISO or ASTM. These standard problems should cover both a variety of fire types and structures as well as contain features known to be difficult to solve for such as long, vertical shafts or atria. In addition to defining the standard problems, what constitutes acceptable performance by a method will need to be defined and what constitutes acceptable uncertainty by a method will also need to be specified.

To date, neither acceptance criteria nor a standard set of problems has been defined. As a result, it is difficult to assess the performance of a code when compared to measured data. What these criteria should be is not an easy thing to define. For example, a criteria could be to predict gas concentrations within $10 \%$. However, for toxic gasses it is the net exposure, an integration of time and concentration, which determines harmful effects. Therefore a more appropriate criteria might be the net amount of a toxic gas exposure to a reference person at the location of interest. In a similar manner a simple error band for temperature is not necessarily sufficient since when including a suppression system in a simulation, it is the time that a location reaches an activation temperature that is important. With a simple temperature error band, a model could be within the band but predict either far too early or far too late an activation of a suppression system.

During the fire test series in the HDR facility, contemporary computer codes were used to simulate some of the fire experiments. In order to evaluate the performance of those codes a panel of nuclear safety and fire protection experts developed a set of guidelines to be used during the evaluation ${ }^{12}$. Table 2.1 gives these guidelines. The $\pm 20{ }^{\circ} \mathrm{C}$ guideline for far-field temperatures was added to account for regions which see little temperature increase from a fire. In this case, it makes little sense to place an accuracy of $20 \%$ on a room whose temperature 
never exceeds $50{ }^{\circ} \mathrm{C}$. In the absence of other guidelines, this table will be used to judge the performance of the calculations performed in this work. The guidelines in Table 2.1 were developed with the following three issues in mind:

1. Maintaining structural integrity of safety-related structures and components

2. Maintaining functionality of safety-related electrical and mechanical facilities

3. Maintain usability of ventilation systems and keep emergency/intervention routes smoke free (maintain their availability for use).

Table 2.1: Fire Simulation Accuracy Criteria

\begin{tabular}{|l|l|l|}
\hline Location & \multicolumn{1}{|c|}{ Parameter } & Desired Accuracy \\
\hline \multirow{5}{*}{ Near-Field } & Temperature of hot gasses, plume, etc. & $\pm 15 \%$ \\
& Temperature of hot structures & $\pm 10-15 \%$ \\
& Pressure & $\pm 20 \%$ \\
& Fire Properties & $\pm 30-50 \%$ \\
& Layer height & $\pm 30-50 \%$ \\
& Event timing & \pm 5 minutes \\
\hline \multirow{5}{*}{ Far-Field } & Temperature of gasses & $\pm 20 \%$ or $\pm 20{ }^{\circ} \mathrm{C}$ \\
& Temperature of structures & $\pm 10-15 \%$ \\
& Pressure difference & $\pm 20 \%$ \\
& Gas concentrations & $\pm 15-20 \%$ \\
& Aerosols & $\pm 20 \%$ \\
& Energy and mass flows & $\pm 30-50 \%$ \\
& Velocities & $\pm 30-50 \%$ \\
& Layer Heights & $\pm 30-50 \%$ \\
& Event timing & \pm 5 minutes \\
\hline
\end{tabular}

The above table divides a fire simulation into two regions: the near-field and the far-field. The near-field is considered to be the compartment in which the fire occurs and any adjoining compartments in the structure being modeled. In this region the high temperatures and heat fluxes must be known in order to evaluate the potential for damage to the structure and to any equipment located in the near-field. The far-field is considered to be the remainder of the structure. Temperatures in the far field are not as likely to reach very high levels, therefore, the concern in the far-field is not temperature. The concern in the far-field is human survivability which is determined by the concentration of toxic gasses and the damage caused by the clogging of building ventilation systems and equipment cooling systems with soot. It is important, therefore, that an analysis method be capable of making sufficiently accurate predictions in both of these regions.

The above table is used in Chapter 6 to discuss the results of the models presented in Chapter 5 . The table is also used to draw conclusions in Chapters 7 and 8. While this table does not necessarily represent the needed performance-based criteria, in lieu of such criteria it is used as a basis for rational judgment of predictive outcomes. 


\subsection{OVERVIEW OF CALCULATIONAL METHODS}

This chapter briefly discuss the three calculation methods used for this work. More extensive discussions of these methods can be found in the references noted for each of the methods. For example, both the CFAST and FDS user manuals are available through the National Technical Information Service. This chapter will not, therefore, go into great detail about the inner workings of the methods

\subsection{Hand Calculations}

In this section, methods for 'hand calculating' basic quantities related to compartment fires are discussed. These methods are computationally simple, and can be performed with either a hand calculator, spreadsheet, or a math toolkit such as MatLab ® or Mathematica ${ }^{\circledR}$. Hand calculations typically have the advantage of being transparent to the underlying physics being modeled and fast to execute. In this manner hand calculations can be used to quickly generate results that are easily understood and easily presented to others, i.e. the results do not require sophisticated plotting software like the results of a field model calculation might require.

Since the governing equations for heat and mass transfer in a series of connected compartments with multiple heat transfer surfaces are complex, numerous simplifications must be made in order to perform a hand calculation. As a result of these simplifications, hand calculations should not be expected to yield the same quality of results as would be anticipated from a more rigorous computational method. However, one would desire that the results from hand calculations be good enough to at a minimum determine whether or not a detailed analysis is warranted for a given fire. With this in mind, in this author's opinion, if a hand computation was accurate to within twice the deviation desired for zone or field model calculations, then it would be useful as tool for allocating computational resources for fire analysis. That is, fast hand computations could be used to quickly determine which of many possible fire scenarios warrant the expense and time of a more rigorous analysis.

\subsubsection{Fire Room Computations}

Two different methods for computing basic parameters of a compartment fire are described in this subsection ${ }^{1}$. The first method applies to fires in which a distinct thermocline exists in the fire compartment. The second method is for post-flashover compartments in which no distinct thermocline exists.

\subsubsection{Two Layer Compartment Fire}

Karlsson and Quintiere ${ }^{1}$ also discuss a method with which one can calculate the mass and energy flux at a doorway to a compartment with two distinct layers. The method assumes that the flow in the doorway can be divided into three regions. The first region is outward flow, the second region is inward flow above the layer interface, and the final region is inward flow below the layer interface. Mass flow equations for each region are generated by applying Bernoulli's equation across the doorway along with a simple loss coefficient for the doorway. The mass flow 
equations in combination with conservation of mass at the doorway, conservation of energy for the upper layer, and an equation of state can be used to find the fire compartment temperature and doorway mass flux. Figure 3.1 shows a diagram of such a compartment.

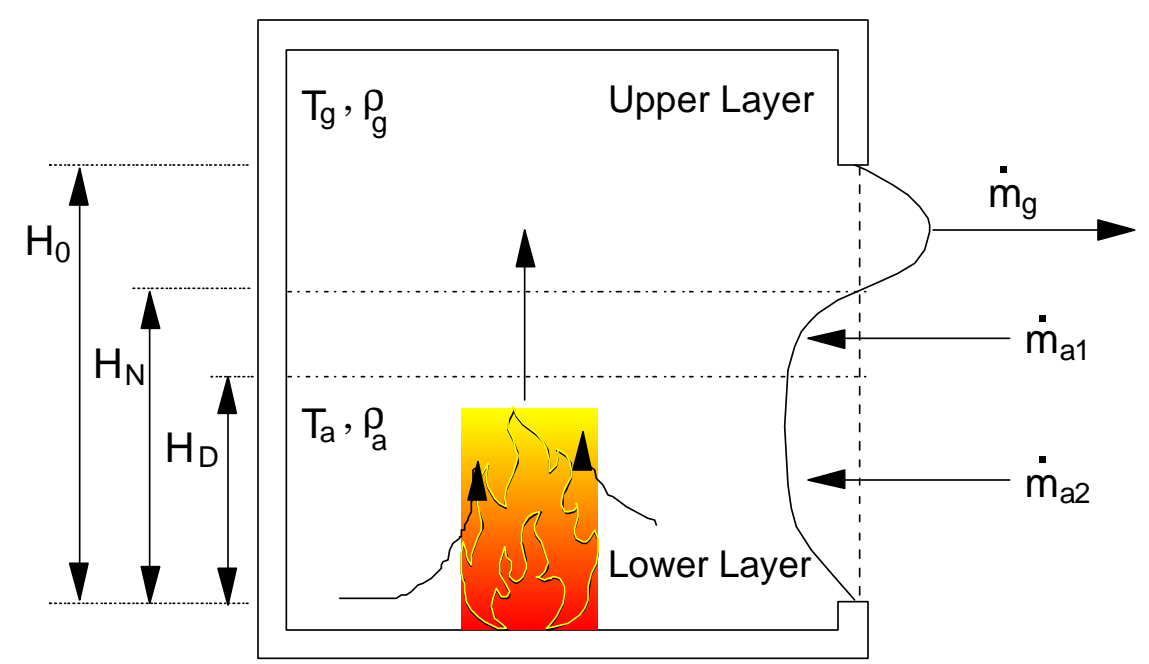

Figure 3.1: Compartment Fire with Two Layers (Distinct Thermocline)

The equations to be solved are:

Region 1 Mass Flow:

Region 2 Mass Flow:

$$
\dot{m}_{g}=\frac{2}{3} C_{d} W \rho_{g} \sqrt{\frac{2(\rho a-\rho g) g}{\rho g}}\left(H_{0}-H_{N}\right)^{\frac{3}{2}}
$$

Region 3 Mass Flow:

$$
\dot{m}_{a 1}=\frac{2}{3} C_{d} W \rho_{a} \sqrt{\frac{2\left(\rho a-\rho_{g}\right)_{g}}{\rho a}}\left(H_{N}-H_{D}\right)^{\frac{3}{2}}
$$

$$
\dot{m}_{a 2}=C_{d} W H_{D} \rho_{a} \sqrt{\frac{2\left(H_{N-H_{D}}\right)\left(\rho_{a}-\rho g\right) g}{\rho a}}
$$

Continuity, Equation of State, and Upper Layer Energy Balance:

$$
\begin{gathered}
\dot{m}_{g}=\dot{m}_{a 1}+\dot{m}_{a 2} \\
\rho=\frac{M P}{R T} \\
\dot{Q}=\Delta T\left(\dot{m}_{g} c_{p}+h_{k} A_{T}\right)
\end{gathered}
$$


Where the variables have the following definitions:

$$
\begin{array}{rlrl}
A_{T}= & \text { Upper layer wall surface area }\left(\mathrm{m}^{2}\right) & \dot{m}_{a 2}= & \text { Lower layer inward mass flow } \\
& & (\mathrm{kg} / \mathrm{s}) \\
C_{d}= & \text { Doorway loss coefficient } & \dot{Q}=\text { Fire power }(\mathrm{W}) \\
c_{p}= & \text { Specific heat }(\mathrm{kJ} / \mathrm{kg} \cdot \mathrm{K}) & =\text { Pressure }(\mathrm{Pa}) \\
H_{0}= & \text { Doorway height }(\mathrm{m}) & \rho_{a}=\text { Ambient gas density }\left(\mathrm{kg} / \mathrm{m}^{3}\right) \\
H_{D}= & \text { Layer height }(\mathrm{m}) & \text { Upper layer gas density }\left(\mathrm{kg} / \mathrm{m}^{3}\right) \\
H_{N}= & \text { Neutral plane }(\mathrm{m}) & R=\text { Real gas constant }(\mathrm{J} / \mathrm{mol} \cdot \mathrm{K}) \\
h_{k}= & \text { Wall heat transfer coefficient } & & \text { temperature }(\mathrm{K}) \\
& \left(\text { W/m } / \mathrm{m}^{2} \cdot \mathrm{K}\right) & & \text { Upper layer temperature }- \text { ambient } \\
M= & \text { Gas molar mass }(\mathrm{kg} / \mathrm{mol}) & T=\text { Temperature }(\mathrm{K}) \\
\dot{m}_{g}= & \text { Upper layer outward mass flow } & W=\text { Doorway width }(\mathrm{m}) \\
& (\mathrm{kg} / \mathrm{s}) & & \\
\dot{m}_{a 1}= & \text { Upper layer inward mass flow }(\mathrm{kg} / \mathrm{s})
\end{array}
$$

The continuity equation merely states that the mass flow into the fire room equals the mass flow out of the fire room. The equation of state is the Real Gas Law. The energy balance states that the heat input into the upper layer from the fire is equal to the heat losses through the walls of the fire room plus the energy used to heat the incoming air up to the fire room temperature. By solving these equations simultaneously, values for the mass flow out of the doorway and the upper layer temperature can be found.

\subsubsection{Single Layer Compartment Fire}

Karlsson and Quintiere ${ }^{1}$ discuss a method with which one can calculate the mass and energy flux at a doorway to a well-mixed compartment. The method assumes that the flow in the doorway can be divided into two regions: an outward flow region and an inward flow region. The first region is outward flow, and the second region is inward flow which occurs beneath the neutral plane. Mass flow equations for each region are created by applying Bernoulli's equation across the doorway along with a simple loss coefficient for the doorway. The mass flow equations in combination with conservation of mass at the doorway, conservation of energy for the fire room, and an equation of state can be used to find the fire compartment temperature and doorway mass flux. Figure 3.2 shows a diagram of such a compartment. 


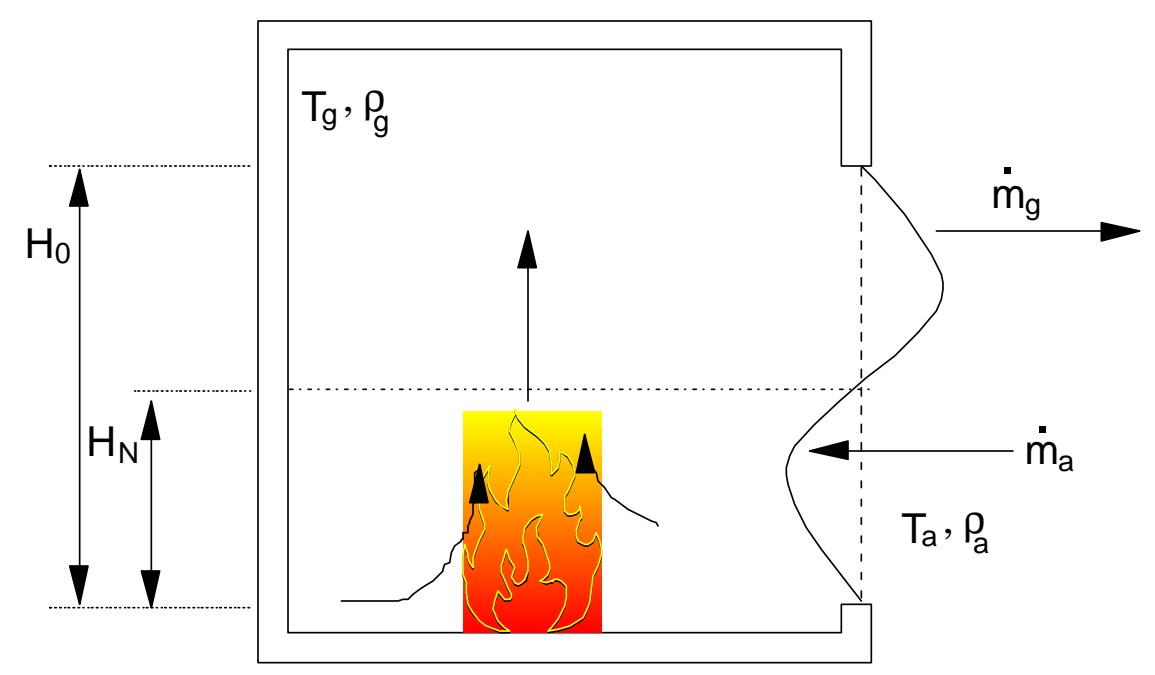

Figure 3.2: Compartment Fire with a Single Layer (No Distinct Thermocline)

The equations to be solved are:

Outward Mass Flow:

$$
\dot{m}_{g}=\frac{2}{3} C_{d} W \rho_{g} \sqrt{\frac{2\left(\rho_{a}-\rho_{g}\right) g}{\rho g}}\left(H_{0}-H_{N}\right)^{\frac{3}{2}}
$$

Inward Mass Flow:

$$
\dot{m}_{a}=\frac{2}{3} C_{d} W \rho_{a} \sqrt{\frac{2\left(\rho a-\rho_{g}\right) g}{\rho_{a}}} H_{N}^{\frac{3}{2}}
$$

Continuity:

$$
\dot{m}_{g}=\dot{m}_{a}
$$

The continuity equation merely states that the mass flow into the fire room equals the mass flow out of the fire room. The equation of state and the heat balance equation are the same as for the two layer analysis. Variable nomenclature is also the same. By solving these equations simultaneously, values for the mass flow out of the doorway, the fire room temperature, and the location of the neutral plane can be found.

\subsubsection{Buoyant, Axisymmetric Plume Analysis}

This subsection discusses two hand-calculation methods for modeling buoyant, axisymmetric plumes. The first method uses the Chen-Rodi correlations ${ }^{13}$. The second method is an integral plume model developed by the author using Mathematica ${ }^{\circledR}{ }^{14}$. Figure 3.3 shows a diagram of an axisymmetric plume. 


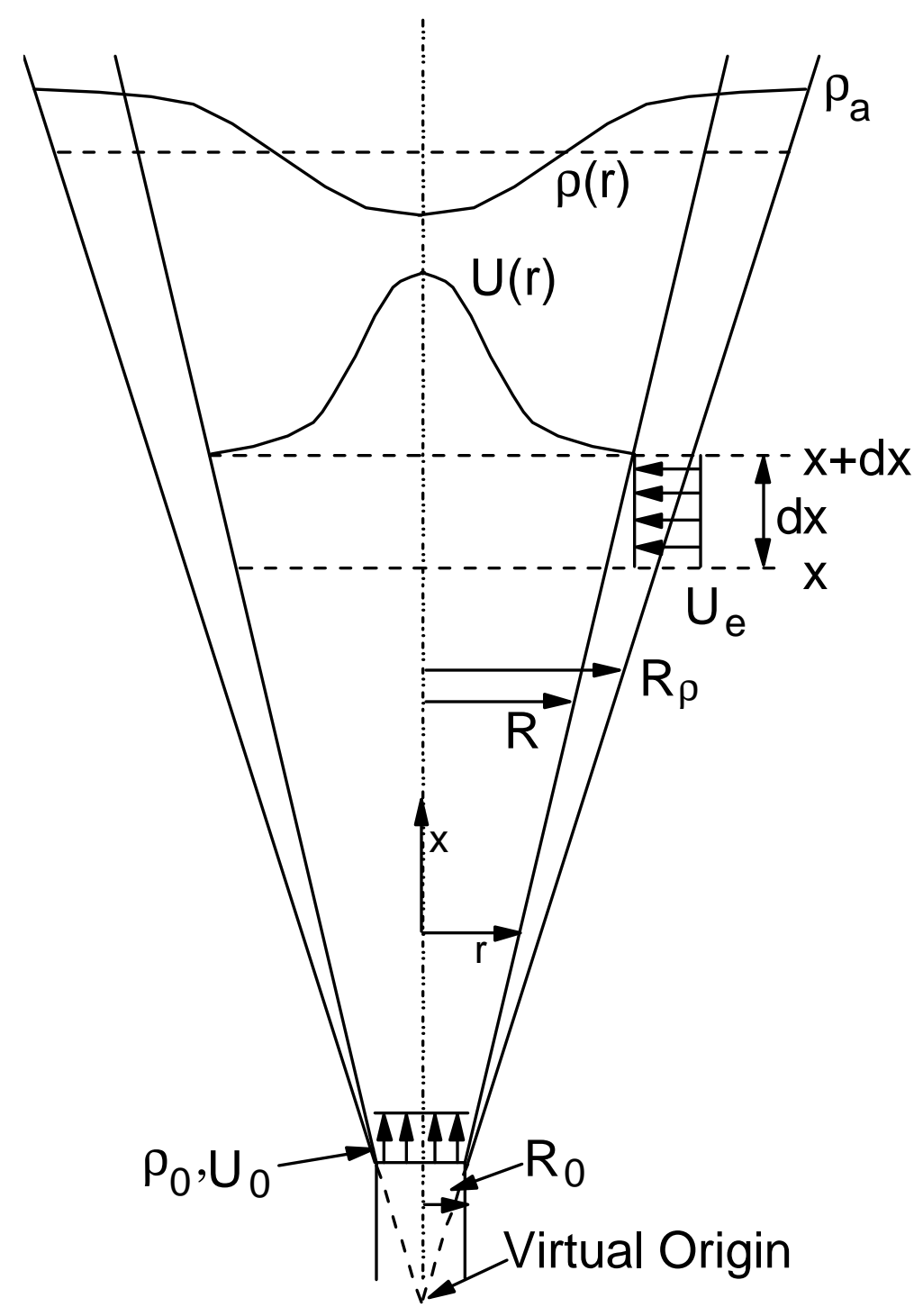

Figure 3.3: Buoyant, Axisymmetric Plume

Where the variables have the following definitions:

$$
\begin{array}{rlrl}
x & =\text { Axial distance from virtual origin } & & R_{0}=\text { Initial plume radius }(\mathrm{m}) \\
& & & \\
r & =\text { Distance from plume centerline }(\mathrm{m}) & U_{0}=\text { Initial plume velocity }(\mathrm{m} / \mathrm{s}) \\
U_{e} & =\text { Entrainment Velocity }(\mathrm{m} / \mathrm{s}) & \rho_{0}=\text { Initial plume density }\left(\mathrm{kg} / \mathrm{m}^{3}\right) \\
U & =\text { Plume velocity }(\mathrm{m} / \mathrm{s}) & \rho_{a}=\text { Ambient gas density }\left(\mathrm{kg} / \mathrm{m}^{3}\right) \\
R & =\text { Plume radius }(\mathrm{m}) & & \rho_{g}=\operatorname{Upper} \text { layer gas density }\left(\mathrm{kg} / \mathrm{m}^{3}\right) \\
\rho & =\text { Plume density }\left(\mathrm{kg} / \mathrm{m}^{3}\right) & & d_{0}=\text { Initial plume diameter }(\mathrm{m})
\end{array}
$$




\subsubsection{Chen-Rodi Correlations}

The Chen-Rodi correlations ${ }^{13}$ are repeated here for completeness. These correlations predict the centerline values of axial velocity and density for a buoyant jet as a function of the distance from the virtual origin of the plume. These correlations are broken into three regimes: a momentum driven regime, a buoyancy driven regime, and a transition regime between the momentum driven and the buoyancy driven regimes. In these correlations $\mathrm{x}$ is the distance from the virtual origin of the jet, 0 represents the value at the jet origin, $m$ represents a value along the jet axis, 'a' represents the ambient condition, and Fr is the jet Froude number given as:

Momentum Driven for $F r^{-\frac{1}{2}}\left(\frac{\rho o}{\rho a}\right)^{-\frac{1}{4}} \frac{x}{d_{0}}<0.5$

$$
F r=\frac{U_{0}^{2}}{g 2 d_{0} \frac{\rho_{a}-\rho_{0}}{\rho_{0}}}
$$

$$
\begin{gathered}
\frac{U_{m}}{U_{0}}=6.2\left(\frac{\rho_{0}}{\rho a}\right)^{\frac{1}{2}}\left(\frac{x}{d_{0}}\right)^{-1} \\
\frac{\rho a-\rho_{m}}{\rho a-\rho_{0}}=5.0\left(\frac{\rho_{0}}{\rho a}\right)^{-\frac{1}{2}}\left(\frac{x}{d_{0}}\right)^{-1}
\end{gathered}
$$

Transition for $0.5 \leq F r^{-\frac{1}{2}}\left(\frac{\rho o}{\rho_{a}}\right)^{-\frac{1}{4}} \frac{x}{d_{0}} \leq 5$

$$
\begin{aligned}
& \frac{U m}{U_{0}}=7.26 F^{-\frac{1}{10}}\left(\frac{\rho_{0}}{\rho a}\right)^{\frac{9}{20}}\left(\frac{x}{d_{0}}\right)^{-\frac{4}{5}} \\
& \frac{\rho_{a}-\rho_{m}}{\rho a-\rho_{0}}=0.44 F r\left(\frac{\rho_{0}}{\rho a}\right)^{-\frac{7}{16}}\left(\frac{x}{d_{0}}\right)^{-\frac{5}{4}}
\end{aligned}
$$

Buoyancy Driven for $5<F r^{-\frac{1}{2}}\left(\frac{\rho o}{\rho_{a}}\right)^{-\frac{1}{4}} \frac{x}{d_{0}}$

$$
\begin{gathered}
\frac{U m}{U_{0}}=3.50 \mathrm{Fr}^{-\frac{1}{3}}\left(\frac{\rho_{0}}{\rho a}\right)^{\frac{1}{3}}\left(\frac{x}{d_{0}}\right)^{-\frac{1}{3}} \\
\frac{\rho_{a}-\rho_{m}}{\rho a-\rho_{0}}=9.35 \mathrm{Fr}^{-\frac{1}{2}}\left(\frac{\rho_{0}}{\rho a}\right)^{-\frac{1}{3}}\left(\frac{x}{d_{0}}\right)^{-\frac{5}{3}}
\end{gathered}
$$

The virtual origin of a jet is obtained by extrapolating the radius of the jet backwards from the jet source to obtain a zero radius. The virtual origin is given by Papanicolaou ${ }^{15}$ as 2.56 diameters $^{2}$ based on velocity and 2.51 diameters based on concentration width. For the comparisons made in this report a value of 2.5 diameters was used.

\subsubsection{Integral Analysis}

A set of equations was derived to yield an integral analysis of jet behavior. This derivation was based on the derivation performed by Badre $^{10}$ for computing the rise of radioactive jets. This derivation assumes axisymmetric, fully turbulent, Boussinesq flow with a hydrostatic pressure 
distribution. The conservation equations for mass, momentum, and energy are given below ${ }^{16}$ with $\vec{F}$ being the body forces and $e$ being the internal energy:

Mass:

$$
\int_{S} \rho \vec{U} \cdot \widehat{n} d A=0
$$

Momentum:

$$
\sum \vec{F}=\int_{S} \rho \vec{U}(\vec{U} \cdot \hat{n}) d A
$$

Energy:

$$
\dot{Q}-\dot{W}=\int_{V} \rho e d V
$$

Beginning with Equation 17 a number of simplifications are made. Since the jet is axially symmetric, there is no tangential velocity component. Equation 17, therefore, simplifies to

$$
\frac{d}{d x} \int \rho_{j} U_{j} d A=2 \pi R_{j} \rho_{a} U_{e}
$$

where $\mathrm{j}$ represents a quantity in the jet, $\mathrm{x}$ is the axial direction, and 'a' represents a quantity in the ambient. The entrainment velocity, $\mathrm{U}_{\mathrm{e}}$, can be represented by an entrainment coefficient, $\alpha$, times the centerline velocity of the plume. This coefficient differs depending on whether or not the jet is momentum or buoyancy dominated. A correlation for $\alpha$ is given by Sneck ${ }^{17}$ as:

$$
a=a_{1}+\frac{a_{2}}{F r}=0.044+\frac{0.25}{F r}
$$

where Fr is given in Equation 10. Froude numbers were on the order of 100 for the development of the above correlation.

In Equation 18, there is only an axial component of momentum as the net radial momentum must be zero due to the axial symmetry. The body force in the case of buoyant flow is the buoyancy force.

$$
\frac{d}{d x} \int_{S} \rho_{j} U_{j}^{2} d A+\int_{V}\left(\rho_{j}-\rho_{a}\right) g d V=0
$$

Lastly, the energy equation, Equation 19, is simplified. The work and heat addition terms are 0. The energy term consists of enthalpy, kinetic energy, and heat transfer. Since velocities in the flows of concern are low, kinetic energy is small compared to the enthalpy of the gas in the plume and can be ignored. Furthermore, the transfer of energy by conduction is ignored by assuming that density, which is equivalent to temperature, changes are caused solely by entrainment.

$$
\frac{d}{d x} \int_{S} \rho_{j} h_{j} U_{j} d A=2 \pi R_{j} \rho_{a} h_{a} U_{e}
$$

With the assumption that the working fluid is a real gas, the following simplification is made

$$
h=C_{p} T=C_{p} \frac{P}{\rho R g}=\frac{P}{\rho} \frac{\gamma}{\gamma-1}
$$


As the pressure is assumed to be hydrostatic and the gas in the plume is assumed to be the same as the product of enthalpy and density cancels in Equation 23 as the ambient gas's $\gamma$ is the same as the plume's $\gamma$.

$$
\frac{d}{d x} \int_{S} U_{j} d A=2 \pi R_{j} U_{e}
$$

Lastly, it is assumed that both the velocity and density profiles are Gaussian with the density profile width increased by a parameter $\lambda$ which comes from experimental data. Henderson-Sellers ${ }^{18}$ gives a value of 1.16 for $\lambda$.

$$
U_{j}(r)=U_{j}(0) e^{-\left(\frac{r}{R_{j}}\right)^{2}}, \rho_{j}(r)=\rho_{j}(0) e^{-\left(\frac{r}{\lambda R_{j}}\right)^{2}}
$$

Equations 20, 22, and 25 along with Equations 21 and 26 constitute a set of integro-differential equations which can be solved using a variety of simple iterative methods. For this work the equations were input into Mathematica $\AA$ and numerically solved to yield predictions for $U_{j}, R_{j}$, and $r_{j}$.

\subsection{Fire Dynamics Simulator}

\subsubsection{Code Description and History}

Fire Dynamics Simulator (FDS) is a computational fluid dynamics code written by staff members of the Building \& Fire Research Laboratory at the National Institutes of Standards and Technology in Gaithersburg, MD. The code has been developed to calculate fire-driven flows both in enclosures and in the ambient ${ }^{4,19}$. FDS v1.0 is written in standard Fortran 90, and, thus, can be run on any platform for which a Fortran 90 compiler exists.

Version 1.0 of FDS was released in 2000, and contained a relatively simple combustion and radiation model. Version 2.0 is currently under development ${ }^{20,21}$ and will contain a mixture-fraction based combustion model ${ }^{22}$ and a more sophisticated radiation solver ${ }^{23}$. The FDS simulations in this work were calculated by a pre-release Version 2.0 and are designated hereafter as FDS v2.0 $\alpha$. FDS solves a modified form of the Navier-Stokes equations referred to as the "low Mach number" equations ${ }^{23}$. The mathematical nature of this modified form allows the use of a high-speed solver capable of solving transient flows for a large number of nodes in a relatively short time as opposed to other CFD codes. The Navier-Stokes equations are reduced from their full form to a thermally-expandable, multi-component perfect gas form that eliminates acoustic waves (i.e. Mach number $<<1$ ). This results in a set of equations with a Poisson equation for the pressure term. The end result of all this is that a fast Fourier transform method (FFT) can be used for a direct solution of the pressure equation which typically must be solved in an iterative fashion in most CFD schemes. 


\subsubsection{Solution Algorithm and Restrictions}

The governing equations are discretized in space and time. Time differencing takes the form of a second order, explicit predictor-corrector method. Spatial differences, taken on a uniform computational grid, are either second order, central differences or upwind differences depending on the parameter and the local CFL number. The CFL number, Courant-Friedrichs-Lewy, is used to judge stability of a time-dependent numerical scheme by comparing the transport distance of a parameter to the grid size ${ }^{25}$. Scalar parameters are defined at grid cell centers and vector parameters are defined at cell surfaces in order to create a staggered grid and reduce numerical diffusion.

The solution algorithm places a number of restrictions on the type of problems that FDS can solve. Use of the FFT pressure solver requires that the number of grid cells along an axis be of the form $2^{\mathrm{k}} 3^{\mathrm{m}} 5^{\mathrm{n}}$ where $\mathrm{k}, \mathrm{m}$, and $\mathrm{n}$ are positive integers ${ }^{4}$, thus there could be 15 grid cells along an axis $\left(3^{1} 5^{1}\right)$ but not $14\left(2^{1} 7^{1}\right)$. The low Mach-number assumption requires that flow speeds be less than a Mach number of 0.3 . Only coordinate transforms that are continuous and monotonic can be used to convert the problem domain to the computational domain. Furthermore the magnitude of stretching and shrinking in a grid transformation should be limited to avoid computational instabilities.

\subsubsection{Turbulence}

FDS has two different methods for determining $\tau$, the viscous stress tensor: Direct Numerical Solution (DNS) and Large Eddy Simulation (LES). DNS requires the use of very small nodes as it directly calculates the dissipative terms from first principles during the solution process. As such, DNS is not practical for the large-scale domains seen in compartment fires due to the impractical number of nodes that would be required. Thus, the DNS method will not be discussed further.

In a LES calculation, the method of Smagorinski ${ }^{26}$ is used. In the Smagorinski method, the viscosity used in the calculation of the stress tensor in the momentum equation is assumed to be proportional to the magnitude of the local deformation tensor ${ }^{27}$. That is, LES calculates only the large-scale eddies and makes assumptions for modeling eddies smaller than the computational grid.

Since fire driven flows are driven by the fire plume which is a large-scale eddy structure, this method works well. Second, since the desired accuracy in flow resolution is not high, use of a more complex and perhaps more accurate method is not warranted as it would reduce the computational speed of FDS.

Use of the LES model for turbulence does place limitations on the grid resolution for an input file. The Smagorinski method assumes that one is resolving adequately the dominant eddies in the flow field. For a fire-driven flow, this is accomplished if one resolves the plume structure scale. Thus, for an FDS computation using the LES submodel, the code user must span the plume length scale with approximately ten nodes, or the maximum node size must approximate ${ }^{28}$ : 


$$
L \approx 0.1\left(\frac{Q}{\rho c p T \sqrt{g}}\right)^{\frac{2}{5}}
$$

Where $\mathrm{Q}$ is the heat release rate of the fire and $\rho, \mathrm{c}_{\mathrm{p}}$, and $\mathrm{T}$ are the ambient gas properties taken at the ambient conditions.

\subsubsection{Combustion}

FDS v2.0 $\alpha$ uses a mixture-fraction concept in modeling combustion. The mixture fraction is a dimensionless quantity ranging from 0 to 1 . It represents the amount of gas at a location that originally was fuel. Thus, a mixture fraction of 0 would represent pure ambient air and a mixture fraction of 1 would represent pure fuel. The mixture fraction obeys the same conservation laws as a gas species, and it can be correlated through state relationships to the local concentrations of combustion product species as well as the local heat release rate. Thus, the mixture fraction model incorporates some combustion chemistry as opposed to the original "thermal element method" used in v1.0. It also uses more physics since both convective and diffusive transport is being accounted for with the mixture fraction approach as opposed to the solely convective transport with the prior model.

\subsubsection{Heat Transfer Submodels}

FDS contains three heat transfer submodels: a radiation heat transfer model, a wall heat transfer model, and a sprinkler model.

In v2.0 $\alpha$, the radiation heat transfer model uses the finite volume method. In this method the radiation field is updated at each time step by calculating the local production and absorption of radiation in each grid cell and propagating that radiation along a number of directional angles throughout the computational domain. The actual form of the radiation transport equation used for this solver is analogous to an advection equation. Thus, the radiative solution evolves over time. With this method, the surface and gas interactions neglected in v1.0 are now included for a greatly improved prediction in cases where the fire is not the sole significant source of radiation, such as large fires in small compartments.

The convective heat transfer model for an LES calculation makes use of a mixed convection heat transfer correlation. For each conducting surface a forced convection heat transfer coefficient and a natural convection heat transfer coefficient are calculated using flat plate correlations. The larger of the two is utilized for calculating the heat transfer. In FDS v1.0 only the natural convection correlation was used which could result in low heat transfer in regions of higher velocity.

In the sprinkler submodel, the user specifies surface locations which contain a sprinkler nozzle along with the activation characteristics of the nozzle. If a nozzle reaches its activation threshold it inputs droplets of water in a user defined spray pattern into the flow. These droplets are assigned a size distribution and droplet heat transfer is calculated using evaporative and convective heat transfer correlations. 


\subsubsection{Boundary Conditions}

FDS users have access to four flow and five surface boundary conditions. The four flow conditions are forced vent, passive or open vent, symmetry, and blocked cell. The five surface conditions are adiabatic, combusting, isothermal, thermally thin wall, and thermally thick wall.

The four flow conditions are defined by the user in the input file as part of the geometry description. As a default, the problem domain is defined to be closed. The user can create further blockages by defining rectangular parallelepiped regions to be blocked. At domain boundaries, the user can define a plane to be a symmetry plane, in which case no flow or heat transfer is allowed across the surface but flow parallel to the surface is not impeded. A user can also define a rectangular portion of a domain boundary to be an open boundary. In this case it is assumed that a vent exists to an infinite reservoir of ambient fluid; outgoing fluid has its pressure term, $\mathrm{H}$, set to be the stagnation pressure and incoming fluid to 0 . For any surface, either a blocked one or part of the domain boundary, the user can define a rectangular region for which a fixed velocity or mass flow in or out of the domain is specified.

The first three surface types are self explanatory. The temperature of a thermally thick surface cell is governed by the 1D heat conduction equation. A thermally thin surface's temperature is assumed to be uniform and calculated from the material density, thickness, and specific heat. In v2.0 $\alpha$ a combusting surface can be defined additionally as thermally thick or thin. In this manner, the influence of surface heat transfer on the pyrolysis rate can be accounted for.

\subsubsection{Input Files}

An FDS input file is an ASCII, card-type, FORTRAN 90 readable file. Each line of the input file consists of a card declaration, for example OBST to define a blockage, and a comma-delimited series of variable names and values. FDS currently lacks an input preprocessor; however, any utility which creates an ASCII file can be used.

\subsubsection{Output Options}

There are six types of output in FDS v2.0 $\alpha$. These are particle files, sensor files, slice files, dump files, boundary files, and iso-surface files. Each of these can be toggled on or off by the user along with limited control of the rate of output. The particle file stores particle positions and temperatures or other user specified parameters at fixed time intervals. This file can be used to create movies of the flow field and the particles can be used to represent water droplets from sprinkler systems. Sensor files are created by the user defining a sensor type, such as a thermocouple or heat flux gauge, and location. The sensor parameters are then dumped to a file at fixed intervals in time. In this manner the user can simulate test instrumentation or examine in detail key parameters for a number of fixed points. The slice file stores a single parameter for a rectangular region of the computational space at fixed time intervals. The dump file is a complete dump of velocity, temperature, and heat release or other user specified parameters for the entire computational domain at fixed time intervals. Boundary files dump a surface parameter such as wall temperature at fixed time intervals. Lastly, iso-surface files dump a set of 
triangles at fixed time intervals that represents a user defined constant value surface within the domain, such as the surface of velocity equal to $0 \mathrm{~m} / \mathrm{s}$.

An output postprocessor visualization program, called Smokeview ${ }^{29}$, is available for FDS. This program is written in OpenGL and, thus, is portable to any platform that can use OpenGL. This program is mouse driven and allows the user to walk through a 3D geometry, rotate the geometry, view movies of output files, view contours from dump files, and plot sensors.

\subsubsection{Summary of NIST Validation Efforts}

FDS was tested against both experiments and correlations. A discussion of these efforts is presented in this section.

\subsubsection{Open Plumes}

One correlation test was simulating an open fire plume, perhaps the most basic computation. This was compared to McCaffrey's plume correlations ${ }^{30}$ with the results of velocity predicted within 5 $\%$ in the near field and within $11 \%$ in the far field and temperature predictions within $5 \%$ in the far field. Temperature predictions in the near field, i.e. at the plume source, are over $100 \%$ in error, but this is due to the primitive heat source model in FDS v1.0 which does not yield accurate temperatures immediately at a source. The "thermal element" method is a purely convective process and since normal velocities at a burning surface are near zero, a particle spends much of its lifetime near the surface before it is advected upwards into the flow field. As a result heat releases are biased towards burning surfaces resulting in over predictions of the local temperature. In the far field temperature predictions are predicted extremely well. Since the total heat release rate is being achieved with FDS, in the far field the temperature prediction is essentially a function of the entrainment prediction, that is how much cooler ambient air is being mixed into the plume. Success in the far field indicates that FDS is correctly solving the governing equations. FDS v2.0 $\alpha$ calculations of the same plume show similar behavior in the far-field, but a much improved near-field temperature predictions with a $36 \%$ error.

\subsubsection{Backdraft}

Backdraft occurs when an oxygen depleted, fuel rich environment, such as a sealed compartment with a smoldering fire, is suddenly exposed to a sudden inrush of oxygen rich air. If this inrush is the result of fire fighters penetrating a structure, the resulting violent increase in the heat release rate is liable to cause injury or death. An effort to improve the understanding of backdraft used the mixing of salt and fresh water to simulate the mixing of cold, dense, oxygen rich air and hot, oxygen depleted gas ${ }^{31}$. FDS v1.0 was used to simulate these experiments.

The experiments consisted of a smaller compartment filled with fresh water containing phenolphthalein and a larger, elevated compartment filled with salt water containing sodium hydroxide. A partition separating the two compartments was removed and a resulting flow was videotaped. As the two fluids mix a reaction between the phenolphthalein and the sodium hydroxide changes the fluid color from clear to red and allows visualization of the mixing 
process. The parameter of importance in these experiments is the total transport time to the wall opposite the partition.

The results of the FDS v1.0 simulations were as follows. Transport times were well predicted, within $20 \%$, however, FDS v1.0 consistently ovepredicted the transport times. Velocity profile predictions in the compartment opening were within $10 \%$ near the center of the opening and within $25 \%$ near the edges of the opening. Since this particular simulation does not have any combustion, FDS v2.0 $\alpha$ results will be similar as only hydrodynamic solver is unchanged from v1.0.

\subsubsection{Hangar Fire}

A third effort was the simulation of two JP-5 pool fires conducted in an Navy hangar in Hawaii ${ }^{32}$. The two tests consisted of a round pool centered beneath $24.4 \mathrm{~m}$ x $18.3 \mathrm{~m}$ x $3.7 \mathrm{~m}$ draft curtain in a hangar with a ceiling height of $15 \mathrm{~m}$. The two fires were a $500 \mathrm{~kW}, 0.6 \mathrm{~m}$ diameter fire and a 2.7 MW, $1.5 \mathrm{~m}$ diameter fire. A summary of the comparisons were made between the FDS predictions and the measured data are given below:

- There was approximately a $35 \%$ error in the plume centerline prediction over the height of the plume.

- Errors in the ceiling jet temperature and velocity predictions were $60 \%$ and $40 \%$ respectively.

- Errors in the draft curtain filling and spilling times were $45 \%$ and $60 \%$ respectively.

- There was an $8 \%$ error in the temperature jump from inside to outside of the draft curtain.

- In general the FDS v1.0 performance for these cases was poor; however, a coarse grid was used which may have had a negative impact on the results.

\subsubsection{Flashover}

This simulation was part of a broader effort to evaluate computational methods for fire simulation $^{33}$. The experiment being simulated consisted of a $5.2 \mathrm{~m} \mathrm{x} 4.6 \mathrm{~m} \times 2.4 \mathrm{~m}$ room with a standard residential doorway in one corner. The room was fully furnished with sofas, chairs, and tables, carpet, etc. A cushion on a loveseat was ignited by tipping over a halogen torchiere lamp and the room was allowed to progress towards flashover. The compartment was instrumented with three thermocouple trees and a heat flux gauge.

FDS v1.0 predictions for this scenario were poor. FDS predicted the time to flashover at six minutes whereas the data indicates flashover near nine minutes. FDS also over predicted the upper layer temperatures by $40 \%$. This failure was attributed to three factors. The first was errors in the material properties for the combustible materials required for field model simulation. The second was the primitive combustion model in FDS v1.0 which used a very simple oxygen consumption model. The last factor was the Monte-Carlo radiation method in v1.0 which did not properly account for radiation heat transfer from hot gasses or hot surfaces. 
FDS v2.0 $\alpha$ shows a number of improvements for this diffucult scenario. Its predicterd time to flashover was 7.2 minutes. Peak temperature predictions were $16 \%$ below the measured values, which is just outside the desired $15 \%$ error. The same error sources for v1.0 still exist for v2.0 $\alpha$, however, the contributions to the error by the radiation model and combustion model have been greatly reduced.

\subsubsection{Tank Farm Fire}

This study was a purely numerical study to explore the use of FDS in predicting the smoke transport and radiative heat transfer resulting from large, outdoor pool fires ${ }^{34}$. FDS v1.0 was used to simulate two fire scenarios at an oil tank farm. The first was a fire burning at the top of the tank. The second was a fire burning in the spill containment trench surrounding the tank. The tanks were $84 \mathrm{~m}$ in diameter. FDS v1.0 predicted that $6 \%$ of the heat release from the tank fires was occurring as thermal radiation, and FDS v $2.0 \alpha$ predicted $11 \%$. This compares well with data which indicates the radiative fractions from very large pool fires is on the order of $8 \%{ }^{35}$.

\subsubsection{Warehouse Fire}

FDS was also tested against a series of 22 heptane burner fires in the Underwriters Laboratories' (UL) Large Scale Test Facility ${ }^{36}$. This test involved a heptane burner located beneath an array of sprinklers bounded by a draft curtain. Up until the sprinkler activations, FDS calculates temperatures near the sprinklers within $10 \%$ of the measured values. FDS correctly predicted all but one of the sprinkler activations; it predicted an activation where it did not occur. After the sprinkler activations, FDS results continue to be within $10 \%$ for those sprinklers which did not activate; however, FDS greatly over predicts temperatures near sprinklers that do activate indicating that more work is needed on the FDS droplet model which is relatively primitive at this stage. For FDS v2.0 $\alpha$, a more sophisticated droplet model is being developed which should result in lower temperatures near activated sprinklers. The new droplet model will make use of the local vapor pressure of water to determine the droplet evaporation rate rather than only evaporating the droplet once it reach the boiling temperature of water as in v1.0. This change will result in some evaporation occuring near the sprinkler head.

\subsection{CFAST}

\subsubsection{Code Description}

CFAST, the Consolidated model of Fire Growth And Smoke Transport, was developed by the Building and Fire Research Laboratory at the National Institute of Standards and Technology to give both fire researchers and fire protection specialists a relatively easy to use computer code with low computational requirements to predict the effects of a fire on a building's interior ${ }^{3,37}$. CFAST was first released by the BFRL in 1990, and the latest release is version 4.0.1.

CFAST belongs to a group of fire codes known as zone model codes. A zone model code is a lumped-parameter code in which each room is divided into two lumped-parameter volumes, an upper layer and a lower layer. Fires originating in the lower layer entrain air into a smoke plume 
and transport heat and mass into the upper layer, see Figure 3.1. This entrainment is calculated from McCaffery's correlation. As time progresses the upper layer will grow downward as more mass is transported into it. If the upper layer grows down below the soffit of a doorway or window, heat and mass from the upper layer can be transported to neighboring compartments. Early versions of zone models were only capable of computing one level of a structure. That is, heat and mass transfer between floors was not computed. CFAST currently has provisions for handling multilevel structures.

CFAST can model a fire as either a source of heat or with a simple combustion model. In the former case, CFAST calculates heat and mass transfer but does not track the concentration of gas species such as $\mathrm{O} 2$ and $\mathrm{CO} 2$. In the latter case, the user specifies the rate of pyrolysis, the rate at which gaseous fuel is released by a burning object, the basic chemical composition of the fuel, how much hydrogen, oxygen, nitrogen, and chlorine are present, and the combustion products emitted by the fuel. CFAST will then combust the fuel on the basis of the oxygen available. Unburned fuel is transported where it can continue burning if both oxygen is available and the layer temperature is above a user defined ignition temperature. Transport of combustion products is accomplished simply by calculating the mass transfer between compartments and layers and allocating the mass transferred by means of the species concentration from the originating compartment and layer.

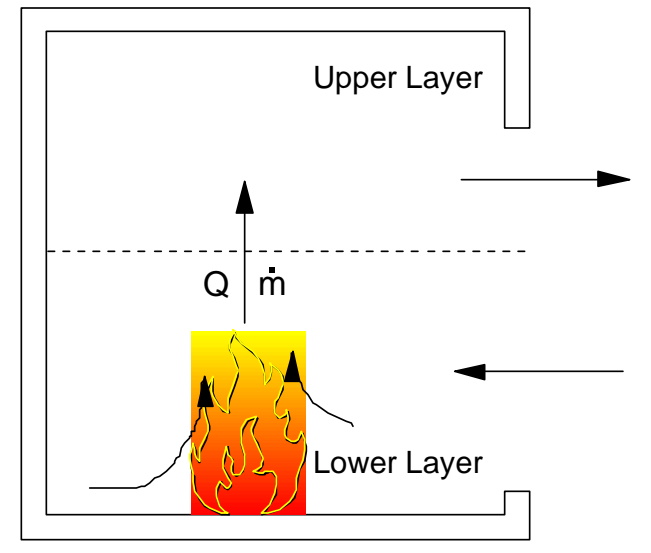

Figure 3.1: Zone Model Overview

\subsubsection{CFAST Mass Transfer}

There are three methods in CFAST by which a user can connect compartments. Doors and windows may be specified by specifying their heights, widths, and positions above the floor. Doorway connections may be specified in a time-dependent fashion. A connection between adjacent floors can be specified by providing a flow area and a connection shape, square or circular cross section. Connections between floors may not change state during code execution. The final method of connecting compartments is to use a ventilation system. A ventilation system is constructed by creating nodes within compartments and attaching ducts to those nodes. Ducts, which are given flow loss coefficients, can be connected to other compartment nodes or to user defined fans for which the user defines the fan curve, mass flow rate, based on the pressure difference across the fan. 
Horizontal flow through vertical openings, e.g. doors and windows, is solved for by the use of Bernoulli's equation. The assumption is made that the flow stagnates in the destination compartment and the velocity being solved for is from the originating compartment. Flow is calculated from upper layer to upper layer and from lower layer to lower layer in both directions. Depending on the relative layer heights between the two compartments, a mixing flow may occur which allows flow from the upper layer to the lower layer or vice versa.

Vertical flow through the floor between compartments is a function of two phenomena. The first is the pressure difference between the compartments which acts to cause flow in the direction of the gradient. The second is the density differences between the compartments which in the case of cooler air over warmer air causes a buoyancy driven flow upwards. A correlation by Cooper ${ }^{38}$ is used that accounts for these two phenomena along with a correction for the shape of the opening, square or circle. The layer into which the mass is placed is determined by calculating the enthalpy of the incoming flow and comparing it to the layer enthalpies for the compartment. The mass is placed in the lower layer if its enthalpy is less than that of the lower layer.

If the user defines a ventilation system, that system is expressed in CFAST as a nodal network. Flow through the system is solved by a joint application of Bernoulli's equation along with Kirchoff's Law for electrical networks. The Kirchoff's Law implementation sets the condition that flow into a node must equal flow out of a node. In the present version of CFAST, ventilation systems can only posses one state during a code execution; that is, a ventilation system is either always on or always off.

In addition to the above modes of mass transfer, CFAST contains to primary submodels. These submodels modify the horizontal mass transfer routine. One submodel attempts to correct zone model physics for high ceilinged spaces such as an atrium. The other submodel delays mass and energy transfer through a compartment to simulate the effect of a long hallway through which flow disturbances take time to propagate.

\subsubsection{CFAST Heat Transfer}

CFAST has separate models for each of the three heat transfer modes: convection, conduction, and radiation. To implement heat transfer calculations the user must define one or more of the room surfaces to be a conducting material. A separate multilayer slab definition can be specified for the walls, floor, and ceiling of each room. Objects within a room can also be specified, and CFAST will combust those objects if user defined heat flux and temperature limits for the object are reached.

Convective heat transfer within CFAST is implemented as a Grashof number correlation. The correlation is evaluated in one of three manners depending on whether the surface is vertical, the surface is horizontal with the wall temperature greater than the gas temperature, or the surface is horizontal with the wall temperature less than the gas temperature. Therefore, for each room two sets of four convection calculations are made, one each for the ceiling, the floor, the upper layer portion of the walls, and the lower layer portion of the walls. The two sets are one set for the 
room interior and one set for the room exterior in order to set the boundary conditions for the wall conduction. The room exterior calculation uses the user-defined ambient conditions.

Radiative heat transfer within CFAST is calculated using a modified version of an N-surface radiation equation developed by Siegel and Howell ${ }^{39}$. For rooms with no fires the radiation heat transfer is solved as a two-wall problem. The two walls are the ceiling and upper layer portion of the room walls and the floor and lower layer portion of the room walls. View factors are calculated assuming the two walls are hemispheres. If there is a fire in the room a four-wall computation is made. In this case the four walls are the ceiling, the floor, the upper layer portion of the walls, and the lower layer portion of the walls.

Conduction heat transfer is computed by solving a transient, $1 \mathrm{D}$, heat conduction problem for each of the four wall types, the same types as in the convection calculation. The 1D heat conduction solver divides the multilayer walls into a non-uniform mesh. The mesh is denser at the wall boundaries and the mesh distribution is skewed towards the wall interior. A backwards or implicit Euler method is used to perform the time stepping ${ }^{25}$. The wall boundaries can either be compartment and ambient or compartment and compartment. That is heat can be transferred through the walls to another compartment

\subsubsection{Input Files}

Input files for CFAST are card style, free format, ASCII input files. Since the input files are ASCII files, any text editor can be used to create them

\subsubsection{Code Output}

There are two manners in which output from the code can be obtained. The user can specify a few parameters to plotted during the code execution or the user can allow the code to display a summary table to the screen at fixed time intervals. The user can also specify a time interval for which complete dumps of the variable space will be written to a binary file.

The binary output file can be viewed with a primitive DOS based postprocessor or by running a second program to extract data from the binary file into a comma-delimited ASCII file suitable for importing into a spreadsheet. Unfortunately, the ability to specify which data to extract by the second method is limited, and for multi-compartment problems with constrained fires the number of columns can quickly exceed the import capability of common spreadsheet programs.

\subsubsection{Summary of NIST Validation Efforts}

As CFAST has been in existence for almost a decade, there is a large body of work documenting its use. A few examples of this work are presented herein. 


\subsubsection{Original Validation Study}

NIST performed a validation of CFAST using posttest predictions of five different fire experiments. These computations were used to demonstrate the validity of the CFAST code ${ }^{3}$ and were included as part of the original program documentation. The five experiments included two single room tests with and without wall burning, two multiroom and single level tests with three and four compartments, and one multiroom and multilevel test. A summary of these results are presented to indicate the level of accuracy seen by CFAST at that time, 1993. The overall results shown below are mixed indicating that at the time still CFAST needed improvements to its algorithms.

Table 3.1 below summarizes the errors in predicting the peak upper layer temperature of the five experiments. From Table 2.1 we obtain the criteria of $\pm 15 \%$ for the fire room and $\pm 20 \%$ for other rooms. This table indicates that CFAST only meets the fire room criteria for one of the tests and only meets the far field criteria for half of the far-field compartments. This is not a favorable assessment of predictive capability.

Table 3.1: CFAST Validation Results for Upper Layer Peak Temperature

\begin{tabular}{|c|c|c|}
\hline Test & Compartment & Error \\
\hline Single room w/ furniture & Fire room & $18 \%$ \\
\hline Single room wall burning & Fire room & $5 \%$ \\
\hline & Fire room & $30 \%$ \\
Three room test & $\# 2$ & $19 \%$ \\
& $\# 3$ & $29 \%$ \\
\hline & Fire room & $22 \%$ \\
Four room test & $\# 2$ & $35 \%$ \\
& $\# 3$ & $6 \%$ \\
& $\# 4$ & $23 \%$ \\
\hline \multirow{2}{*}{ Multiple level test } & Fire room & $40 \%$ \\
& $\# 1$ & $13 \%$ \\
\hline
\end{tabular}

The recommended accuracy criteria for gas concentrations is given in Table 2.1 as $\pm 15-20 \%$. Table 3.2 below presents a summary of the minimum $\mathrm{O}_{2}$ concentrations and the maximum $\mathrm{CO}_{2}$ concentrations for three of the five experiments. Only in the four room test did CFAST have success predicting gas concentrations. 
Table 3.2: CFAST Validation Results for $\mathrm{O}_{2}$ and $\mathrm{CO}_{2}$ Concentrations

\begin{tabular}{|c|c|c|c|}
\hline Test & Compartment & $\mathrm{Gas}$ & Error \\
\hline Single room w/ furniture & Fire Room & $\mathrm{O}_{2}$ & $6 \mathrm{v} /{ }^{*}$ \\
& & $\mathrm{CO}_{2}$ & $80 \%$ \\
\hline Four room test & Fire Room & $\mathrm{O}_{2}$ & $15 \%$ \\
& $\# 2$ & $\mathrm{O}_{2}$ & $8 \%$ \\
& Fire Room & $\mathrm{CO}_{2}$ & $39 \%$ \\
& $\# 2$ & $\mathrm{CO}_{2}$ & $8 \%$ \\
& $\# 3$ & $\mathrm{CO}_{2}$ & $4 \%$ \\
\hline Multiple level test & Fire Room & $\mathrm{O}_{2}$ & $59 \%$ \\
& Fire Room & $\mathrm{CO}_{2}$ & $75 \%$ \\
\hline
\end{tabular}

${ }^{*} \mathrm{O}_{2}$ concentration in test was $0 \mathrm{v} / \mathrm{o}$.

Table 3.3 shows the peak mass flow rates predicted by CFAST versus the experimental data. These should be compared to the criteria of $\pm 30-50 \%$. Data are shown for two of the tests for the flow exiting the fire room. In both cases CFAST makes excellent predictions of the mass flow, falling well within the acceptable error band.

Table 3.3: CFAST Validation Results for Mass Flow Rates.

\begin{tabular}{|c|c|}
\hline Test & Error \\
\hline Single room w/ furniture & $20 \%$ \\
\hline Three room test & $19 \%$ \\
\hline
\end{tabular}

\subsubsection{Wall Heat Transfer Validation}

The United States Navy has a great interest in being able to predict heat transfer through walls. Since a typical naval vessel has metal walls, a fire in one compartment could conceivably ignite materials in a neighboring compartment due to the high conductivity of the wall materials. As part of its ongoing effort to improve fire safety on naval vessels the U.S. Navy conducted a series of experiments aboard the ex-USS Shadwell to measure temperature changes in compartments adjacent to compartments with fires. After development of new heat transfer algorithms for CFAST v3.1, the data from the ex-USS Shadwell tests was used to validate the code ${ }^{40}$.

The particular test examined involved a diesel spray fire in an interior compartment two levels below the deck. CFAST was used to predict the temperatures in that compartment and the two compartments above it during the fire. In the fire compartment CFAST temperature predictions during the early phase of the test were poor; however, the fire was started as a pool fire into which diesel fuel was sprayed and the pool mass loss rate was not measured. During the latter portions of the test when the diesel spray was activated, CFAST predictions in the fire compartment are within $5 \%$ of the measured data. In the compartment directly above the fire compartment, CFAST predicted a slightly faster temperature rise than measured by the data; however, the near equilibrium temperatures towards the end of the test were within $5 \%$. The final compartment, two decks above the fire room, saw only a slight increase in temperature. 
CFAST matched well both the rate of temperature increase and the final temperature. CFAST predictions were slightly higher than indicated by the data.

\subsubsection{Hangar Fire}

A third effort was the simulation of two JP-5 pool fires conducted in an Navy hangar in Hawaii ${ }^{32}$. The two tests consisted of a round pool centered beneath $24.4 \mathrm{~m}$ x $18.3 \mathrm{~m}$ x $3.7 \mathrm{~m}$ draft curtain in a hangar with a ceiling height of $15 \mathrm{~m}$. The two fires were a $500 \mathrm{~kW}, 0.6 \mathrm{~m}$ diameter fire and a 2.7 MW, $1.5 \mathrm{~m}$ diameter fire. A summary of the comparisons were made between the CFAST predictions and the measured data are given below:

- For the 2.7 MW fire predictions were made of the temperature decrease along the ceiling jet created by the fire plume impingement on the ceiling of the hanger. From $75 \mathrm{~s}$ to $225 \mathrm{~s}$ after ignition the fire measured temperature decrease changed from $14{ }^{\circ} \mathrm{C}$ to $9{ }^{\circ} \mathrm{C}$. CFAST predictions decreased from $1{ }^{\circ} \mathrm{C}$ to $-2{ }^{\circ} \mathrm{C}$. Thus, CFAST was in error for both the magnitude of the temperature change and the sign of the temperature change as $225 \mathrm{~s}$ into the fire CFAST predicted that the temperature would increase along the length of the ceiling jet.

- Measured velocities in the ceiling jet $6 \mathrm{~m}$ from the $500 \mathrm{~kW}$ fire ranged from 0.5 to $0.8 \mathrm{~m} / \mathrm{s}$ over the $75 \mathrm{~s}$ to $225 \mathrm{~s}$ time period. CFAST predicted velocities ranged from 1.6 to $1.1 \mathrm{~m} / \mathrm{s}$, close to a $100 \%$ error. Similar errors existed for the $2.7 \mathrm{MW}$ fire.

- The time to fill the draft curtain with smoke for the $500 \mathrm{~kW}$ and $2.7 \mathrm{MW}$ fires was $100 \mathrm{~s}$ and $50 \mathrm{~s}$ respectively. CFAST predictions were $50 \mathrm{~s}$ and $30 \mathrm{~s}$ respectively. While the error is large, the prediction is conservative.

- Smoke detector activiations for the $500 \mathrm{~kW}$ at $3.0 \mathrm{~m}, 6.1 \mathrm{~m}, 8.5 \mathrm{~m}, 9.1 \mathrm{~m}$, and $11.6 \mathrm{~m}$ from the fire were recorded as $30 \mathrm{~s}, 50 \mathrm{~s}, 45 \mathrm{~s}, 75 \mathrm{~s}$, and $90 \mathrm{~s}$ respectively. The corresponding CFAST predictions were 105 s, 110 s, 125 s, 130 s, and 150 s. In all cases CFAST was a minute or more late in its predictions, though the error percentage decreased with distance from the fire.

\subsubsection{Smoke Layer Development}

A series of experiments were performed in the Building Research Institute at the University of Tokyo to generate $\mathrm{t}^{2}$ fire data with which to validate zone model performance in calculating the properties of smoke layers ${ }^{41}$. The tests consited of burning a polyurethane mattress in a compartment connected to a hallway. Load cell measurements of the fire showed $\mathrm{t}^{2}$ fire with a peak power of $200 \mathrm{~kW}$.

CFAST calculations for two of the tests showed the same behavior. CFAST calculates too quick of a drop in the corridor layer height. For both cases CFAST predicted that the equilibrium layer height was reached about one minute earlier than the data indicated. The layer height predictions, however, were quite good with the predictions being within 20 to $30 \mathrm{~cm}$ of the data. CFAST also had a mixed performance in predicting the layer temperature. For both cases CFAST correctly predicted the time of the maximum temperature; predictions were within $30 \mathrm{~s}$. However, CFAST predicted twice the temperature increase, a $40^{\circ} \mathrm{C}$ change as opposed to a $20^{\circ} \mathrm{C}$ change. 


\subsection{HDR FACILITY}

\subsection{SUMMARY OF FACILITY AND FIRE TEST SERIES}

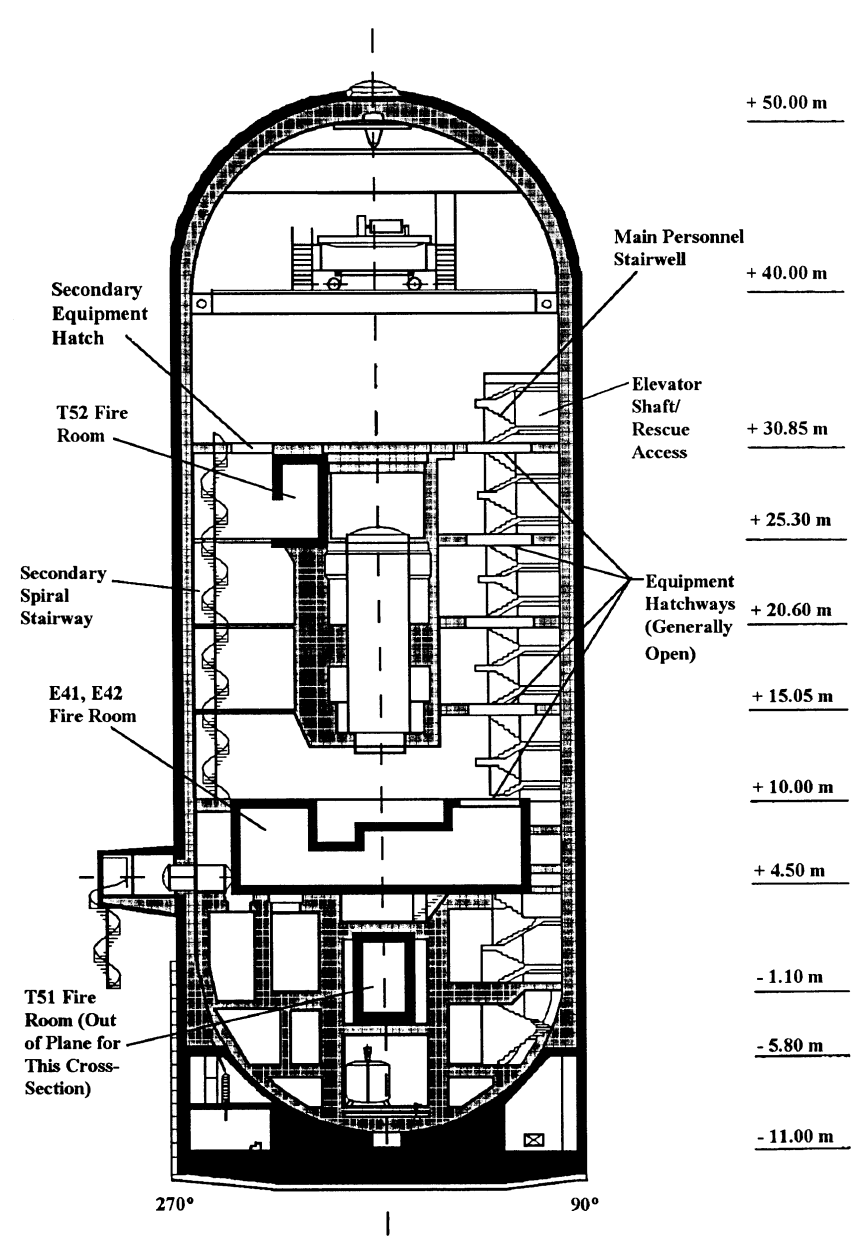

Figure 4.1: HDR Facility and Fire Test Locations
The HDR (Heiss-Dampf Reaktor) facility, shown in Figure 4.1, was the containment building for a decommissioned, experimental nuclear power reactor in Germany. The building was a cylinder 20 $\mathrm{m}$ in diameter by $50 \mathrm{~m}$ in height topped by a $10 \mathrm{~m}$ radius hemispherical dome for a total facility height of $60 \mathrm{~m}$. Internally the building was divided into eight levels with each level further subdivided into smaller compartments. The total number of compartments was between 60 to 70 depending on the configuration of removable partitions. The facility contained two fixed, staircases, and three adjustable vertical flow paths, an elevator shaft, and two sets of equipment hatches running the axial length of the building. The total free air volume of the facility was $11,000 \mathrm{~m}^{3}$ of with $4,800 \mathrm{~m}^{3}$ above the operating deck, the topmost floor of the facilty. The HDR containment, its compartments, internal structural materials, vent flow openings and other pertinent data are documented by Schall $^{42}$.

From 1984 to 1991 a total of four fire test series divided into seven fire test groups were performed inside the HDR facility ${ }^{5}$.

The fire tests consisted of the T51 series consisting of eleven propane gas tests and three wood crib tests, the T52 series consisting of four hydrocarbon oil pool tests, the E41 series with ten hydrocarbon oil pool tests, and the E42 series consitisting of three cable fire tests. Figure 4.1 shows the location of the various test series inside the HDR facility.

The two sections that follow will give a brief overview of the two test series that were simulated in this work. These were the T51 gas fire test series and the T52 oil pool fire test series. Further details about the test series including instrumentation maps, protocols, and measurement uncertainties can be found in a number of prior reports by this author ${ }^{2,43,44,45}$. 


\subsection{T51 GAS FIRE TEST DESCRIPTION}

The T51 test series consisted of a total of fourteen subtests. Test execution for the gas fire tests consisted of three separate testing periods. Approximately one half-hour before the scheduled start of a fire, the data acquisition system would be activated, its operation verified, and a pretest baseline data set taken. After the taking of baseline data, the burners would be ignited and fed at a constant flow rate for approximately one hour. After the gas supply was terminated, data collection continued for another forty minutes to collect cool down data.

\subsubsection{Layout of T51 Fire Rooms}

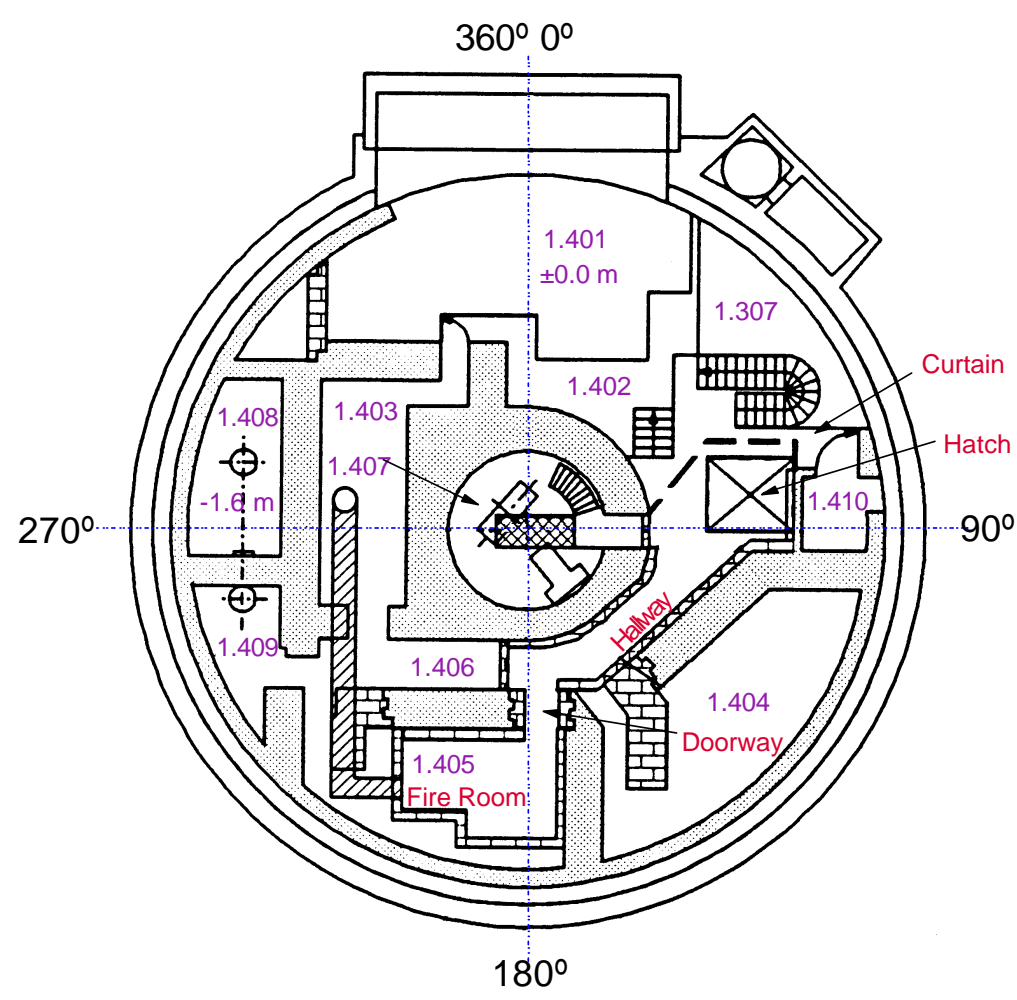

Figure 4.2: T51 Fire Floor (1.400 Level)

To avoid damaging the structure of the HDR facility, as the building was still considered a nuclear facility under German law, a special set of fire test rooms was prepared at the 1.400 level of the containment building, see Figure 4.1 for the location of the 1.400 level. These rooms also served to control the flow of gases in and out of the fire room. Figure 4.2 shows a cross section view of the 1.400 level and indicates the location of these rooms which consisted of the fire room with a narrow doorway, a long hallway wrapping around the reactor vessel shield wall, and a curtained area centered beneath the maintenance hatch next to the main staircase. For the remainder of the facility no special precautions were undertaken with respect to

insulation as gas temperatures outside the fire floor were anticipated to be below damage causing levels. Table 4.1 below gives the geometric data of the prepared compartments ${ }^{46}$.

The fire room, vertical cross section through the $0-180^{\circ}$ line and horizontal cross section at the $+0.0 \mathrm{~m}$ elevation, is shown in Figure 4.3, was constructed inside of room 1.405. The floor, walls, and ceiling of the fire room were lined with $25 \mathrm{~cm}$ of Ytong fire brick. The ceiling, which would be exposed directly to the fire plume, had additional protection in the form of a $3 \mathrm{~cm}$ thick layer of Alsiflex matting, a fire resistant, ceramic fabric. The floor of room 1.405 below the Ytong fire bricks consisted of a $1 \mathrm{~m}$ thick layer of concrete coated with a $1.5 \mathrm{~mm}$ thick coating of paint. Along the wall of the fire room opposite the doorway were the six gas burners used for the gas 


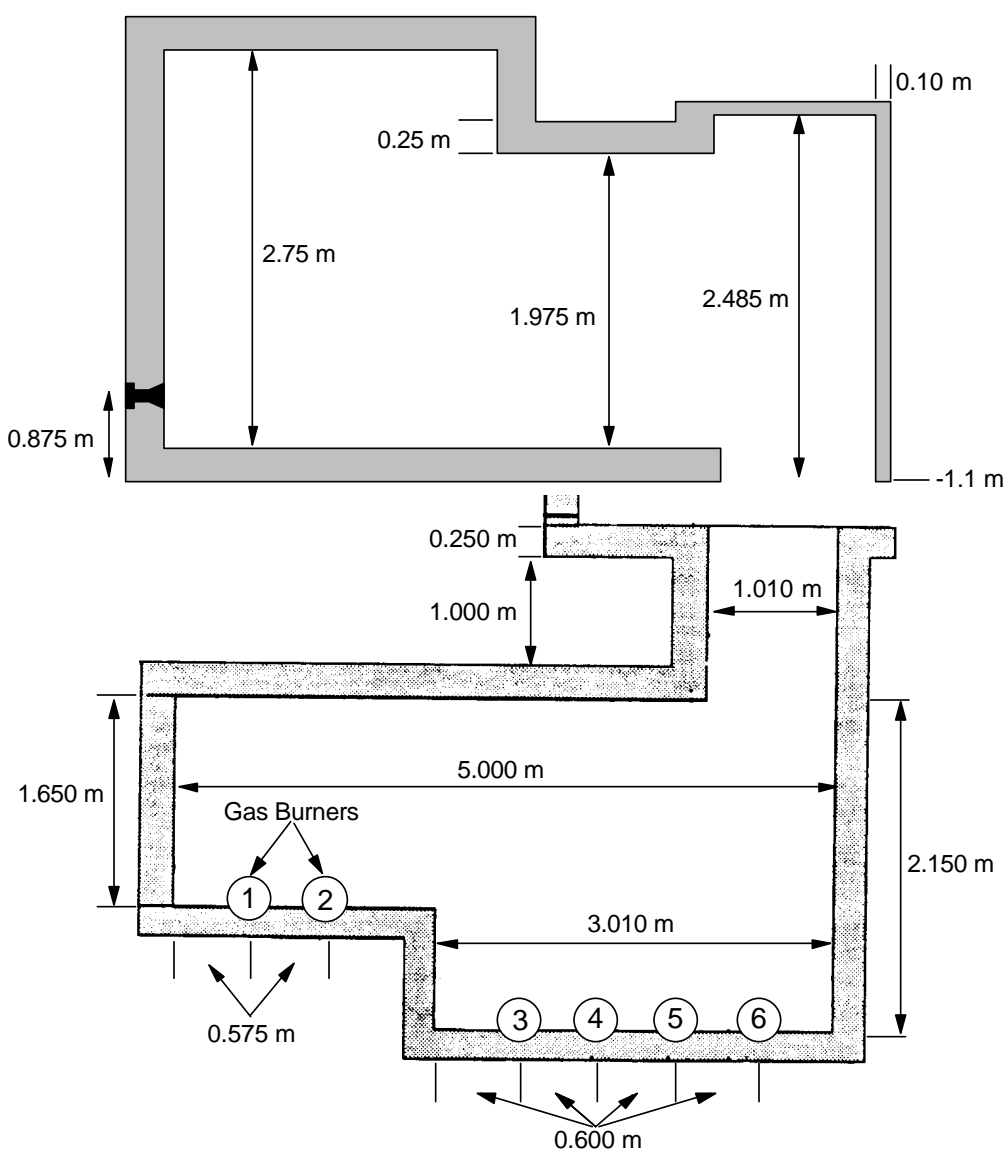

Figure 4.3: T51 Fire Room + Doorway fire tests. The gas burners were mounted $0.675 \mathrm{~m}$ above the floor of room 1.405 or $0.425 \mathrm{~m}$ above the brick lining of the fire room.

The doorway to the fire room had the same construction as the fire room itself. The doorway's height was less than both that of the fire room and the hallway. Unlike most test chambers created for fire experiments, the doorway had a significant depth of $1.5 \mathrm{~m}$. This will cause a reduction in flow rate through the doorway compared to a standard door due to friction losses along the walls in addition to the typical orifice losses of a standard door.

The hallway was constructed inside of room 1.406. This compartment wrapped around the reactor vessel shield wall, thus, the walls along the length are not parallel planes, but instead the wall around the vessel is an arc. The

doorway from the fire room enters the hallway slightly off set from the end of the hall. The walls and ceiling of the hallway were constructed of a $10 \mathrm{~cm}$ thick layer of Ytong fire brick. The floor of the hallway was not insulated and was of the same concrete and paint as in the remainder of the HDR. This results in the floor of the hallway being $25 \mathrm{~cm}$ below the floor of the fire room and doorway. The hallway had a constant ceiling height, and its width varied from $1.14 \mathrm{~m}$ at the door to the fire room to $1.8 \mathrm{~m}$ at the entrance to the curtained area. This curvature of the hallway and the general layout of neighboring compartments create a fairly complex flowpath for the exhaust gasses from the fire.

Table 4.1: T51 Fire Compartment Dimensions

\begin{tabular}{|c|r|r|r|c|c|}
\hline Compartment & $\begin{array}{c}\text { Height } \\
(\mathrm{m})\end{array}$ & $\begin{array}{c}\text { Area } \\
(\mathrm{m})\end{array}$ & $\begin{array}{c}\text { Volume } \\
(\mathrm{m})\end{array}$ & $\begin{array}{c}\text { Doorway } \\
(\mathrm{m} \text { wide } \mathrm{x} \text { m tall })\end{array}$ & $\begin{array}{c}\text { Hatch } \\
(\mathrm{m} \times \mathrm{m})\end{array}$ \\
\hline Fire room & 2.750 & 10 & 27 & $1.01 \times 1.975$ & $\mathrm{n} / \mathrm{a}$ \\
\hline Doorway & 1.975 & 2 & 3 & $1.01 \times 1.975$ & $\mathrm{n} / \mathrm{a}$ \\
\hline Hallway & 2.485 & 11 & 22 & $1.80 \times 2.485$ & $\mathrm{n} / \mathrm{a}$ \\
\hline Curtained & 5.350 & 12 & 63 & $7.40 \times 0.50$ & $2.3 \times 2.0$ \\
\hline
\end{tabular}


The curtained area was constructed next to the main staircase under an open maintenance hatch and was created primarily to force flue gasses from the fire away from the inside steel shell and up through the vertical shaft of the open maintenance hatches. This area was created by draping Alsiflex mats from the ceiling down to $0.5 \mathrm{~m}$ above the floor. This $0.5 \mathrm{~m}$ gap allowed for a cold air return flow to the fire room and attempted to force a better separation of the hot and cold gas streams. It is important to note that the gap below the curtain opened up towards both the main staircase and towards compartment 1.403 which had a floor elevation that was $1.1 \mathrm{~m}$ above the floor of the fire hallway or $0.6 \mathrm{~m}$ above the top edge of the gap beneath the curtain.

\subsubsection{T51 Fire Source}

The gas fires for the T51 tests used propane gas fed at a constant rate through one or more of the six burners located along the wall of the fire room opposite the fire room doorway. Each burner was located $0.625 \mathrm{~m}$ above the floor of the fire room. Before being injected into the burners the propane gas was premixed with $10 \%$ excess air, i.e. $10 \%$ more air than required by stoichiometry, to insure complete combustion of the propane.

\subsubsection{Subtest Selected for Modeling}

The particular T51 subtest which was modeled was the T51.23 test. This test had a fire power of 1.011 MW and was a repeat of the T51.14 test. The T51 gas subtests in general make for superb tests for fire modeling due to the simplicity of specifying the test boundary conditions. This simplicity is due to a couple of factors. First, the fire source is very well defined. Since the propane gas is being fed to the burners with $10 \%$ excess air, nearly complete combustion is occurring at the burners. Second, the geometry for these tests is very well defined. The simple fire source makes this test well suited for examining the performance of a computational method's heat and mass transfer algorithms without the added uncertainty usually associated with a liquid pool fire or solid fuel.

\subsection{T52 TEST DESCRIPTION}

The second test series of fire experiments was the T52 oil fire test series which consisted of four oil pool fire tests performed in $1986^{47,48,49}$. The tests ranged in power from two to four megawatts with the fire lasting approximately 30 minutes. Whereas the previous test series, the gas and wood fires, were performed at a level low in the containment building, it was decided to position this test series high up in the containment building as shown in Figure 4.1. Thus, the fires were positioned in a special fire compartment constructed on the 1.900 level, the level just below the operating deck. It was anticipated that this would confine smoke and soot to the dome region. The fire compartment, see Figure 4.4, was located such that it vented directly into the dome through the maintenance hatch next to the spiral staircase.

Fuel for the fires consisted of an initial volume of oil in a pool with a surface area ranging from 1

$\mathrm{m}^{2}$ to $3 \mathrm{~m}^{2}$ in size. A nozzle augmented the initial amount of fuel by feeding a continuous supply of oil once the initial pool was nearly consumed. The nozzle mass flow rate varied with each test. Each fire lasted approximately 30 minutes. 
For this test series special attention was paid to the buoyant fire plume entering the upper dome. Three two-dimensional grids of instrumentation were placed in the vertical flow path of the plume exiting the fire room. These grids contained thermocouples, velocity probes, and $\mathrm{CO}_{2}$ sensors. The grids were located at the exit of the maintenance hatch leading from the 1.800 level to the 1.900 level, at the exit of the maintenance hatch leading to the dome from the 1.900 level, and centered over the maintenance hatch at near the elevation of the polar crane mounted in the dome.

\subsubsection{Layout of T52 Fire Rooms}

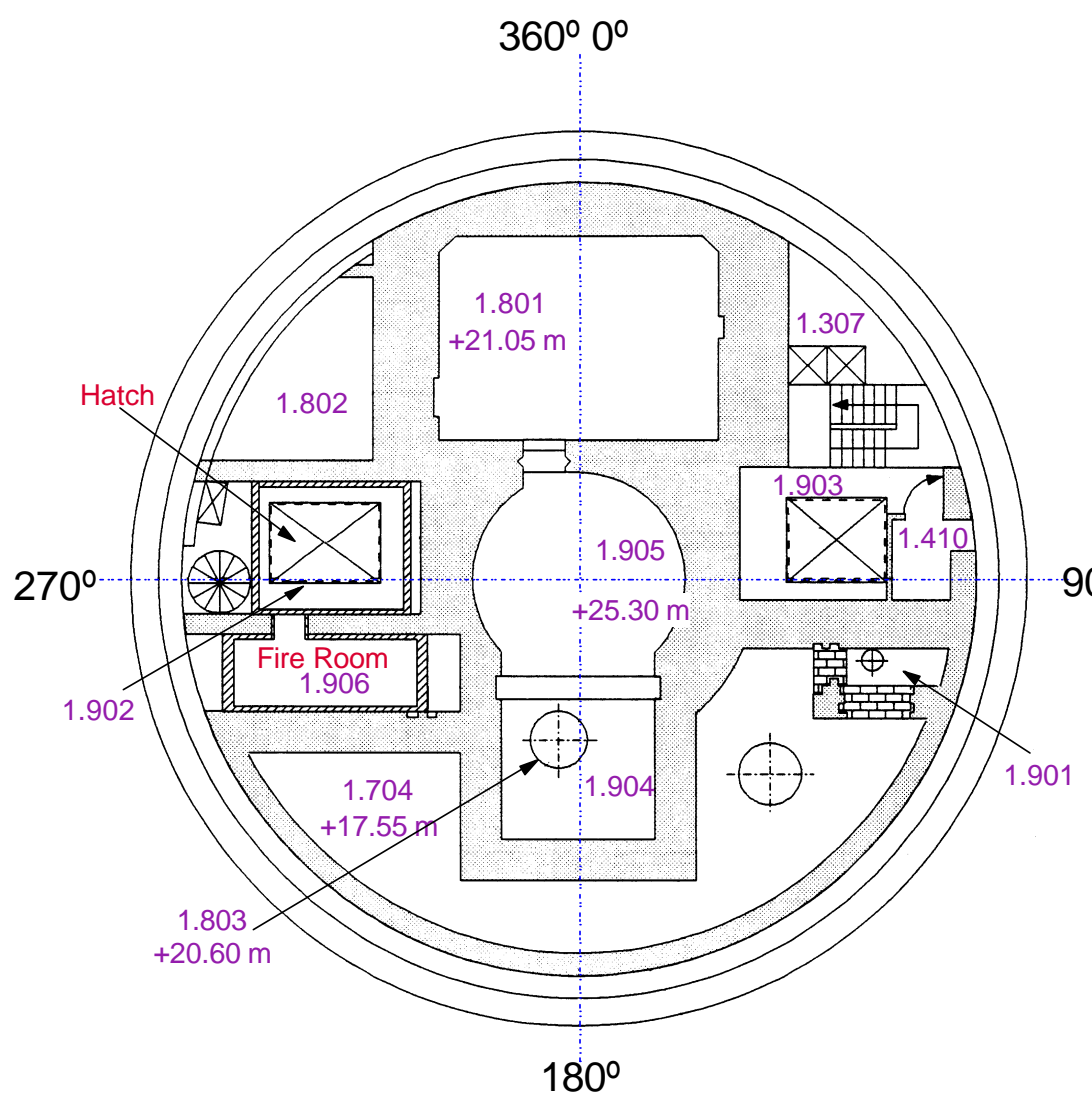

Figure 4.4: T52 Fire Floor (1.900 Level)
The T52 test series took place in a set of specially constructed compartments inside of rooms 1.902 and 1.906, see Figures 4.5 and 4.6 for horizontal and vertical cross-sections of the compartments. As with the T51 test series, there was concern about the intense heat in the immediate vicinity of the fire damaging the HDR structure. In particular there were concerns about the steel shell of the containment being damaged by high temperatures. These compartments consisted of a fire room, a doorway region, and a region below the auxiliary maintenance hatch located near the spiral staircase. Table 4.2 gives some geometric details of the compartments.

Table 4.2: T52 Fire Compartment Dimensions

\begin{tabular}{|c|c|c|c|c|}
\hline Compartment & $\begin{array}{c}\text { Height } \\
(\mathrm{m})\end{array}$ & $\begin{array}{c}\text { Floor Area } \\
\left(\mathrm{m}^{2}\right)\end{array}$ & $\begin{array}{c}\text { Volume } \\
\left(\mathrm{m}^{3}\right)\end{array}$ & $\begin{array}{c}\text { Flow Area } \\
\left(\mathrm{m}^{2}\right)\end{array}$ \\
\hline Fire Room & 2.8 & $4.58 \times 1.75=7.88$ & 24 & $\mathrm{n} / \mathrm{a}$ \\
\hline Doorway & 3.0 & $0.95 \times 0.78=0.74$ & 2 & $3.0 \times 0.95=2.85$ \\
\hline Maintenance Hatch Area & 5.0 & $3.6 \times 3.05=10.98$ & 52 & $1.85 \times 2.6=4.81$ \\
\hline
\end{tabular}




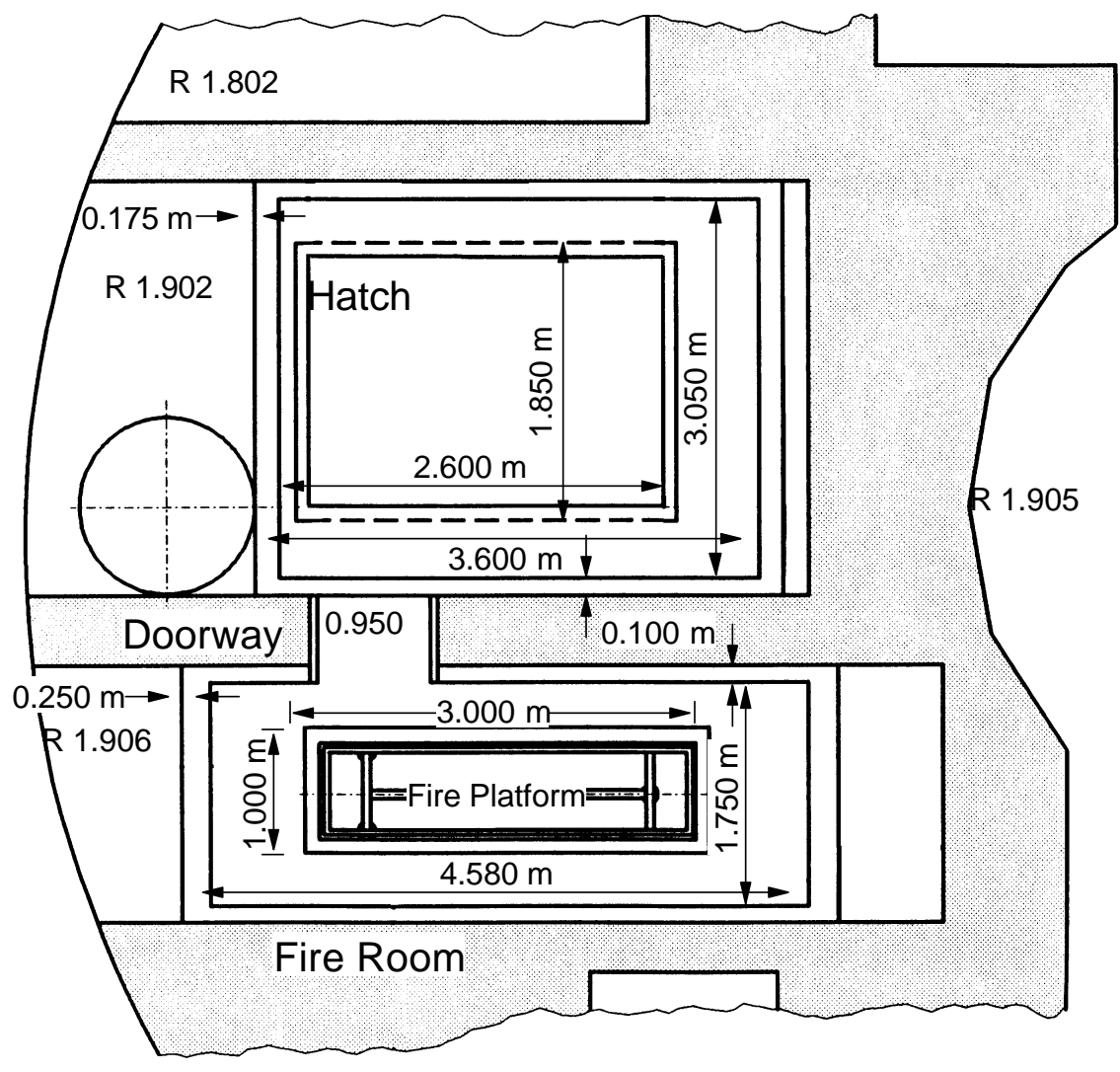

Figure 4.5: T52 Horizontal CX

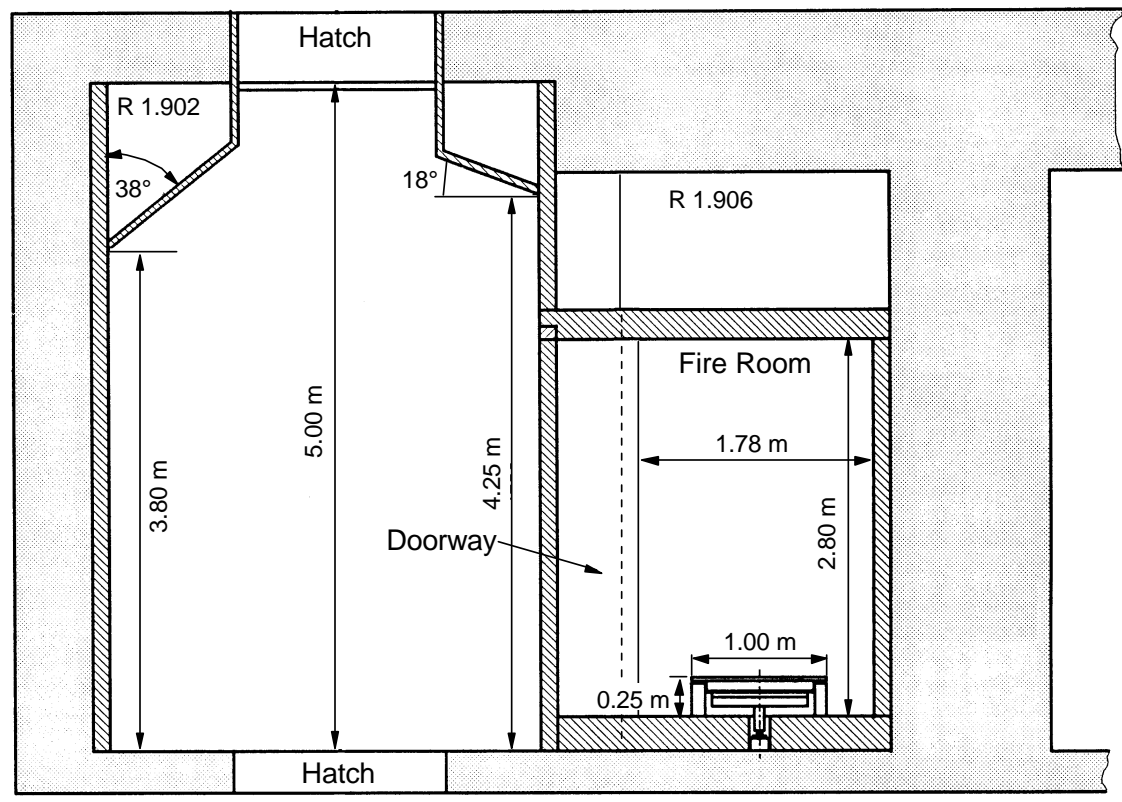

Figure 4.6: T52 Vertical CX

The fire itself was located in a compartment constructed in room 1.906 . This compartment was constructed out of Ytong firebrick. The floor, the ceiling, and the shorter length walls were constructed of a 25 $\mathrm{cm}$-thick layer of firebrick. The other two walls had a $10 \mathrm{~cm}$-thick layer. The ceiling was given an additional insulative layer consisting of a $3 \mathrm{~cm}$ thickness of Alsiflex matting. In the center of the fire room a $25 \mathrm{~cm}$ high platform was constructed to suspend the oil pans in which the fire would occur above three digital scales used to measure the burning.

The fire room was connected to the area beneath the maintenance hatch by a doorway similar in size to the doorway in the T51 tests. To avoid creating too narrow of a doorway, it was lined on the side walls with only a 3 $\mathrm{cm}$ thickness of Alsiflex matting. The floor and ceiling of the doorway were lined with a 25 $\mathrm{cm}$-thick layer of Ytong firebrick.

Since the steel shell had no protective concrete layer in the region below the maintenance hatch in room 1.902, a compartment was also constructed in this room. This compartment was created by building a wall to isolate the spiral staircase and the 
steel shell. The wall was created with a $17.5 \mathrm{~cm}$ layer of Ytong firebrick. The other walls were lined with a $10 \mathrm{~cm}$ layer of Ytong firebrick. To enhance the flow of the combustion products into the dome, the ceiling of room 1.902 was modified to create a tapered chimney like structure. This was created using $2 \mathrm{~cm}$ thick Promatec plates.

\subsubsection{T52 Fire Source}

The fire source for the T52 test series was Shellsol T. Shellsol T is a hydrocarbon solvent manufactured by Shell Chemicals of Norway. Shellsol T is a liquid isoparaffin consisting of 11 to 13 carbon atoms with $80 \%$ of the molecules having 12 atoms. It is a clear liquid that generates less soot than common fuel oils such as kerosene. Shellsol T materials properties at standard temperature and pressure conditions are shown below in Table 4.3 ${ }^{47,50}$.

Table 4.3: Shellsol T Material Properties

\begin{tabular}{|c|c|c|c|}
\hline $\begin{array}{c}\text { Density } \\
\left(\mathrm{kg} / \mathrm{m}^{3}\right)\end{array}$ & $\begin{array}{c}\text { Boiling Temperature } \\
\left({ }^{\circ} \mathrm{C}\right)\end{array}$ & $\begin{array}{c}\text { Flashpoint } \\
\left({ }^{\circ} \mathrm{C}\right)\end{array}$ & $\begin{array}{c}\text { Heat of Combustion } \\
(\mathrm{kJ} / \mathrm{kg})\end{array}$ \\
\hline 761 & $181-213$ & 60 & 42,500 \\
\hline
\end{tabular}

\subsubsection{Subtest Selected for Modeling}

The T52.14 test was selected for modeling with CFAST and FDS. The primary reason for selecting this test was that it was used in a prior international effort of computer modeling of containment fires ${ }^{12,51}$. In order for that effort to have

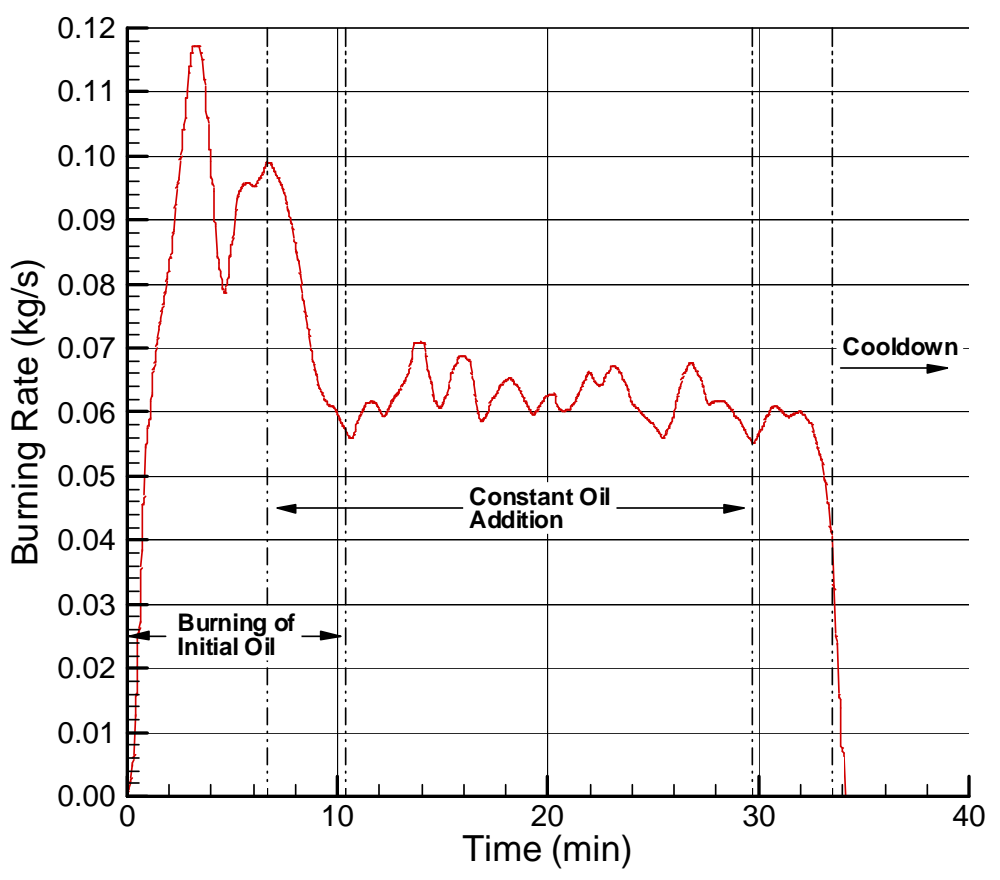

Figure 4.7: T52.14 Burning Rate and Test Phase Definitions occurred, more care was given to generating the burning rate function for this test than for the other tests in the series. Since a fire model is highly dependent on the accuracy of the input burning function, the T52.14 test was the clear choice for modeling. Figure 4.7 shows the burning rate function for the T52.14 test. The various stages of the test, burning of the initial oil volume, constant fuel addition, and post-fire cooldown are labeled on the plot. 


\subsection{TEST SIMULATIONS}

This chapter briefly discusses the CFAST and FDS input files for the T51.23 and T52.14 fire tests and the hand calculations performed for each test. For both fire tests, only one input file for each computer code was executed for this report. The input files utilized resulted from a number of years of prior effort in using both FDS and CFAST for simulating the HDR fire tests. Lessons learned from the successes and failures of the prior modeling efforts were used to develop the final input files discussed in this Chapter. For a more detailed discussion of the input files for CFAST and FDS and a discussion of prior modeling efforts by this author for the T51 and T52 fire tests, the reader is referred to references 2, 44, 45, 52, 53, and 54. For more details on the hand calculations performed, including copies of the Mathematica files used, the reader is directed to reference 2 .

\section{$5.1 \quad$ T51.23 SIMULATION}

The T51.23 fire test was selected mainly because it represented the best combination of known boundary conditions and instrumentation map of all the HDR fire experiments ${ }^{46}$. Since the T51.23 fire test used propane gas burners fed with a gas-air mixture, the heat release rate and the combustion chemistry can be specified with little error. Furthermore, the T51.23 test did not involve the use of any of the HDR facility's ventilation systems which eliminates a source of added complexity. If a computer model cannot reasonable simulate a test with such a simple fire source, one would be forced to question if the model's results could be applied to any test simulation.

The following three sections describe the inputs for the FDS and CFAST simulations of the HDR T51.23 gas fire test and the methodology used for the hand calculations. The FDS simulation of the test encompassed the fire room, the hallway, and the curtain area for a period of 10 minutes from the start of the fire. The CFAST simulation encompassed the entire HDR facility at or above the elevation of the fire room and covered the duration of the fire, 60 minutes, plus 30 minutes of the cool down period after the fire. Hand calculations were performed for the fire room only. Results of the model simulations are compared with data in Chapter 6.

\subsubsection{FDS Model}

\subsubsection{Geometry}

As FDS is very memory intensive, it was decided, therefore, to only include the fire room, the hallway, and the curtained region beneath the hatch in the T51.23 FDS input file. Modeling these regions of the T51.23 test presented an interesting challenge for FDS modeling. The current version of FDS nodalizes a geometry in purely rectilinear coordinates. The T51.23 test, however, contains a mix of orthogonal surfaces, non-orthogonal surfaces, and cylindrical surfaces on the fire floor. This mix of surfaces results from the hallway leading from the fire room to the curtained area. The hallway wraps around the cylindrical reactor vessel shield wall at the center of the containment building. One wall of the hallway is approximately a $60^{\circ}$ arc. The opposite wall of the hallway is a plane perpendicular to the $135^{\circ}$ radius drawn from the 
center of the HDR. This plane is non-orthogonal to the fire room surfaces. Lastly, the ceiling at the end of the hallway rises up slightly as it reaches the curtained area creating an inclined plane.

Creating the geometry described above in FDS requires specifying a complex series of blockages to approximate the aforementioned surfaces. The side walls of the hallway were modeled by a series of stair steps that approximated each of the two surfaces. Twenty stair steps were used for each wall which results in steps representing about $20 \mathrm{~cm}$ of arc length.. There is conflicting documentation regarding the rise in the hallway ceiling near the curtained area with some figures showing a gradual rise and other figures indicating a sharp rise. Since there is almost no instrumentation in the curtained area, it was decided to not model a form of inclined plane as the inclusion or lack thereof would not have much effect upstream in the hallway at the available sensor locations.

The resulting geometry yielded a computational domain $11.195 \mathrm{~m}$ x $9.645 \mathrm{~m}$ x $4.600 \mathrm{~m}$ in dimension. This region was mapped to a finite differenced volume of 100 nodes $x 90$ nodes x 50 nodes for a total of 450,000 nodes. The resulting geometry is shown in Figure 5.1. This figure shows a top down view (XY plane), a view from the right side (YZ plane), and an oblique view.

\subsubsection{Flow Boundary Conditions}

Experiment T51.23 used 5 of the 6 available gas burners, numbers 1 through 5 . Since the T51 tests series injected a mix of propane gas and air through the burners at a constant flow rate, the five gas burners were defined in FDS as separate vents with a constant inlet velocity. These vents were defined in FDS according to their physical location as shown in Figure 4.3. For FDS v2.0 $\alpha$, two sets of burners were created. The first set at the physical location of the burners was defined as a source of fuel. The second set directly located above the first set was defined as a source of ambient air. This was required as the mixture fraction formulation in FDS v2.0 $\alpha$ precludes the use of premixed fuels.

In addition to the gas burners, two additional vent specifications were needed. They were the flow area under the curtain and the flow area through the maintenance hatch. Both of these were defined as passive vents, i.e. flow of either direction through the vent is allowed (see 3.1.1.5 for more details).

\subsubsection{Output Options}

A number of HDR instrumentation locations were specified in the input file to be output during the code execution. In all, 81 sensors in the T51.23 fire compartments were specified. 

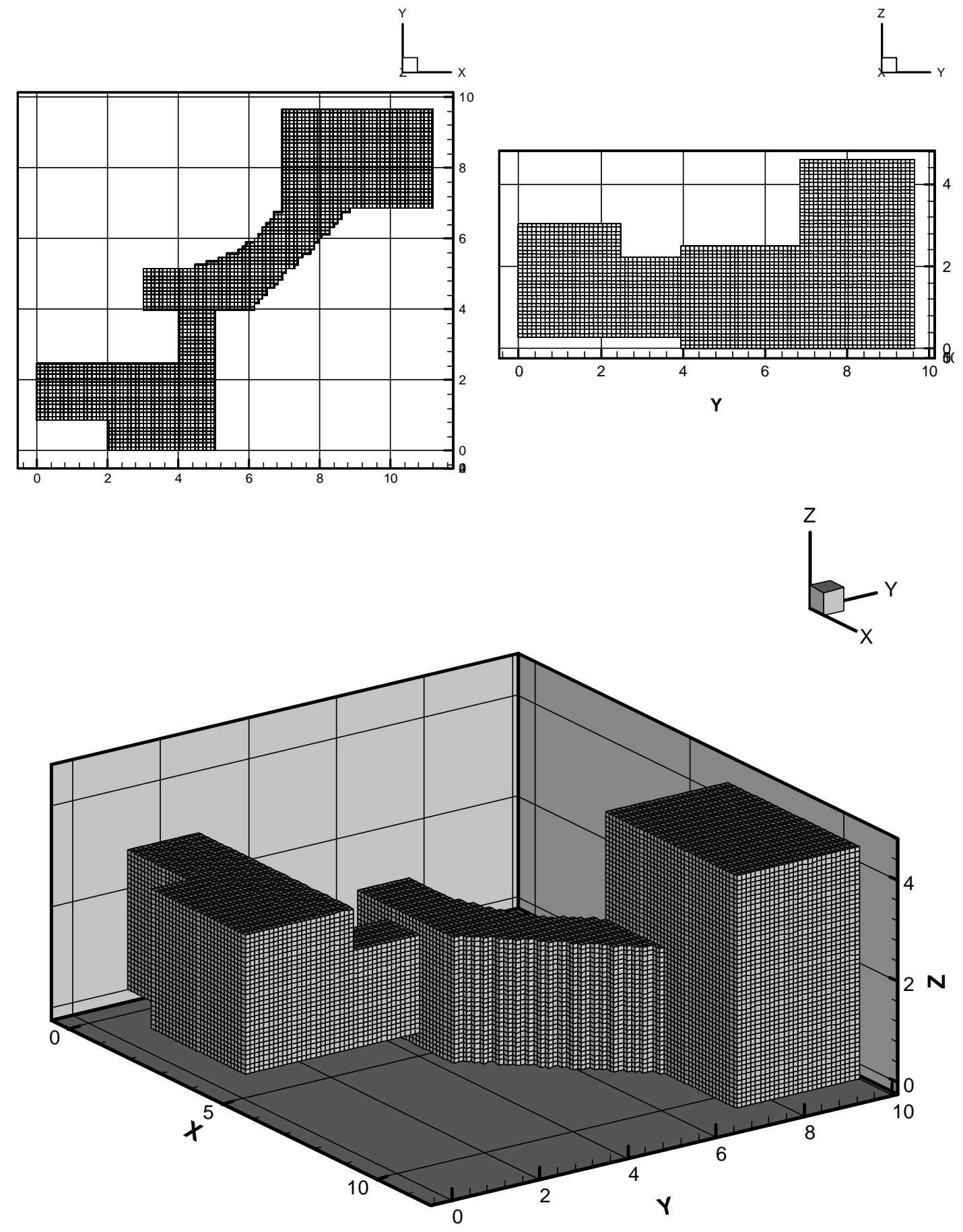

Figure 5.1: T51.23 FDS Nodalization 


\subsubsection{Wall Boundary Conditions}

There were two surface types which required defining in the input file. The first surface type was the Ytong firebrick that lined the fire room and the walls and ceiling of the hallway. The second surface type was the exposed concrete on the floor of the hallway and the floor and ceiling of the maintenance hatch. All surfaces of the fire room and doorway were set to be firebrick as were the walls and ceiling of the hallway. The wall of the hatch area near the HDR centerline was also defined as firebrick as was the wall of the hatch area where the hallway entered. The remaining surfaces were defined as concrete.

\subsubsection{CFAST Models}

\subsubsection{Overview}

The CFAST input file created for this work was a ten compartment model that included the HDR faciltiy from the fire level to the dome. The case presented here is a subset of the larger body of work by the author discussed at the beginning of this. Results of the CFAST computation are documented in Chapter 6.

For the CFAST input file, the simulation began with a $100 \mathrm{~s}$ null transient, the reason for which will be described in the next subsection which discusses the compartments and compartment interconnections. The heat release rate was ramped up at the start of the fire and down at the end using a $1 \mathrm{~s}$ linear ramp. The fire is followed by a $1 / 2$ hour cooldown period.

\subsubsection{Compartment Specifications and Compartment Interconnections}

This subsection will discuss the compartment layouts and the specifications for compartment interconnections for the T51.23 CFAST model. A total of seven material definitions were required for the T51.23 CFAST model.

The first subsection of the model encompassed the specially built compartments on the 1.400 level including the fire room and the fire room doorway, the hallway, and the curtained area. Connections are defined from the fire room to the doorway, from the doorway to the hallway, from the hallway to the curtained area, from the curtained area to the 1.500 level and from the curtained area to the remainder of the 1.400 level. The latter two connections are to the ambient. In addition to these flow connections a simple ventilation system representing the air flow through the gas burners was defined consisting of an inlet duct from Room 1.603, a blower, and an outlet duct to the fire room.

Using the data in Table 4.1, the models of the four compartments were created. Since only the doorway and the curtained area were rectangular spaces, length and width dimensions had to be created for the other two compartments. For the fire room it was decided to preserve the distance from the back wall of the fire room, $2.51 \mathrm{~m}$, to the doorway entrance plane. For the hallway and the curtained area, it was important to maintain a room dimension equivalent to the dimension of the largest flow connection. For the hallway, this meant maintaining the hallway width of $1.8 \mathrm{~m}$ 
were it connected to the curtained area. Heights for the fire room, the doorway, and the hallway were given as the actual compartment heights. The height for the compartment was given as the total height from the floor of the curtained area to floor of the 1.500 level. The floor level for the fire room and the doorway were set to an elevation of $0.25 \mathrm{~m}$ to account for the raised floor due to the layer of Ytong firebrick placed in those areas. The floor level for the hallway and curtained area was set to an elevation of $0 \mathrm{~m}$.

Compartment interconnections were defined according to the data in Table 4.1 with the exception of the under-the-curtain connection in the curtained area. An examination of curtained area reveals that although the length of the curtain is $7.3 \mathrm{~m}$, only a portion of the length is available for flow. Those portions of the curtain near the reactor vessel shield wall and the elevator, room 1.410, are not contributing to the return flow under the curtain due to flow obstructions present at those locations. Therefore, it was only the length of the curtain neighboring the stairs, $4.3 \mathrm{~m}$, that was specified for a flow connection.

The last portion of this model subsection addressed the ventilation system for supplying air to the propane gas burners. This system took its suction from room 1.603 next to the spiral staircase and the discharge node was placed in the fire room $0.625 \mathrm{~m}$ above the floor. A constant speed fan was placed in between the suction and discharge locations to create a constant flow of air into the fire room.

The next subsection contains compartments for the maintenance hatch region of the 1.500 level and three compartments to represent the 1.600 level (one for the main staircase hatch, one for the spiral staircase hatch and R1.603 where the air supply intake was located, and one for R1.606 which connected the two sides of the building). These additional compartments were added with two issues in mind. The first is that the total height of the HDR facility should be preserved as well as the height of the individual levels. The second was that only the volume of the facility which communicated with the fire room be included in the model.

The first item fixed the height of the additional compartments. These heights were determined from Schall ${ }^{42}$ which gave elevations for selected locations in the facility. This fixed the 1.500 level compartment to a height of $5.5 \mathrm{~m}$, the 1.600 level hatch compartments to $5.05 \mathrm{~m}, \mathrm{R} 1.606$ to $4.6 \mathrm{~m}$, the upper region compartment to $34.395 \mathrm{~m}$, and the 1.600 level to 1.400 level connecting compartment to $6.6 \mathrm{~m}$.

The second item was not as obvious. On the 1.500 level, which lacked a single large return connection from higher levels, it was decided to only model that portion of the level adjacent to the maintenance hatch. Thus, the 1.500 level compartment dimensions were set to be the same as the curtained area dimensions on the 1.400 level. The 1.600 level included a number of features which needed to be accounted for in the compartment definitions. These included the main staircase hatch, the large return connection from the dome region (the spiral staircase hatch), the air supply intake, and the hallway connecting the two halves of the facility. Therefore, the main staircase hatch area was given the net volumes of R1.604 and R1.337 (main staircase), the connecting hall was given the volume of R1.606, and the spiral staircase side was given the volumes of R1.611 (spiral staircase) and R1.603 (air supply location). The flow 


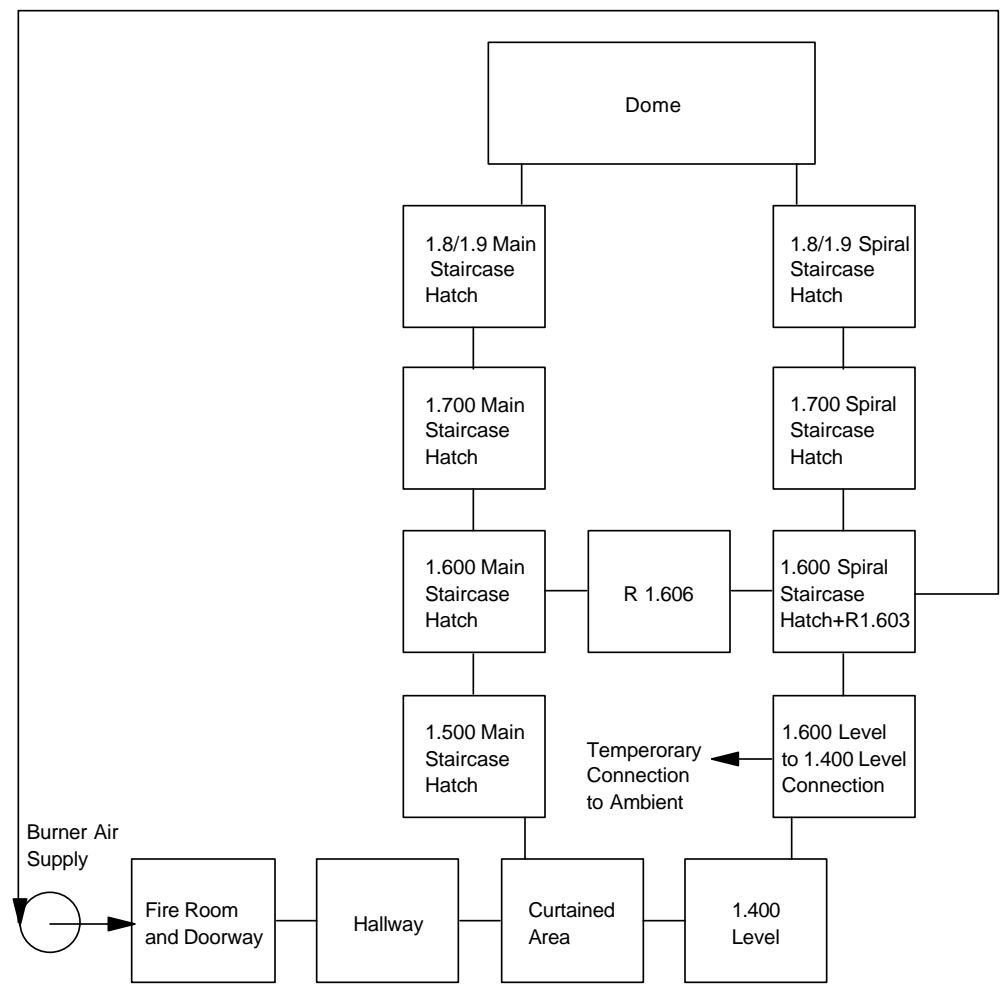

Figure 5.2: T51.23 CFAST Model Compartment Layout connection was given the dimensions of the net flow area between the 1.600 level and the 1.400 level not including the hatches.

Flow connections between the new compartments were given the areas of the maintenance hatches for the vertical connections and the smallest cross-sectional area of R.1606 for the horizontal connections on the 1.600 level. In addition to these connections, another flow connection was required. CFAST would not initialize the ventilation system without a connection to the ambient. Therefore, a null transient of $100 \mathrm{~s}$ was added to the input file during which a small connection to the outside was opened in the 1.600 level to 1.400

level connecting compartment. At the start of the fire this connection was closed at which point CFAST continued to execute.

The remaining compartments were two compartments for the spiral and main staircase side of the 1.700 level, two compartments to represent the 1.800 level and 1.900 level spiral and main staircase side, and a final compartment for the dome. The 1.800 and 1.900 levels were combined into one level since CFAST had difficulties running with the two levels defined separately. For the remainder of the facility only those compartments directly adjacent to the maintenance hatches were included in the active volume. The non-adjacent compartments did not possess significant flow connections to the ones included above, and were thus ignored. The remainder of the facility included (given up the main staircase side and down the spiral staircase side: R1.707 and R1.347, R1.805 and R.1357, R.1903 and R1.367, the dome, R1.902 and R.1906, 1.802 and R.1804, and R1.703 and R1.708. Figure 5.2 below shows the layout for the model.

\subsubsection{Hand Calculations}

A simple hand calculation was performed for the fire room of the T51.23 test using Mathematica v3.0 ®. Hand calculations are a valuable tool in performing safety analyses. Their simplicity and speed enable them to be used for scoping basic details of a problem. While they may not be as accurate as a complex simulation, their results can nonetheless serve as a sanity check for a more detailed method. Therefore, to demonstrate their potential usefulness the methods 
described in 3.1 were applied to the T51.23 experiment. The hand calculation used for the T51.23 test made the following assumptions:

1. The fire has reached steady-state conditions with respect to the wall heat transfer. The measured data show this assumption is valid for the end of the hour long gas fire as all temperatures have ceased rising significantly by the end of the fire.

2. The fire room possesses two distinct layers. Again this assumption is born out by the measured data which shows low temperature near the floor of the fire room, even in the corner furthest from the doorway.

3. The smoke layer height in the fire equals the burner height off the floor. There was not enough instrumentation in the fire room to accurately determine the layer height, however, given the burner arrangement it is unlikely that the layer interface was far from this location.

4. The mass addition of the fuel/air mixture is negligible compared to the mass flow rate into the room at the doorway. Mass addition to the fire room from the fuel and air mixture was approximately $0.1 \mathrm{~kg} / \mathrm{s}$. An average lower layer velocity into the fire room of $1 \mathrm{~m} / \mathrm{s}$ would result in over $1 \mathrm{~kg} / \mathrm{s}$ of mass input.

As a result of the above assumptions, most notably the second assumption, the method described in 3.1.1.1 was used to analyze the T51.23 fire room. Results are presented in Chapter 6 and the Mathematica ${ }^{\circledR}$ notebooks are documented in Appendix C.

\subsection{T52.14 SIMULATION}

The following two sections describe the inputs for the FDS simulations and the CFAST simulations of the HDR T52.14 oil pool fire test. The FDS model encompassed the fire room, the fire room doorway, the region beneath the maintenance hatch from the ceiling of the 1.800 level to the top of the operating deck, and a portion of the dome region from the operating deck to the measurement grid located beneath the start of the hemispherical portion of the dome region. The CFAST simulation encompassed the entire HDR facility from the 1.600 level to the dome and covered the duration of the fire plus 15 minutes of the cooldown period after the fire. This encompassing modeling effort resulted from a prior assessment of the data for all the T52 tests $^{3,45}$.

\subsubsection{FDS Model}

\subsubsection{Geometry}

For the FDS model it was desired to simulate enough of the HDR facility in order to make use of the two sensor arrays located in the dome. Thus, the FDS model included the fire room, the hatch area adjacent to the fire room, and a portion of the dome up to the level of the second 
measurement grid. An area around the grid was included to account for the effect of containment steel shell which would serve to restrict entrainment into the plume along one side.

Unlike the T51.23 test, there were few non-orthogonal surfaces to model. The fire room, the doorway, and the lower portion of the hatch region were all composed of surfaces orthogonal to the Cartesian grid. The upper portion of the hatch region, however, had the shape of a truncated pyramid. As with the T51.23 model, this was done by defining a staircase-stepped region to approximate the non-orthogonal surfaces. The combined computational domain was $9.00 \mathrm{~m} \mathrm{x}$ $8.31 \mathrm{~m} \times 14.2 \mathrm{~m}$ and encompassed the fire room, doorway, hatch, and a portion of the dome surrounding the upper sensor grid. The domain was discretized with 72 nodes $\mathrm{x} 64$ nodes $\mathrm{x} 120$ nodes for a node total of 552,960 nodes. Figure 5.3 shows the noding for this geometry. This figure shows a top down view (XY plane), a view from the right side (YZ plane), and an oblique view with part of the dome blanked to show the connection to the lower rooms.

\subsubsection{Flow Boundary Conditions}

Test T52.14 was used for code comparisons during the execution of the T52 test series ${ }^{51}$. Because of this, HDR staff made efforts to define a burnup curve on the basis of the available weight sensor data. A copy of this curve can be found in Travis's report on using the GASFLOW computer code to model the T52.14 test ${ }^{51}$. A piecewise linear curve was fit to the burnup curve and used to define a time-dependent fire source for FDS. A $2 \mathrm{~m}^{2}$ vent was defined at the center of the oil platform nodes and assigned the time-dependent function.

In addition to the oil pan, further vent specifications were needed. The maintenance hatch below the fire room was defined as a passive vent, i.e. flow of either direction through the vent is allowed. Also the following surfaces in the dome region were defined as open vents: $y=0.00 \mathrm{~m}$, $y=8.31 \mathrm{~m}, \mathrm{x}=9.00 \mathrm{~m}, \mathrm{z}=14.2 \mathrm{~m}$. The $\mathrm{x}=0.00 \mathrm{~m}$ surface was the steel shell of the dome, and as such was not open for flow.

\subsubsection{Output Options}

Since FDS will output user selected variables at user specified locations during its computation, a number of HDR instrumentation locations were specified in the input file to be output during the code execution. In all, 86 sensors were specified. 


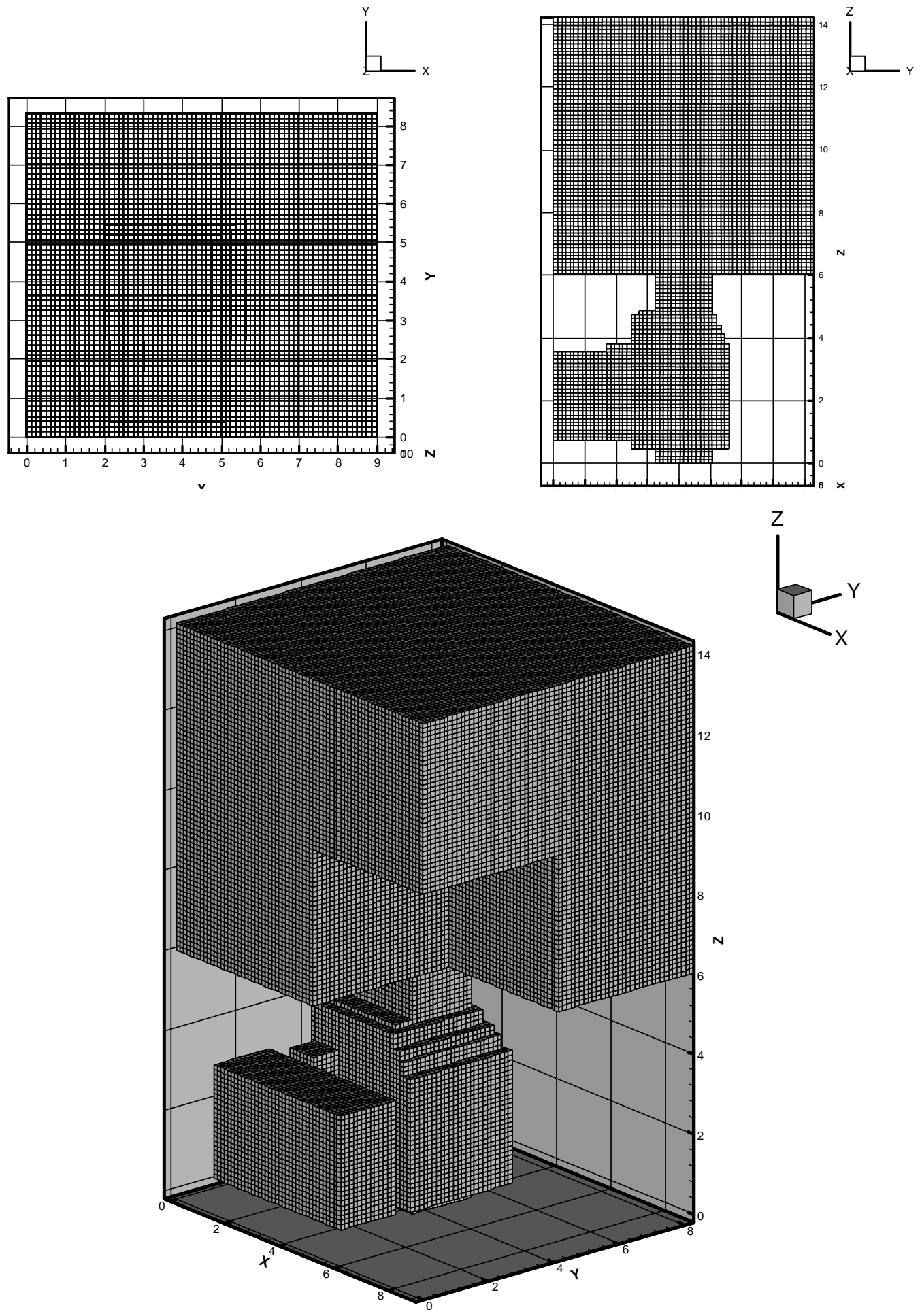

Figure 5.3: T52.14 FDS Nodalization for Fire Level and Dome Input Geometry with Cut-away to Show Hatch Connection to Dome 


\subsubsection{Wall Boundary Conditions}

Three surface definitions were used for the T52.14 input files. These surfaces were the $0.25 \mathrm{~m}$ thick Ytong firebrick walls in the fire room, the $0.10 \mathrm{~m}$ thick Ytong firebrick walls below the maintenance hatch, and the HDR concrete. All surfaces of the fire room and the ceiling and floor of the doorway were set to be the thick firebrick material. The remainder of the doorway and the side walls of the hatch area were defined as the thin firebrick material. All remaining surfaces were defined as the HDR concrete.

\subsubsection{CFAST Models}

\subsubsection{Overview}

The CFAST input file was a 12 compartment model that encompassed the HDR facility from the 1.600 level through the dome and included three nodes in the dome. This model resulted from a series of prior model development efforts ${ }^{3,45,53,54}$ (Floyd, et al., 2000a-c and Floyd, 2000d).

\subsubsection{Combustion Related Input Cards}

The combustion product values were based on information in Karlsson and Quintiere ${ }^{1}$. Chapter 9 of their book contains information on combustion product formation in various fuels. Table 9.2 in the book gives combustion product yields for a variety of fuels in well-ventilated fires and Figure 9.7 gives ratios of well-ventilated to under-ventilated yields for a variety of fuels for a spectrum of equivalence ratios. Hydrocarbon oils were not among the fuel types listed in either table. Of the fuels available in both locations, polystyrene appeared a good match as it is a nongaseous hydrocarbon. From Table 9.2 in the book the yields of $\mathrm{CO}_{2}, \mathrm{CO}$, and soot were used to calculate the percent of the carbon atoms in the fuel that went into the various products for a well-ventilated fire. These fractions were scaled to the chemical formula for Shellsol-T. Figure 9.7 was then used to calculate the product yields for an equivalence ratio of 3, which was selected due to the large $\mathrm{CO}$ concentrations measured during the test. These product yields were then used for the CFAST input.

\subsubsection{Compartment Specifications and Compartment Interconnections}

This subsection will discuss the compartment definitions and the definitions for compartment interconnections for the CFAST model for T52.14. A total of seven material definitions were required for the T52.14 CFAST model. The CFAST models encompassed the HDR facility from the 1.600 level to the dome. Maintenance hatches to the lower levels were sealed as were the doors to the elevator shaft. Therefore, no significant flow path existed to the 1.200 through the 1.500 levels. The model contained the following compartments: fire room and fire room doorway, fire level hatch region, three node dome, one compartment for each level on the main staircase side from 1.900 to 1.600 , and one compartment for each level on the spiral staircase side from 1.600 to 1.800 . The three node dome portion of the model resulted from a series of prior model building efforts undertaking by the author as part of an earlier study of the T52 test series $^{45}$. The resulting compartments are shown in Figure 5.5 below. 


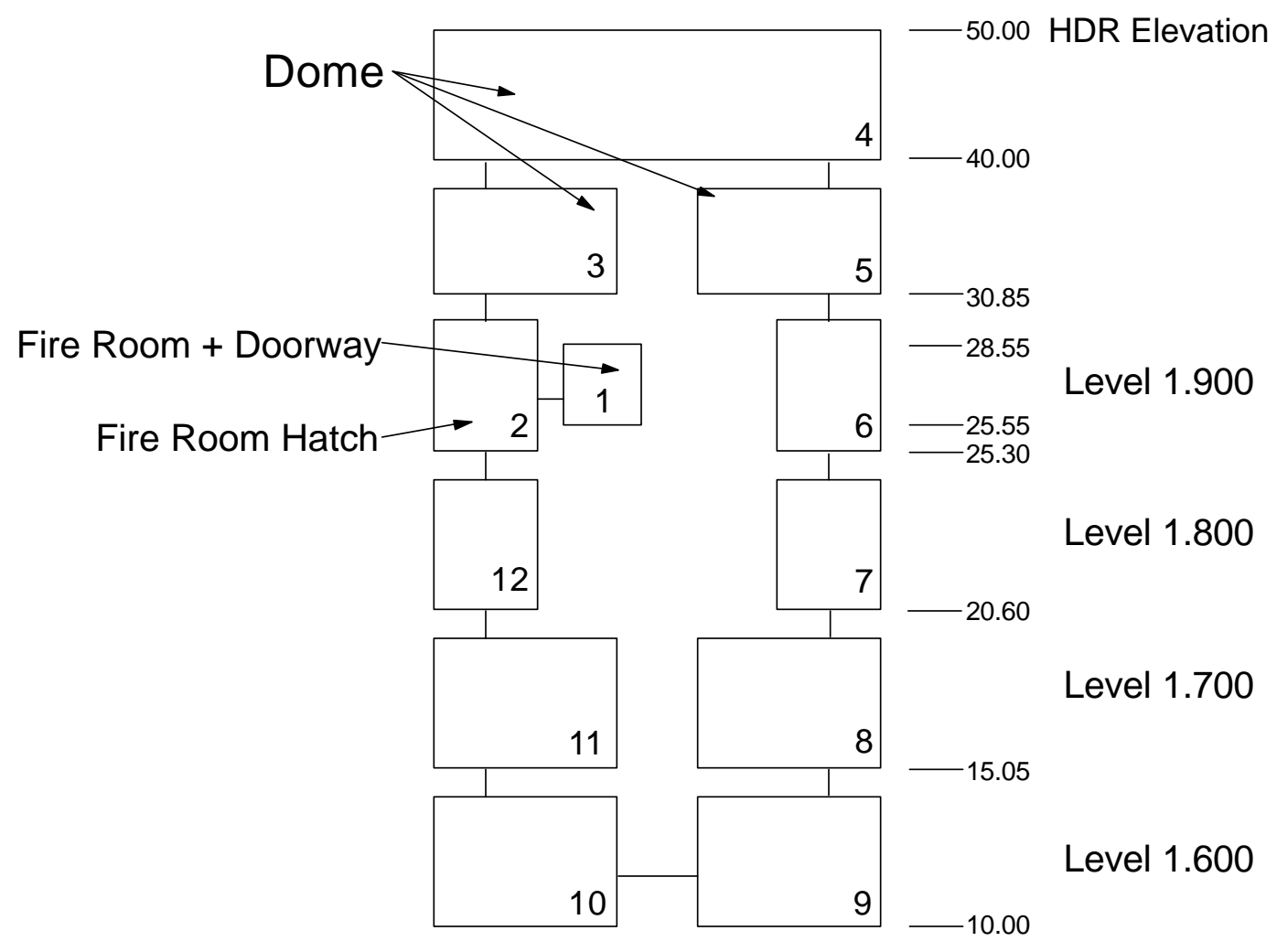

Figure 5.4: CFAST Compartment Layout for T52.14

\subsubsection{Hand Calculations}

The significant driving force of the T52 test series was the large thermal plume leaving the fire room and rising into the dome. One could take basic parameters of the T52.14 test and use hand computations or simple integral models to predict the behavior of the plume and some of the basic impacts on the HDR facility. This approach could be an alternative to a rigorous modeling effort when one only wishes to examine the overall magnitude of a postulated fire's impact in order to determine if further investigation is warranted.

To illustrate this approach, the constant oil addition portion of the T52.14 test was examined with some simple hand calculations. These calculations were performed in two parts. The first part analyzed the fire room itself. The second part used the results from the first and predicted properties of the plume entering the dome.

The analysis of the fire room made the following assumptions:

1. The fire has reached steady state conditions with regards to wall heat transfer in the fire room. As with this assumption in the T51.23 analysis, data for the fire room shows that temperatures in the fire room were stable over this time period. Furthermore, the higher temperatures earlier in the test would have acted to heat 
the fire room walls faster and allow the later portion of the test to reach equilibrium sooner.

2. The atmosphere of the fire room is well mixed. That is no distinct layer exists. The thermocouples in the fire room plus the doorway indicate that the entire fire room reached elevated temperatures during the test.

3. The heat addition by the fire is equal to the total heat of combustion available in the fuel being added to the oil pool.

4. The mass addition rate for the fuel is negligible compared to the mass exchange in the doorway. As with T51.23 the fuel addition rate is less than $0.1 \mathrm{~kg} / \mathrm{s}$. Little flow speed at the doorway would be required to make this a small fraction of the mass flux.

As with the T51.23 hand calculations, the second assumption determines the method from Chapter 3 to be used. In this case it is the method described in 3.1.1.2.

Once the flow from the doorway and the fire room temperature is known, these values can be used to calculate parameters of the plume entering the dome. The fire room temperature, the velocity, and the flow area from the fire room can be used as initial conditions with either the Chen-Rodi correlation or the integral analysis as described in 3.1.2. From these methods we can determine the plume temperature and radius at various elevations in the dome. These are key parameters as the plume mass flow defines the overall mixing throughout the facility. With the fire room mass flow rate calculated as well as the mass flow through the hatch into the dome, application of the conservation of mass would yield the overall flow through the maintenance shafts as well as recirculation within the dome.

Results of using Mathematica ${ }^{\circledR}$ to apply the methods from 3.1.1.2 and 3.1.2 to the T52.14 test are discussed in Chapter 6 along with the CFAST and FDS results and the Mathematica ® used are documented in Appendix C. 


\subsection{RESULTS OF SIMULATIONS}

This chapter presents the FDS simulations and the CFAST simulations of the T51.23 and T52.14 tests. The results are presented along with a discussion of the performance of each method of analysis. The discussion is presented in terms of the desired predictive quality, see Table 2.1 in Section 2.5.4, for a performance-based code regime.

\subsection{T51.23 SIMULATION RESULTS}

The results of the T51.23 gas fire test simulations are discussed in the following four sections. The sections individually describe the results of the three calculation methods applied to the T51.23 test as well as gives an intercomparison of the results of the three methods.

\subsubsection{T51.23 Hand Calculations Results}

The two-layer compartment equations from Chapter 3 were entered into Mathematica v3.0 ®. Before solving these equations a number of variables needed to be defined. The doorway loss coefficient $\mathrm{C}_{\mathrm{d}}$ was defined as $0.7^{1}$. The ambient temperature was defined as $300 \mathrm{~K}$. The upper layer wall surface area was calculated from the room geometry as $39.82 \mathrm{~m}^{2}$. The gas molar mass was taken to be that of air, $0.0288 \mathrm{~kg} / \mathrm{mol}$. The ambient pressure was assumed to be $101 \mathrm{kPa}$. Lastly, the wall heat transfer coefficient was calculated from the wall heat conduction assuming steady-state heat transfer. For simplicity all the fire room walls were assumed to be $0.25 \mathrm{~m}$ of the Ytong firebrick. This results in $\mathrm{h}_{\mathrm{k}}=0.96 \mathrm{~W} / \mathrm{m}^{2} \cdot \mathrm{K}$. Other variables have already been specified in Section 5.2 documenting the test layout. The following solutions were obtained by Mathematica v3.0 ®:

Table 6.1: T51.23 Hand Calculation Results vs. Measured Data

\begin{tabular}{|l|c|c|}
\hline \multicolumn{1}{|c|}{ Variable } & Value & Data \\
\hline $\mathrm{T}_{\mathrm{g}}\left({ }^{\circ} \mathrm{C}\right)$ & 834 & $769-905$ \\
\hline$\rho_{\mathrm{g}}(\mathrm{kg} / \mathrm{m} 3)$ & 0.32 & \\
\hline$\dot{m}_{\mathrm{g}}(\mathrm{kg} / \mathrm{s})$ & 1.21 & \\
\hline Upper Vel $(\mathrm{m} / \mathrm{s})$ & 3.52 & 4.9 \\
\hline Lower Vel $(\mathrm{m} / \mathrm{s})$ & 1.15 & 2.7 \\
\hline $\mathrm{H}_{\mathrm{N}}(\mathrm{m})$ & 0.90 & \\
\hline
\end{tabular}

The hand calculation results performed well for this scenario. The predicted gas temperature lies with in the range of the measured data and is within $4 \%$ of the actual average measured temperature in the upper layer. Since for this test only two velocity probes were used, it is difficult to compare an averaged quantity with a point quantity. However, since the probe placements were near the door centerline a short distance away form the ceiling and floor, they should represent a velocity condition near the maximum velocity. Thus, one would expect the hand calculation quantity to be lower than the measured, and in fact they are. 
The hand calculation method discussed in this section is a fairly simplistic one. Due to this simplicity, it took little time, on the order of an hour, to create the calculational notebook in Mathematica $\AA$ and obtain results. Once created, the calculational notebook could be run for many different permutations in a very short period of time as the actual calculation took only a few seconds. The results obtained by this method are quite good. The upper layer temperature and the mass flow out of the fire room were very well predicted. These quantities were predicted well enough that such hand calculations clearly have a role to play in a performance-based code system. The ability to quickly generate basic results about the effects of a fire could allow one to focus computational resources towards only those scenarios that warrant more in-depth computations.

\subsubsection{T51.23 CFAST Results}

The T51.23 CFAST results in this section are organized according to the predicted parameter, e.g. temperature, velocity, gas concentrations.

\subsubsection{T51.23 CFAST Temperature Predictions}

The first two figures of this section, Figures 6.1 and 6.2, show the predicted temperatures in the upper and lower layers of the fire room. The upper layer is overpredicted consistently by $150{ }^{\circ} \mathrm{C}$. However, this is within $17 \%$ of the measured value and is thus close to the fire room temperature criteria of within $15 \%$, see Table 2.1. The model does show a sudden increase in rate of temperature rise during the last five minutes of the fire which results in an overprediction of $30 \%$ or twice the $15 \%$ criterion. During this period, the layer height shifted $0.75 \mathrm{~m}$ toward the ceiling, This drop in the volume of the upper layer results in the increase in the rate of temperature rise; however, there is no phyiscal cause for the layer height to have shifted in this manner. The model matches well the cooling trend shown after the fire.

In the lower layer, temperature predictions lie within the range of the measured data. However, as these measurement locations were subject to a high radiative flux, and the measured data have not been corrected for this flux, in actuality CFAST is most likely overpredicting the lower layer temperature by some amount. The post fire coolddown is not matched as well in the lower layer as it was for the upper layer. The model shows an oscillatory behavior during the first 12 minutes and a change in trend during the last five minutes of the fire. The oscillatory behavior, which shows $400{ }^{\circ} \mathrm{C}$ shifts in temperature and the trend change result from shift in the layer height trend in the fire room. As with the upper layer results, the fire is at a steady state power, and thus one would not expect the layer height to move towards the ceiling.

Figures 6.3 and 6.4 show upper and lower layer temperatures in the hallway. The temperatures shown are taken from near the center of the hallway's length. This location represents the closest spot from which one could measure the average hallway properties.

From Figure 6.3 it is observed that the predictions are poor for this location. At the onset, the predictions lie on top of the data; however, at 1-2 minutes into the fire, the temperatures sharply decrease. Further oscillations are also seen at the end of the fire. At 50 minutes into the fire the 
model is underpredicting the temperatures by $30 \%$ which is below the $20 \%$ from Table 2.1 . As with the fire room, this behavior is caused by shifts in the layer height.

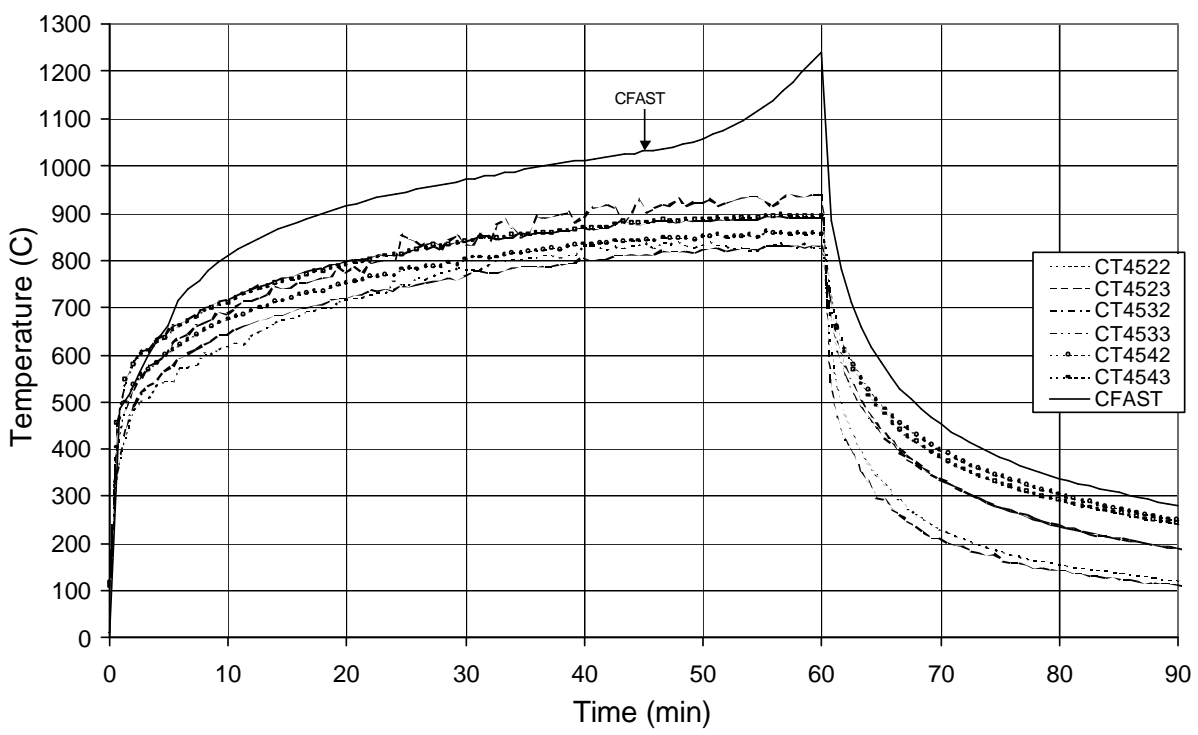

Figure 6.1: T51.23 Fire Room Upper Layer Temperatures, Measured vs. CFAST

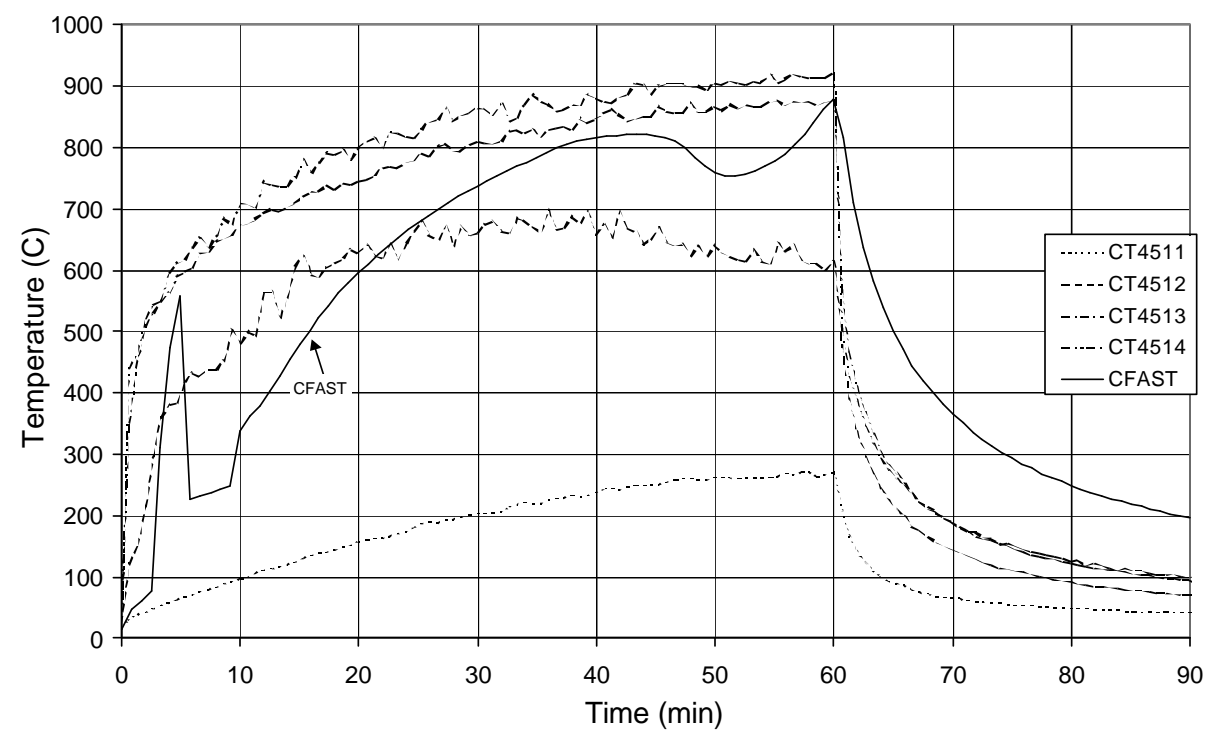

Figure 6.2: T51.23 Fire Room Lower Layer Temperatures, Measured vs. CFAST

Lower layer predictions, Figure 6.4, for the hallway continue the unpredictableness of CFAST results. The model, while at first matching the data, shows a sharp increase starting at 35 minutes into the fire. In fact, the end temperature prediction of this model exceeds the hallway upper layer predictions by $350{ }^{\circ} \mathrm{C}$, a nonsensical result. Examination of other parameters reveals that at 35 minutes CFAST reverses the direction of mass flow in the lower layer of the doorway, resulting in the addition of hot fire room gasses to the hallway lower layer. It would seem though, that the partitioning of the energy from the fire room to the two hallway layers could be improved. 


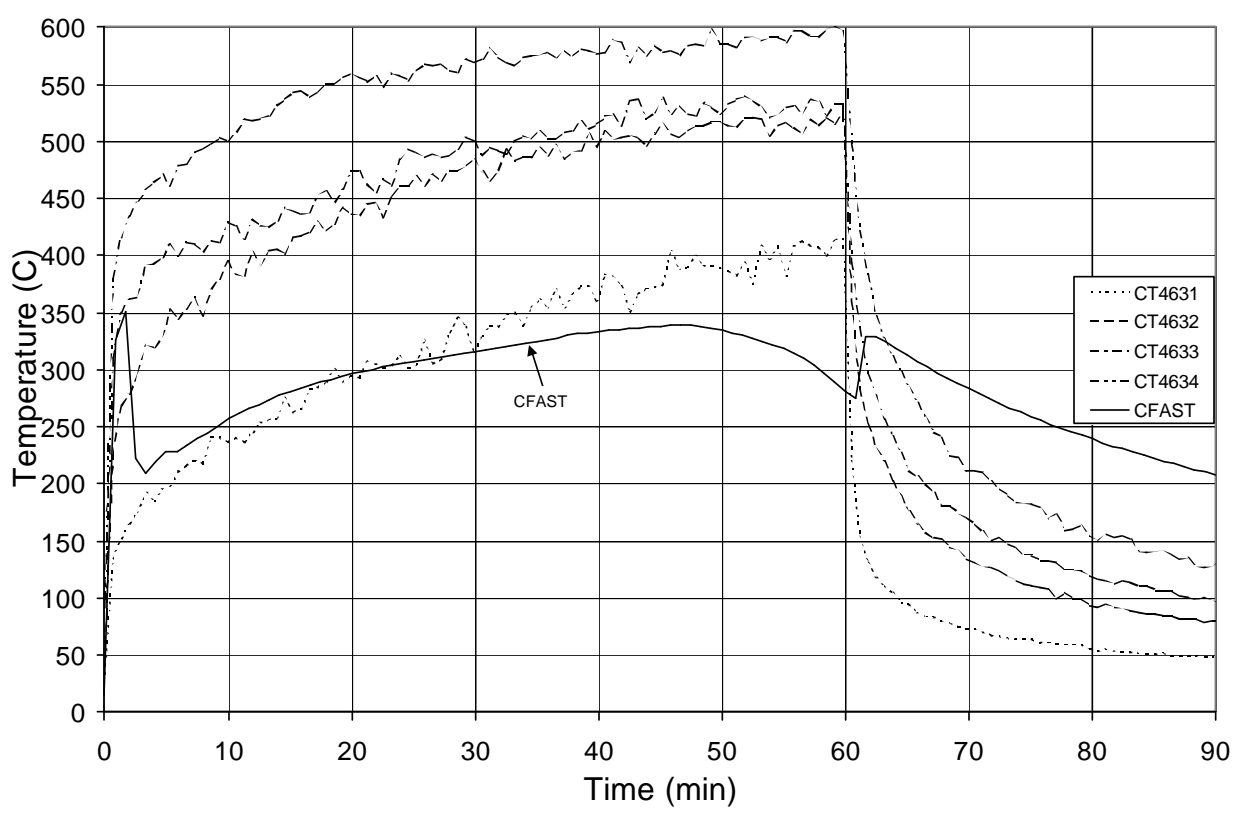

Figure 6.3: T51.23 Hallway Upper Layer Temperatures, Measured vs. CFAST

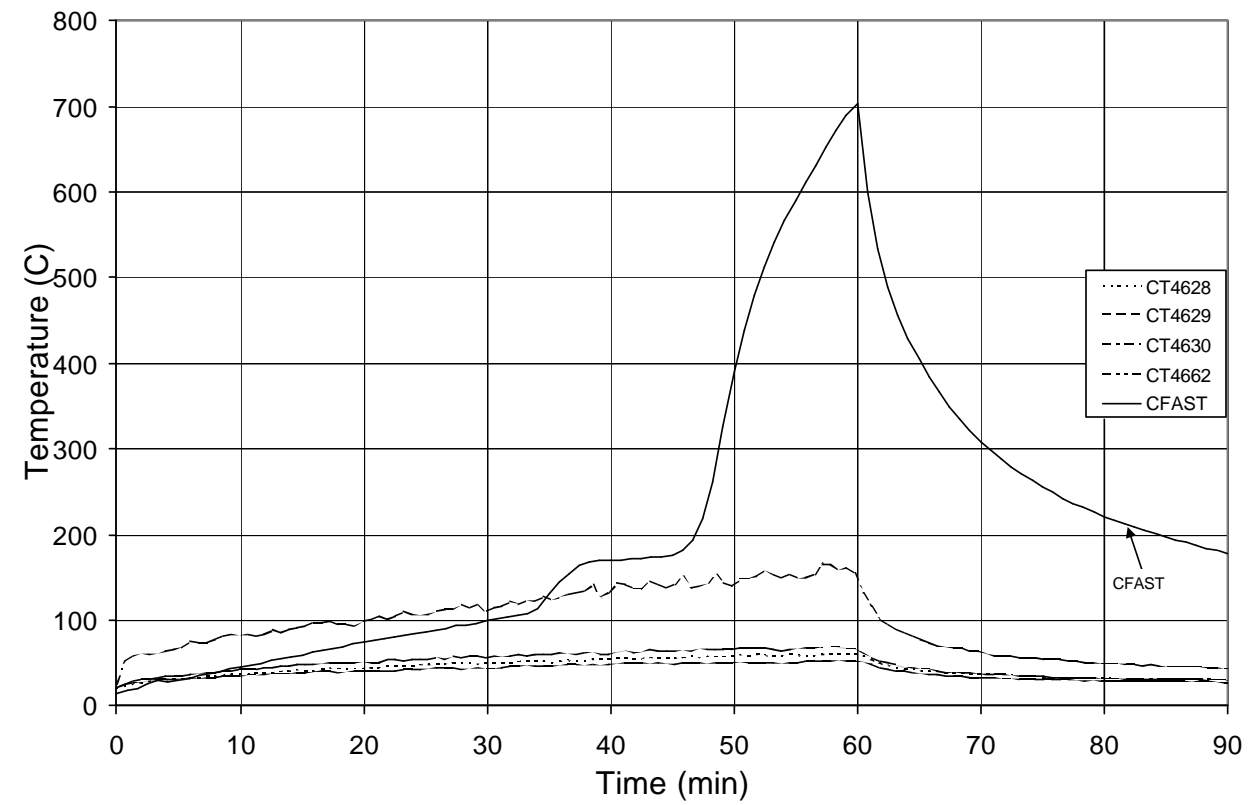

Figure 6.4: T51.23 Hallway Lower Layer Temperatures, Measured vs. CFAST

Temperatures on the 1.600 level near the main staircase are shown in Figure 6.5. The lower layer predictions lie well below the measured data. However, since the layer height in the compartments comprising the vertical flowpaths were nearly zero, this underprediction is not meaningful. The upper layer predictions exceed the measured data a maximum deviation of 23 ${ }^{\circ} \mathrm{C}$. This is close to the $20{ }^{\circ} \mathrm{C}$ criteria. Even though the model shows reasonable deviations, the trends shown are not entirely reasonable. The model reaches its peak temperatures at 50 minutes into the fire whereas the data does not peak until 60 minutes. The model also shows a spike in 
temperature in the first two minutes of the fire followed by a decrease in temperature for the second two minutes of the fire.

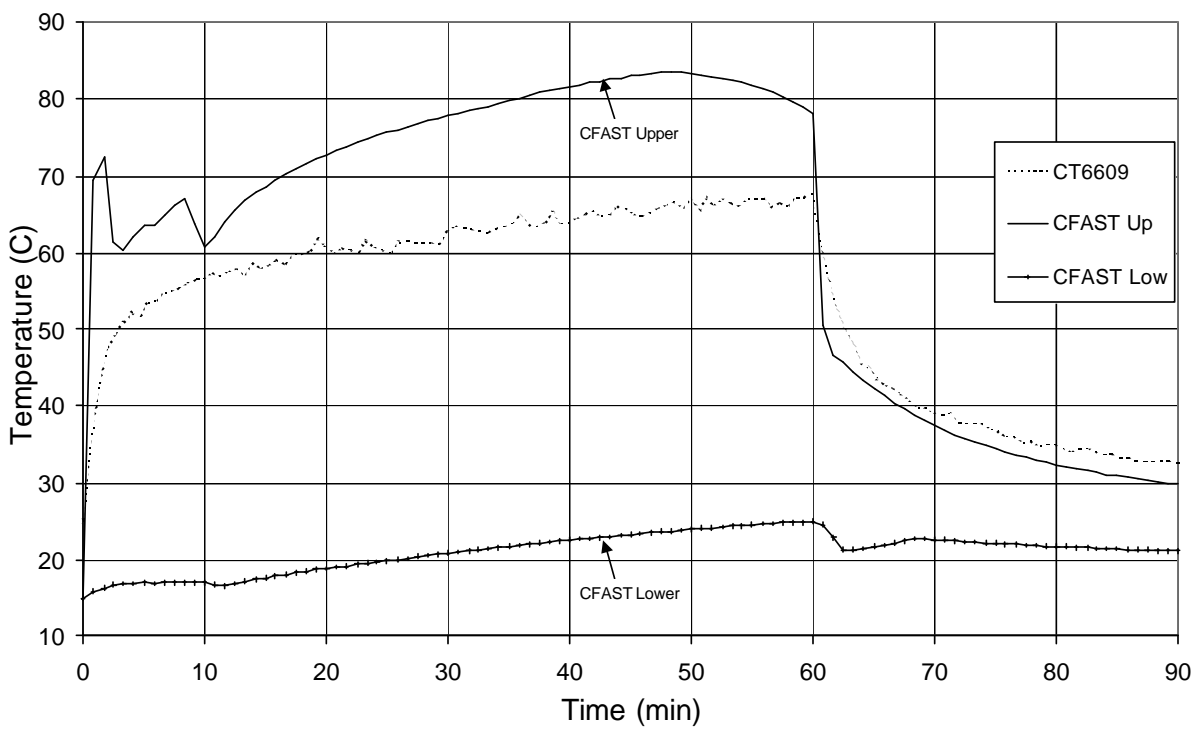

Figure 6.5: T51.23 Level 1.600 Main Staircase Temperatures, Measured vs. CFAST

The following figure, Figure 6.6, shows temperatures measured in the dome along with the corresponding CFAST predictions. The lower layer prediction is shown for informative purposes only, as with the prior plot the layer height is near zero. The CFAST prediction for the upper layer lies within the measured data and is therefore acceptable.

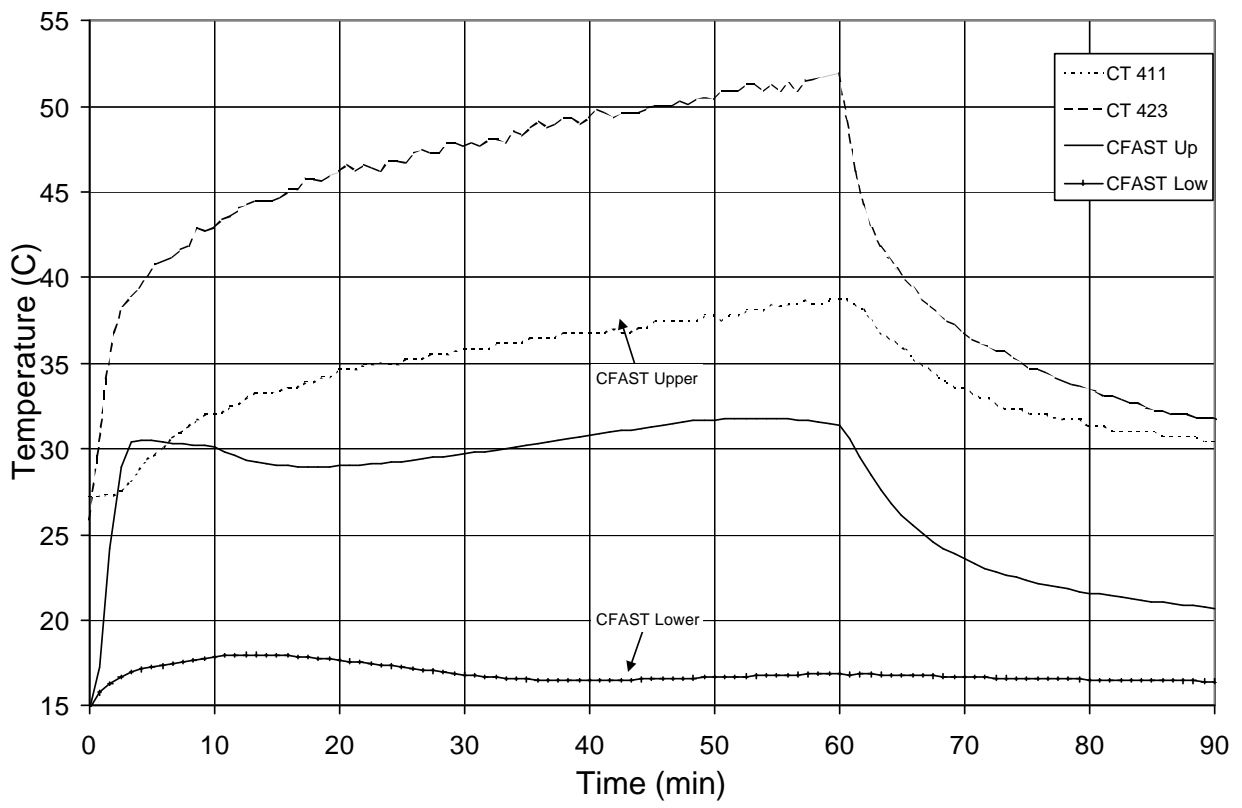

Figure 6.6: T51.23 Dome Temperatures, Measured vs. CFAST 
The last temperature plot, Figure 6.7, shown for the T51.23 CFAST simulation is for the spiral staircase region on level 1.600. This location is at the end of the circulation loop created by the fire and is also the source for the air that feeds the fire room. In general the CFAST predictions are excellent during the fire. The model overpredicts temperatures, but the deviation maximum is $12{ }^{\circ} \mathrm{C}$. Unlike positions earlier in the circulation loop, CFAST does not predict the cooldown well at this location. The data shows a temperature maximum almost 7 minutes after the fire whereas CFAST shows the maximum 5 minutes before the end of the fire. These are time deviations of 12 minutes and 7 minutes respectively; both of which are greater than the 5 minute deviation given in Table 2.1.

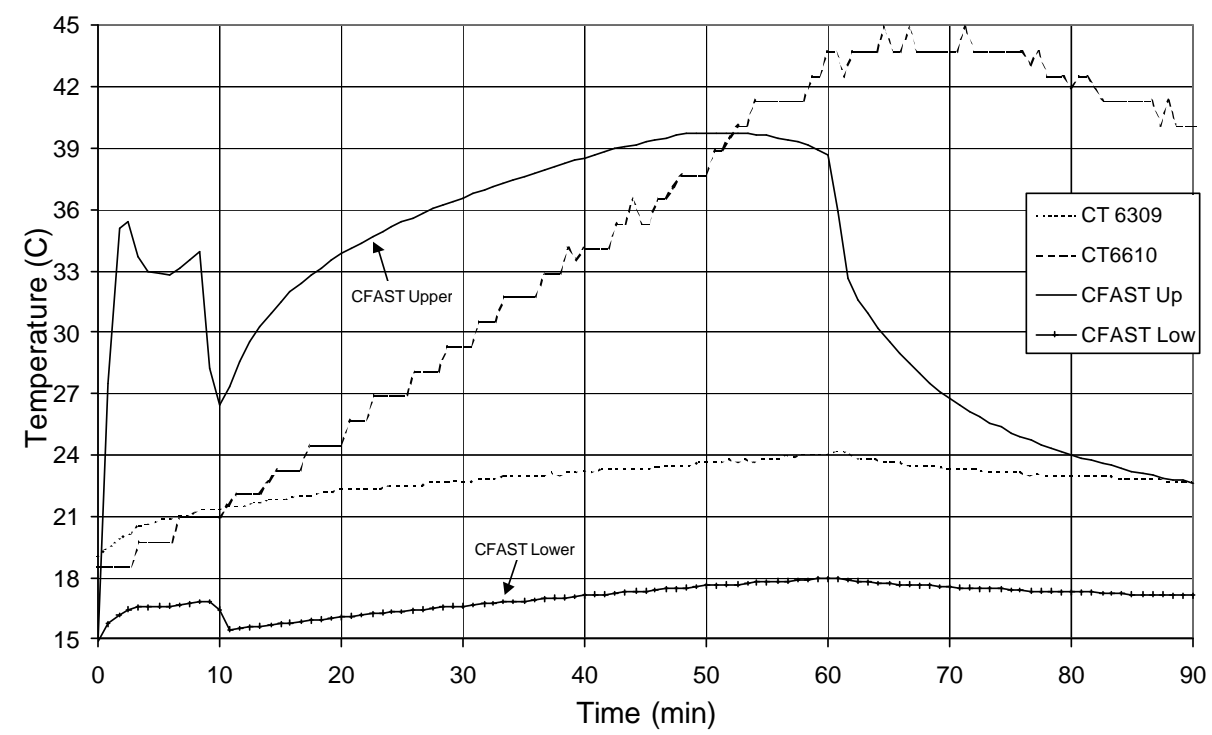

Figure 6.7: T51.23 Level 1.600 Spiral Staircase Temperatures, Measured vs. CFAST

\subsubsection{T51.23 CFAST Velocity Predictions}

CFAST outputs the mass flow rate for connections between compartments. The HDR data set contains velocity measurements. To allow for direct comparison, the CFAST mass flow rates were converted to velocities. This was done by converting the mass flow rate to a volume flow rate using the real gas law, and then using the flow area to convert volume flow rate to velocity. In this manner an average velocity can be derived to compare with the measured data.

The velocity predictions versus measurements for the upper and lower layer of the doorway are shown in Figures 6.8. Since instrumentation in the doorway consisted of two velocity probes, one in the upper layer and one in the lower layer, direct comparisons of CFAST to measured data is not easy to do as CFAST represents the average layer velocity, and the location of the probe in the profile is unknown.

Velocity predictions are difficult to evaluate for this test. With only the two velocity probes and with CFAST given layer averaged velocities, intercomparisons cannot be made easily. However, it is clear the CFAST predicted lower layer velocity of near zero is a very poor prediction. The upper layer velocity shown is $25 \%$ of the measured velocity. However, since the measurement 
location was near the top of the doorway, where the maximum velocity is expected, the only conclusion that can be drawn is that the prediction is plausible. What is not plausible, however, is the sudden spike of upper layer velocity to $10 \mathrm{~m} / \mathrm{s}$ at 2 minutes into the fire.

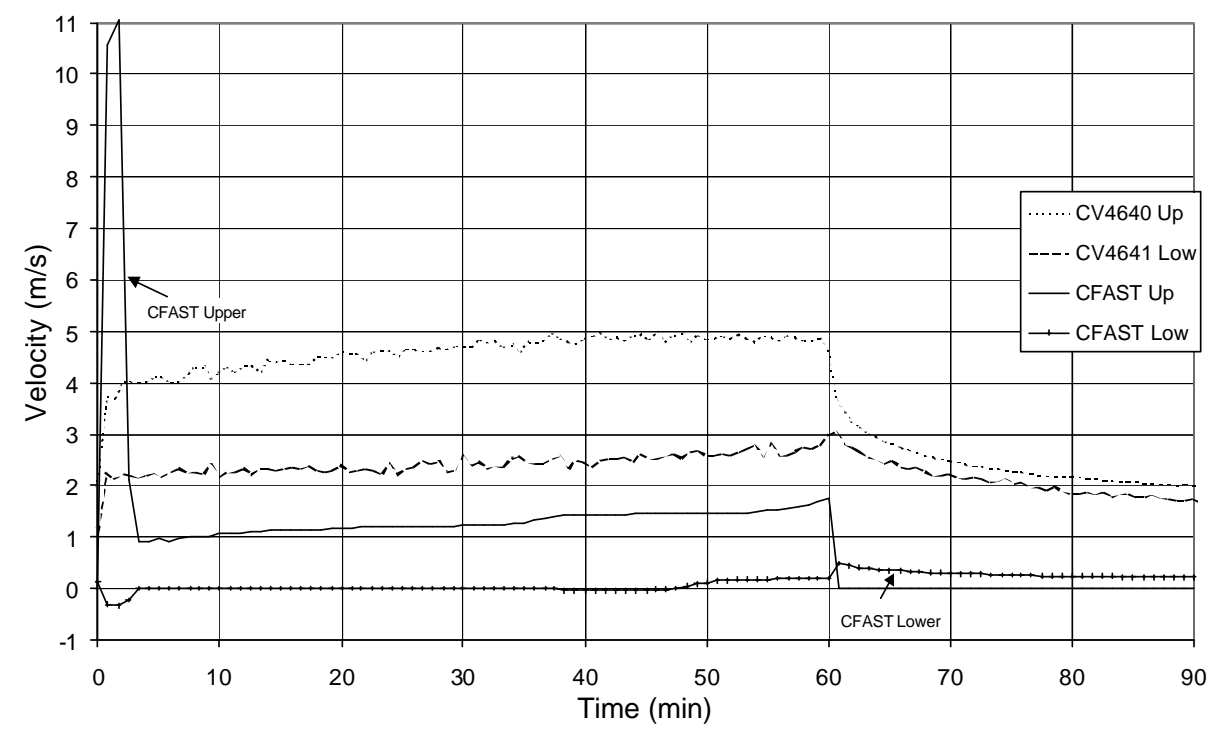

Figure 6.8: T51.23 Doorway Velocities, Measured vs. CFAST

The upper and lower layer velocities for the hallway are shown in Figures 6.9 and 6.10. For the first two minutes of the fire the model makes predictions that lie near the data. However, after the first two minutes the flow through the hallway nearly ceases. Discontinuities are seen again in both layers at the start and end of the test. CFAST is not performing well for this parameter.

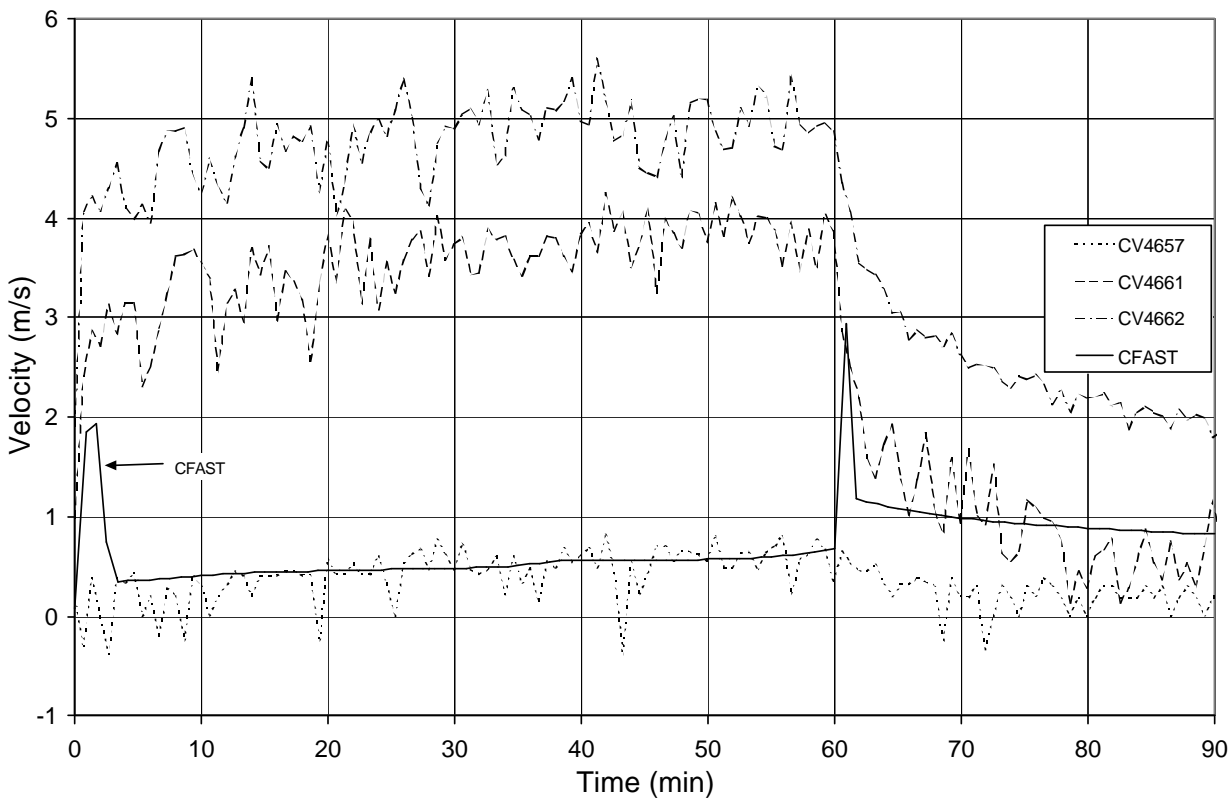

Figure 6.9: T51.23 Upper Hallway Velocity, Measured vs. CFAST 


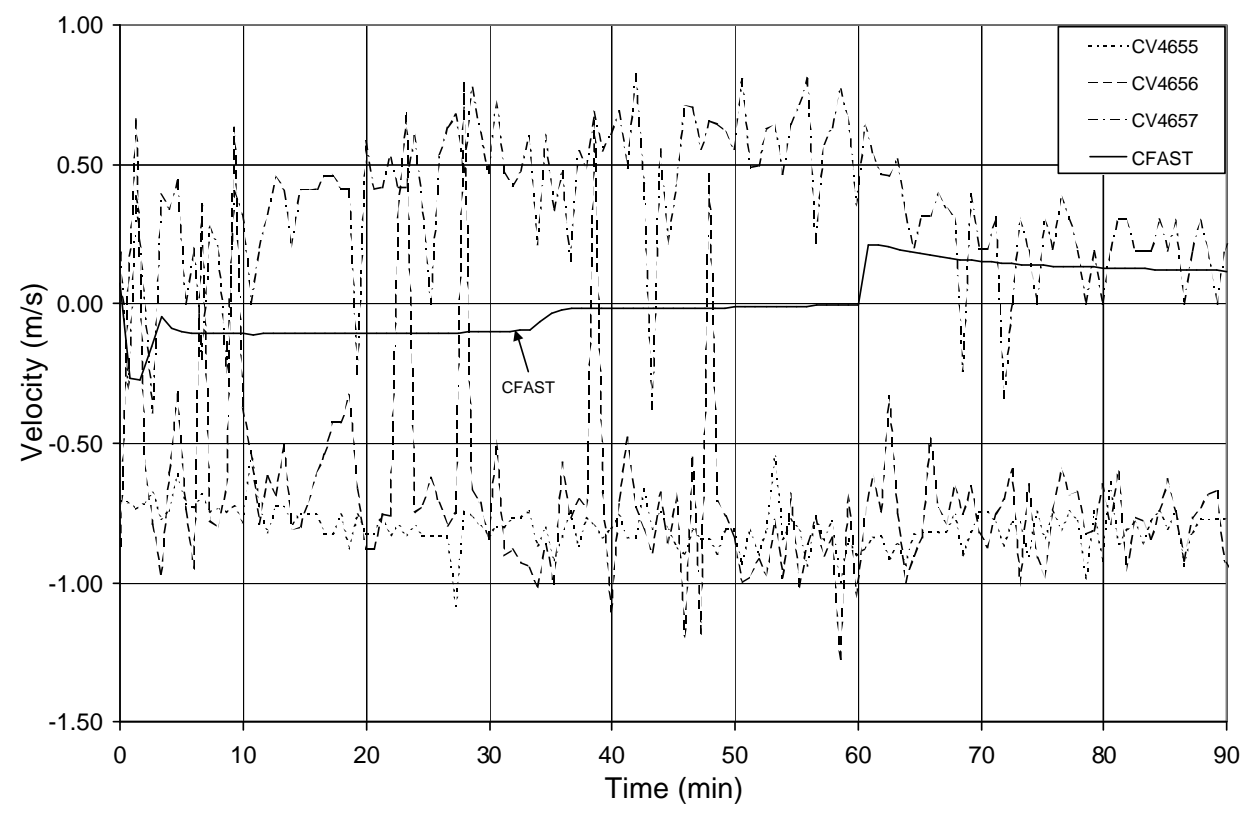

Figure 6.10: T51.23 Lower Hallway Velocity, Measured vs. CFAST

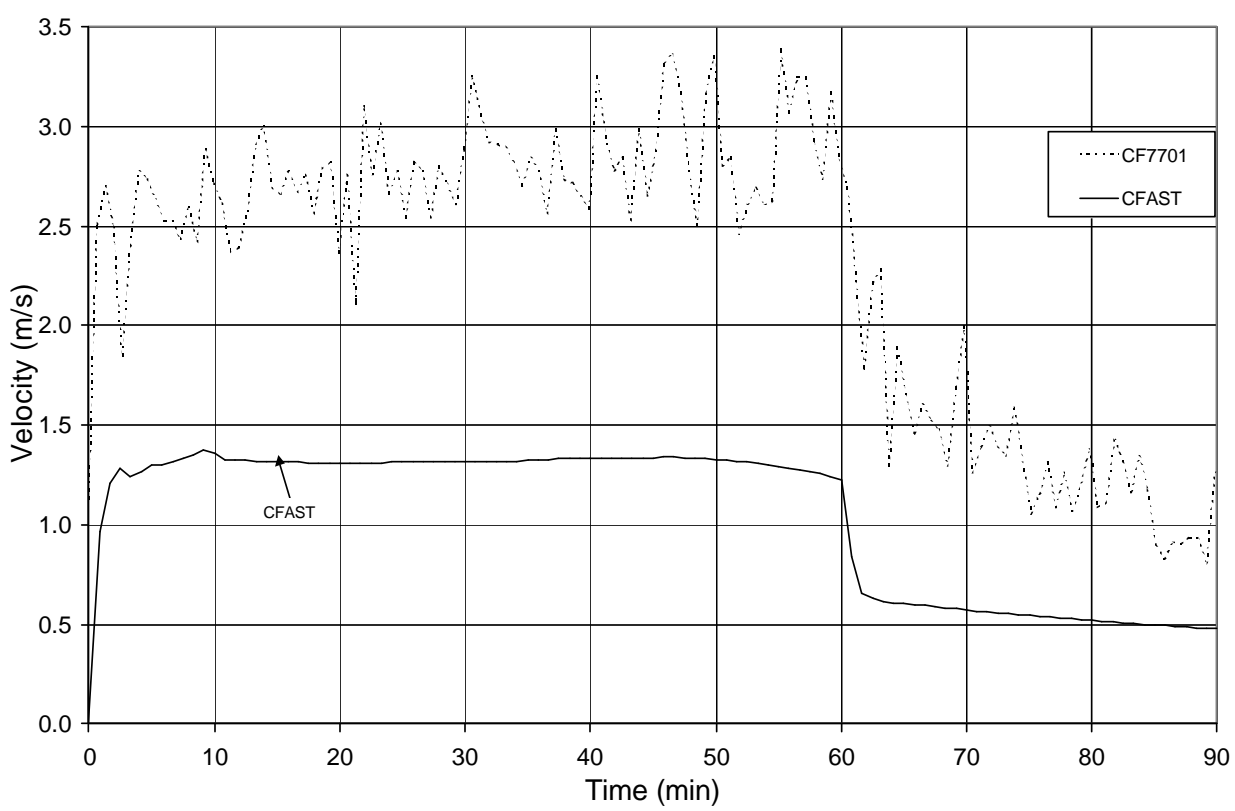

Figure 6.11: T51.23 Velocity in Main Staircase 1.600/1.700 Hatch Measured vs. CFAST

Figure 6.11 shows the upward velocity leaving the level 1.600 on the main staircase side of the HDR. Unfortunately, the velocity sensors at lower elevations in this vertical flowpath were non-functional during this test so comparisons closer to the fire room cannot be made. Strangely, the temperature discontinuities seen in vertical flowpath is not seen in the velocity profiles. The CFAST results, while underpredicted, do show the same trend as the measured data. One would 
expect that some form of velocity discontinuity would exist to go along with the temperature one. Errors in the prediction are in excess of the 30-50\% error band.

\subsubsection{T51.23 CFAST Gas Concentration Predictions}

The first figure of this section, Figure 6.12, shows the oxygen concentration at the interface between the upper layer of the fire room and the doorway. The predictions for track quite well with the data for the first 50 minutes of the fire, within $10 \%$. In the last ten minutes of the fire the predicted concentration drops rapidly until it is almost 6 v/o (volume percent or mole fraction) below the data. Since the temperature shows a large spike during this time frame, the error is at least consistent with the other predicted quantities. Although the model predicts a partial recovery in the post-fire oxygen concentration, it does not come close to predicting the near complete recovery in oxygen concentration shown by the data.

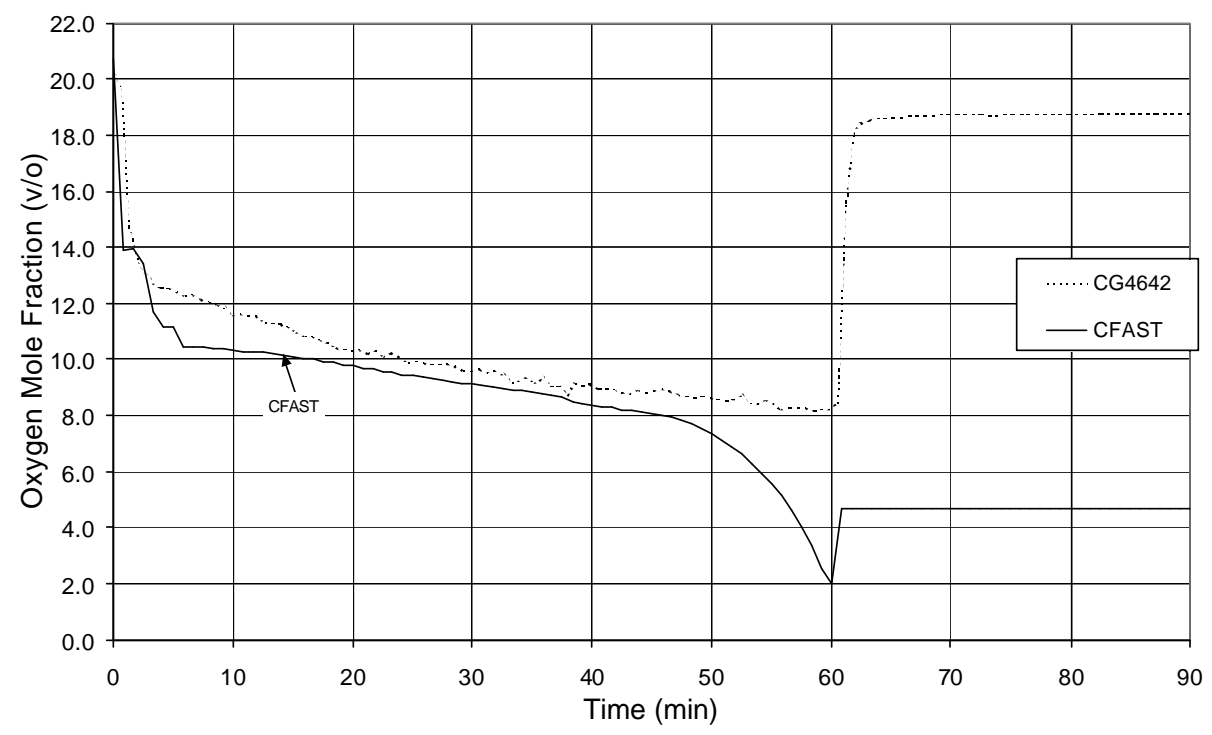

Figure 6.12: T51.23 Oxygen Concentration in the Upper Doorway, Measured vs. CFAST

The carbon dioxide concentration in the doorway is shown in Figure 6.13 below. Since the fuel was propane gas premixed with air, input file specification of the combustion products for CFSAT was trivial. As opposed to a pool fire where the user would have to make assumptions regarding the combustion product formation. As such, one would expect the $\mathrm{CO}_{2}$ concentrations to be well predicted and this is the case with this model. The model makes good predictions for both the upper and lower layer (CG4667 upper layer, CG4666 near interface, CG4665 lower layer). In the upper layer they are within 16 to $30 \%$ of the measured data, except for the sharp increase in concentration seen during the last ten minutes of the fire. For the peak concentrations at the end of the fire this is within the Table 2.1 criteria. In the lower layer the model is within 0.5 v/o for the $\mathrm{CO}_{2}$ concentration.

The final gas concentration figure, Figure 6.14, shows the data from a rake of gas sensors in the center of the hallway compared to the CFAST predictions for the upper and lower $\mathrm{CO}_{2}$ concentrations in the hallway. In the upper layer the models' predictions lie within the span of 
measured data (CG4654 and CG4663). At this location the jump in the last ten minutes seen in prior plots is not seen here. In the lower layer, the model doe not show a rise in $\mathrm{CO}_{2}$ concentration until 45 minutes into the fire. At this point the predictions all rise quickly to match the trend of the measured data only offset by $0.5 \mathrm{v} / \mathrm{o}$.

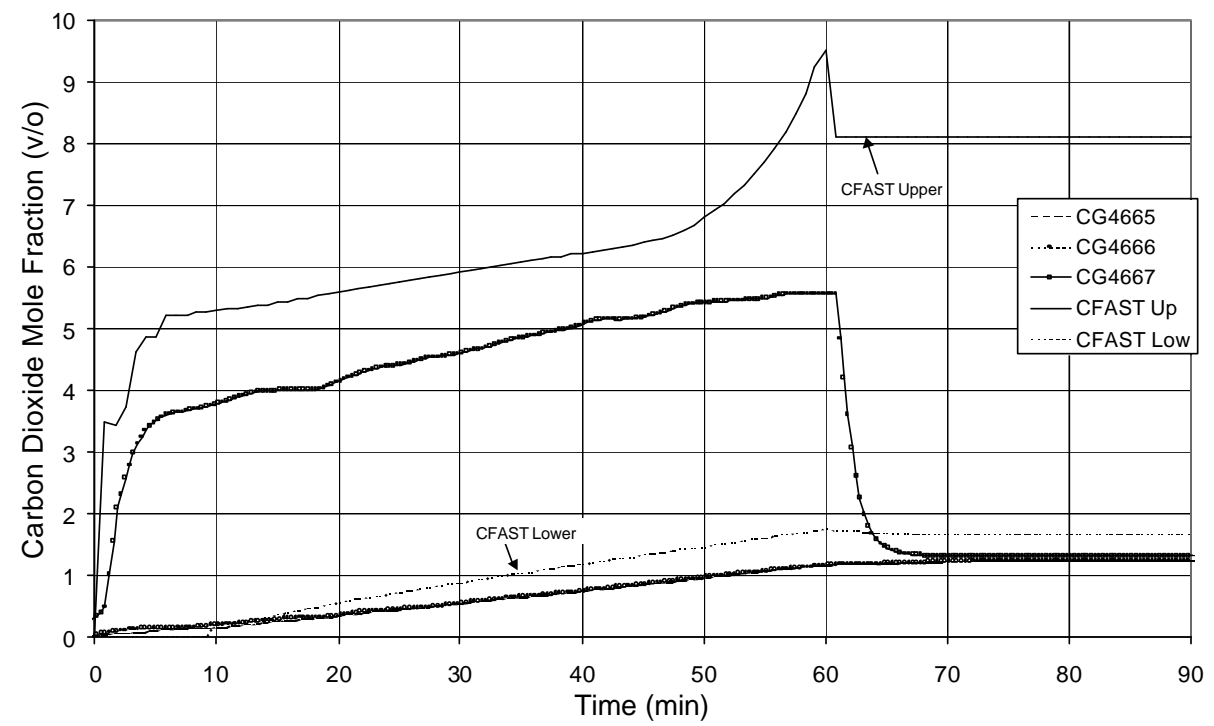

Figure 6.13: T51.23 Carbon Dioxide Concentration in the Doorway, Measured vs. CFAST

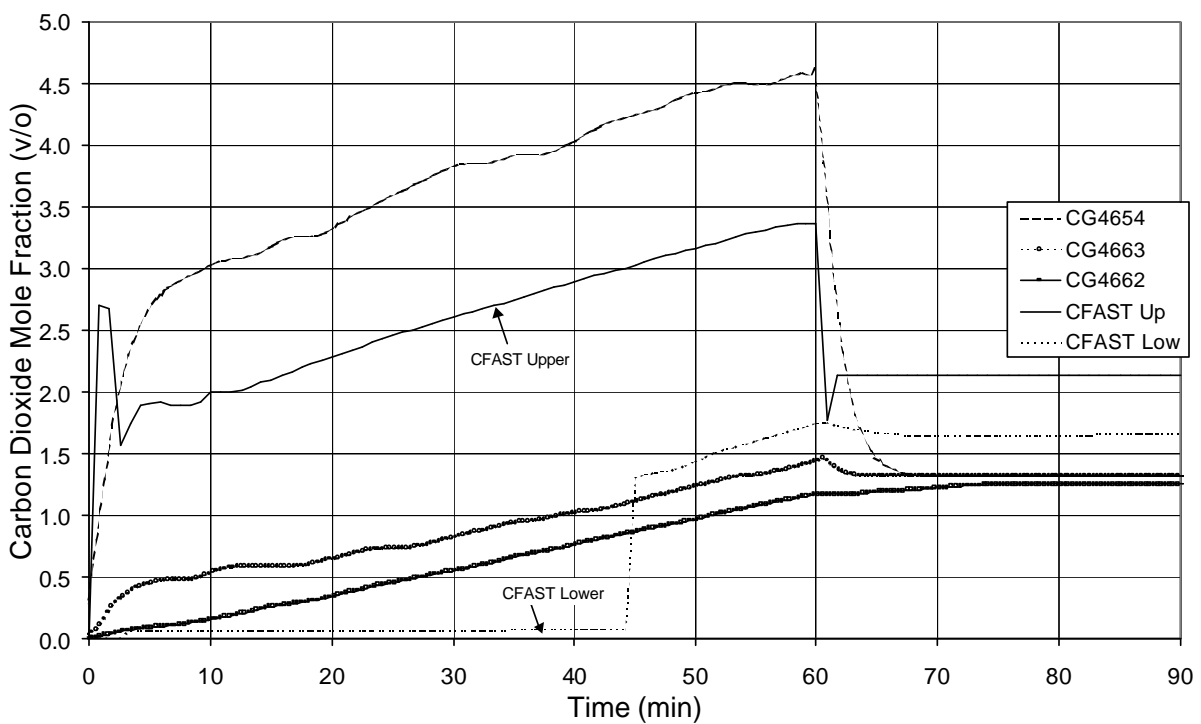

Figure 6.14: T51.23 Carbon Dioxide Concentration in the Hallway, Measured vs. CFAST 


\subsubsection{T51.23 FDS Results}

The FDS results of this subsection are presented in groups based on the geometric divisions of the FDS v2.0 $\alpha$ model. The results are presented in terms of the fire room, the doorway, and the hallway

\subsubsection{Fire Room}

The compartment containing the fire is an especially important one for any fire computer model. For a field model such as FDS, it is critical that both the temperature magnitude and its spatial variance be accurately predicted. This is due to field models having the greatest potential to predict the damaging effects of a fire on a local basis within the fire room and adjoining compartments. That is, the effects that the location of objects within a room and the room's geometry have on the spatial temperature, radiant heat flux, and mass flux can only be predicted by a field model.

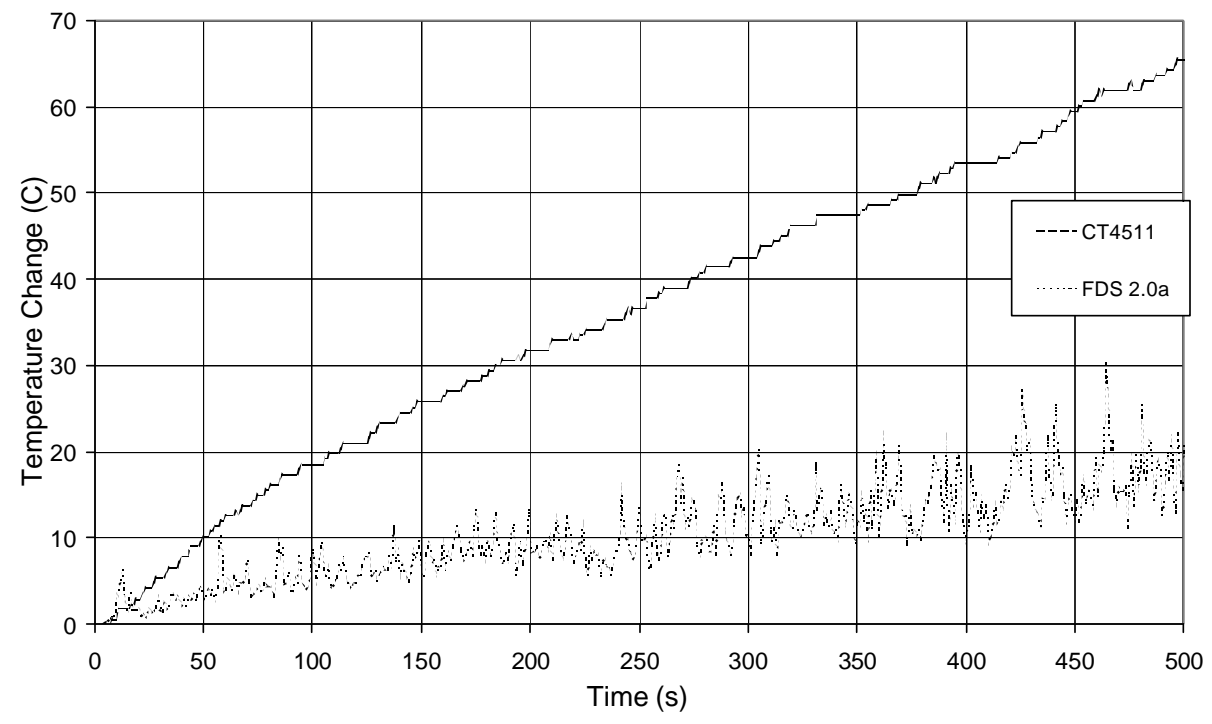

Figure 6.15: T51.23 FDS Results for CT4511

The first figure, Figure 6.15 plots FDS predictions and the measured temperatures at $-0.7 \mathrm{~m}$ in absolute HDR elevation, or $15 \mathrm{~cm}$ above the floor. Thermocouple CT4511 was located in the doorway and, thus, was partially shielded from the radiative flux from burners 1 through 3 . This location of CT4511 represents the temperature of the air entering the fire room from the hallway. The measured data for CT4511 shows a slow temperature rise of $60{ }^{\circ} \mathrm{C}$ over the first ten minutes of the fire. FDS v2.0 $\alpha$ shows an increase of $20^{\circ} \mathrm{C}$ which is $40^{\circ} \mathrm{C}$ lower than the measured data. However, some of the measured increase is due to radiative heating of the thermocouple from burners 4 and 5 . Thus FDS v2.0 $\alpha$ is performing better than the comparison seems to indicate, but how much so is uncertain due to the errors in the thermocouple measurement. It is likely that if radiation could be corrected for that FDS v2.0 $\alpha$ would be within the $20^{\circ} \mathrm{C}$ criteria in Table 2.1. 
The next figure, Figures 6.16, depicts the FDS results for CT4523 which is near burner \#1 at the $+0.2 \mathrm{~m}$ HDR elevation, $1.05 \mathrm{~m}$ above the floor of the fire room. CT4523 shows a temperature increase of $550{ }^{\circ} \mathrm{C}$ over the first ten minutes. FDS v2.0 $\alpha$ makes excellent temperature predictions with the predictions lying on top of the measured data. Since there is likely to be a small error in the measured data from radiation the FDS v2.0 $\alpha$ predictions for this location falls within the Table 2.1 criteria.

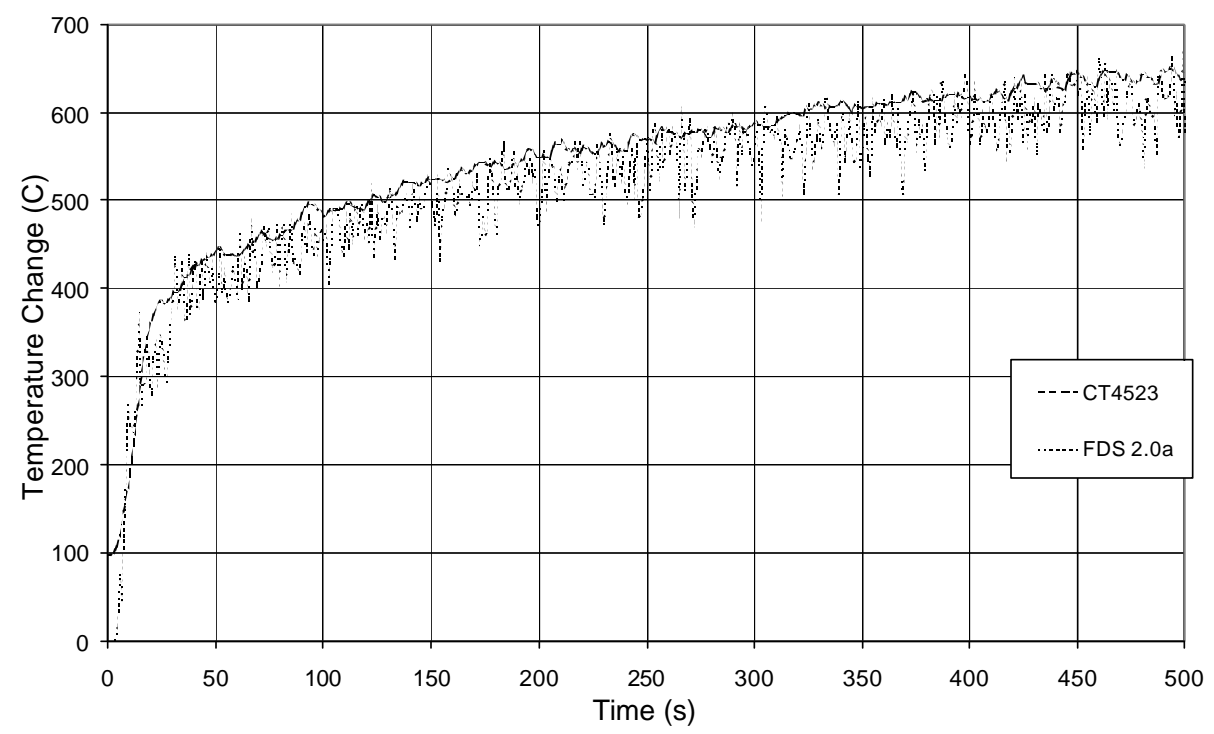

Figure 6.16: T51.23 FDS Results for CT4523

The next figure, Figure 6.17, shows predicted vs. measured data for CT4543 located just beneath the ceiling of the fire room near the center of the room. FDS v2.0 $\alpha$ differs from the measured data by less than $16 \%$ after the initial transient, which meets the $15 \%$ criteria. Fire room temperatures are well predicted by FDS $v 2.0 \alpha$.

\subsubsection{Doorway}

The following figure, Figure 6.18, shows the FDS predicted temperature profile in the doorway at the location of two thermocouple rakes in the doorway. FDS v2.0 $\alpha$ matches the profile in both shape and magnitude over the entire doorway.. FDS v2.0 $\alpha$ predicts values within $15 \%$ over the entire height of the doorway.

Figure 6.19 shows a time averaged velocity contour plot in the doorway exit plane for the FDS simulation. Time averaged values of the two velocity probes in the doorway are shown in text boxes at the probe locations. FDS shows a typical doorway profile of a counterflow with an outward flowing hot layer and an inward flowing cold layer. In v2.0 $\alpha$, the measured velocities in the upper and lower regions of the doorway are close to the measured values. 


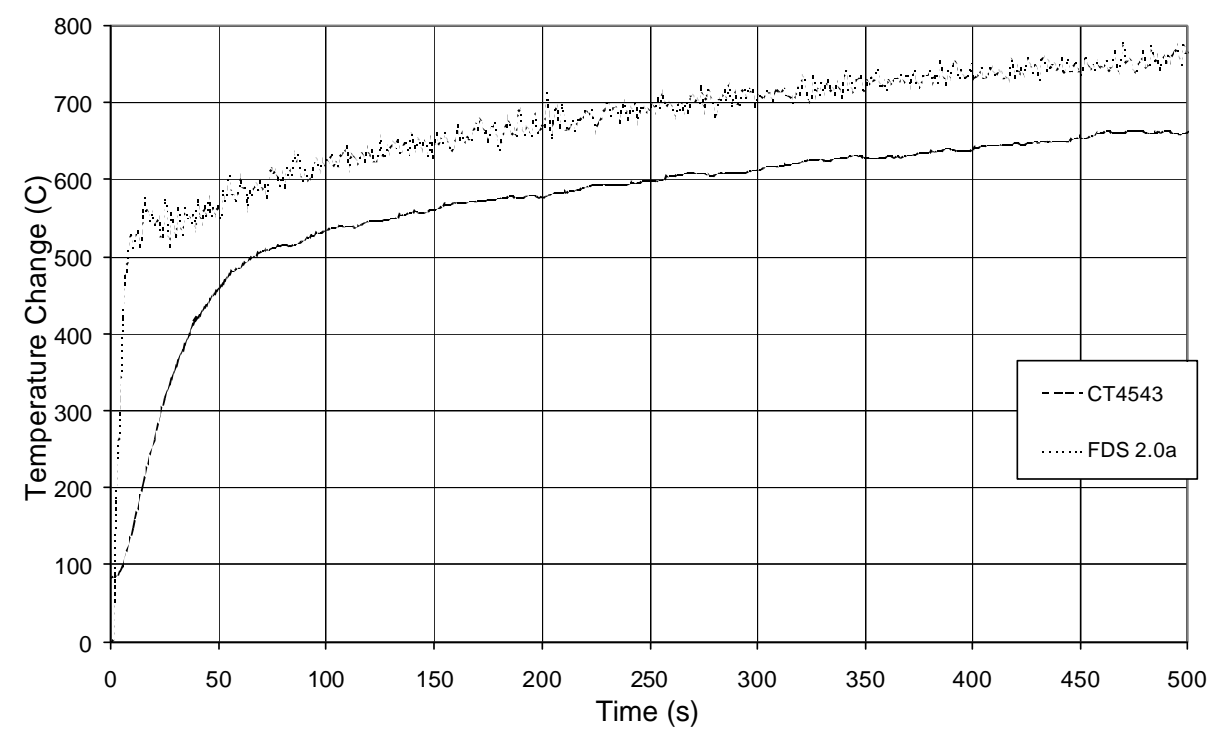

Figure 6.17: T51.23 FDS Results for CT4543

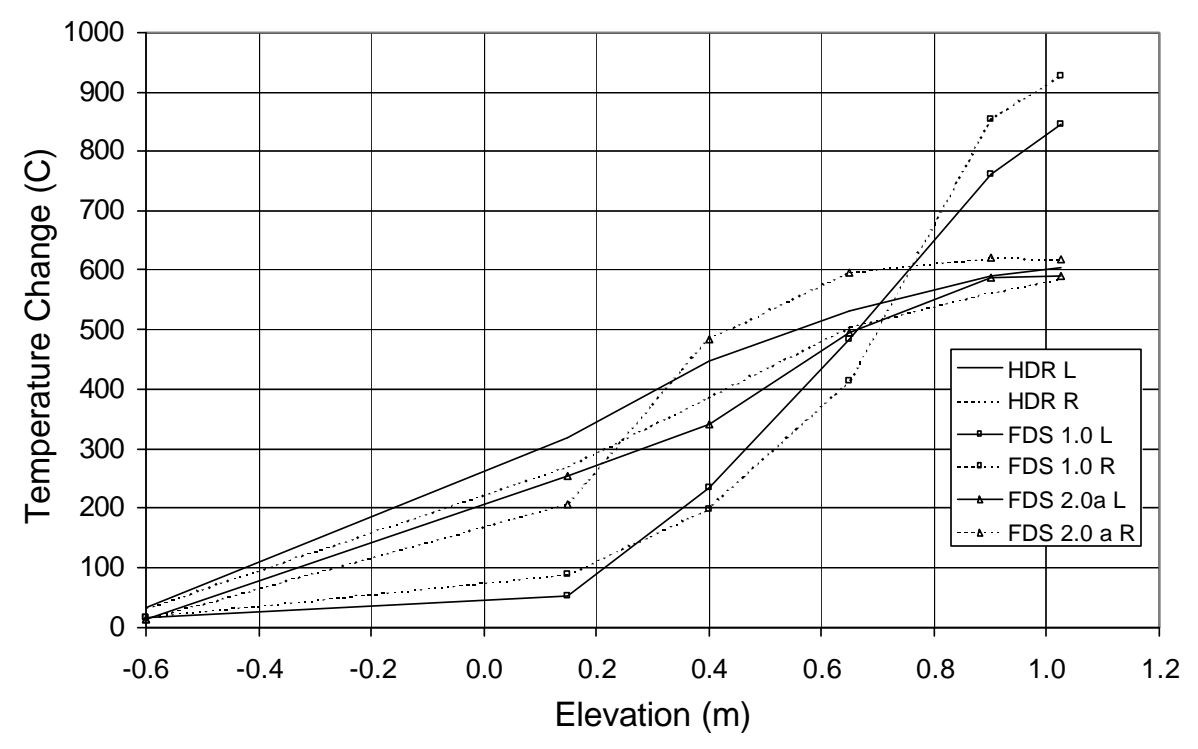

Figure 6.18: T51.23 FDS Doorway Temperature Profile

The final gas concentration figure, Figure 6.20, shown for the doorway is the FDS prediction for the $\mathrm{O}_{2}$ concentration versus the value measured by $\mathrm{O}_{2}$ sensor CG4642. Two observations are made from this figure. The first is that FDS predicts a much faster drop in the $\mathrm{O}_{2}$ concentration than indicated by the data. The data shows a delay of approximately 30 seconds from the start of the fire before the $\mathrm{O}_{2}$ concentration in the doorway starts to drop whereas FDS shows no delay. This is most likely due to numerical diffusion due to the relatively coarse noding. The second observation is that the drop in concentration predicted by FDS is approximately $25 \%$ lower for v2.0 $\alpha$. FDS v2.0 does not give, therefore, oxygen concentration predictions close enough to the measured data. This result probably arises from yet to be resolved numerical integration errors in 
the mixture fraction combustion model. It may also result in part from the lower predictions of velocities in the lower doorway which would result in less air mixing in the fire room and, hence, lower concentrations in the upper doorway.

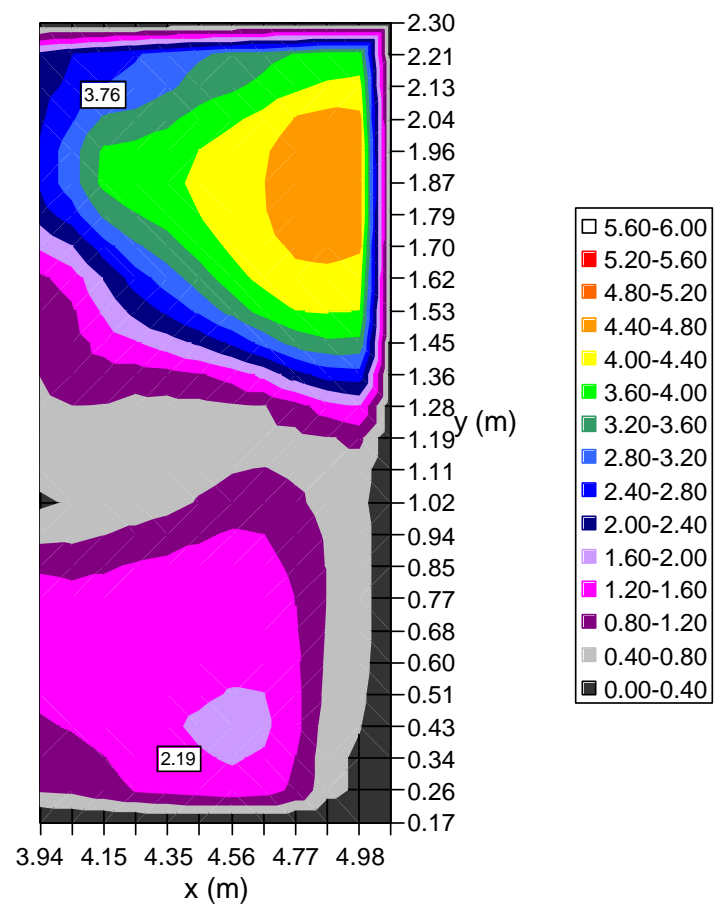

Figure 6.19: T51.23 Doorway Time Averaged Velocity Contours for FDS v2.0 $\alpha$

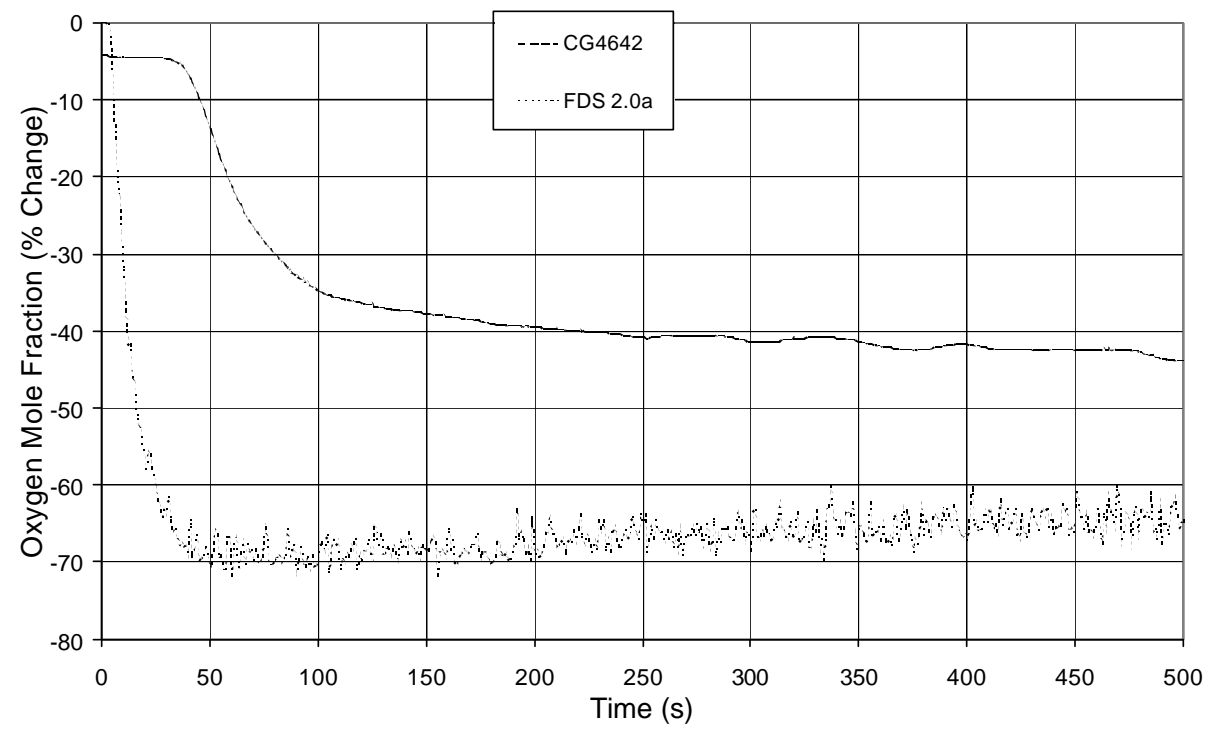

Figure 6.20: T51.23 FDS Results for CG4642 


\subsubsection{Hallway}

The next two figures, Figure 6.21 and Figure 6.22, show the hallway temperature profile for two thermocouple rakes and the velocity profile at a location halfway down the hallway. FDS v2.0 $\alpha$ predicts temperatures within $15 \%$ over the entire height of the hallway and also predicts the same overall temperature gradient as seen in the data. FDS velocity predictions are with $30 \%$ of the data and have the same overall profile.

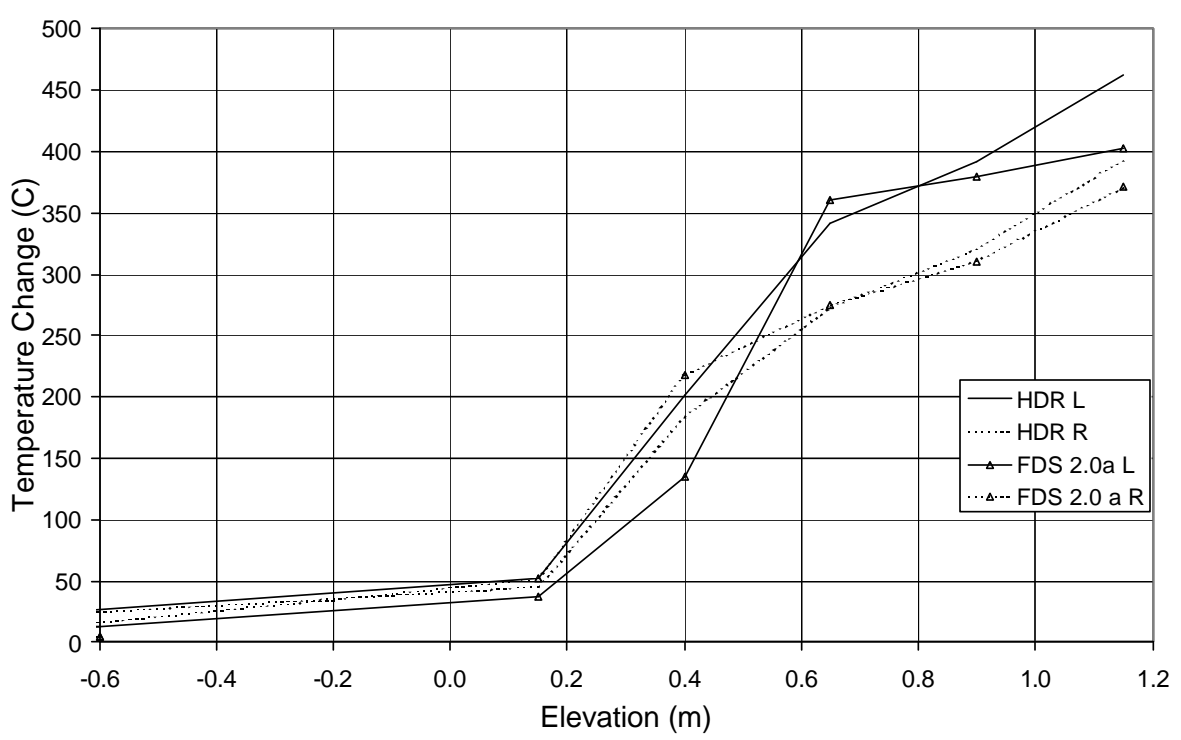

Figure 6.21: T51.23 FDS Hallway Temperature Profiles

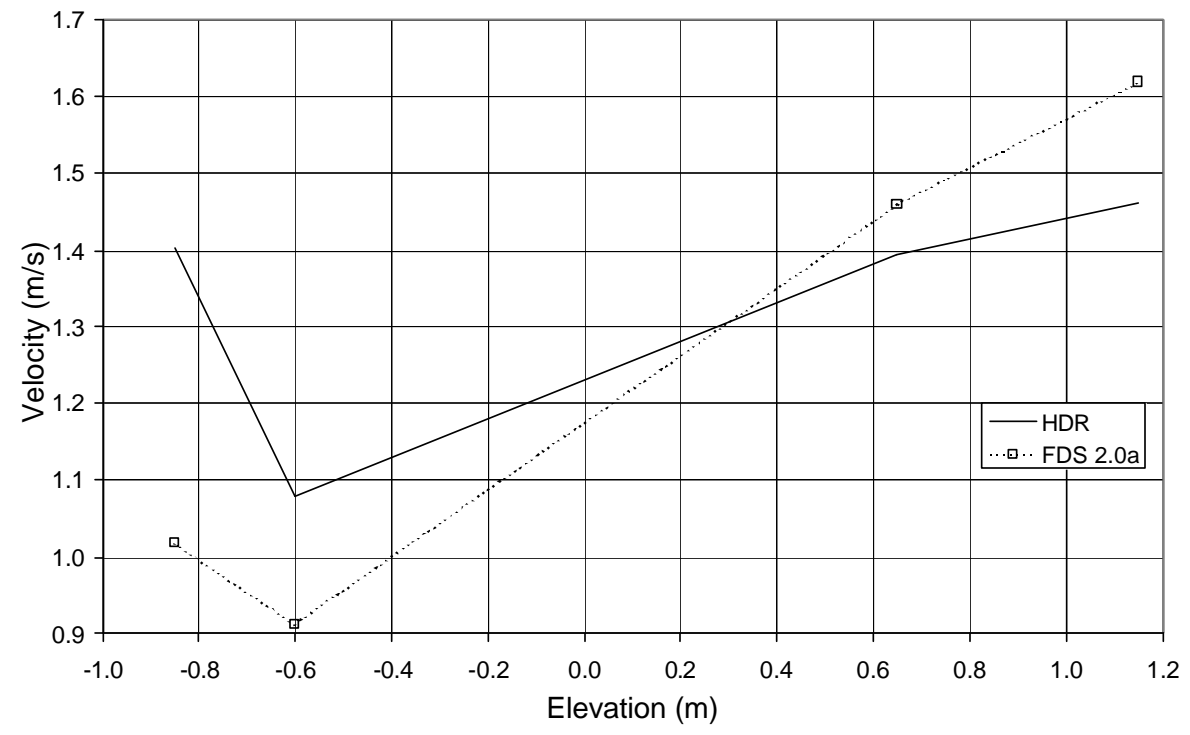

Figure 6.22: T51.23 FDS Hallway Velocity Profile 


\subsubsection{Intercomparison of All Analysis Methods}

This section compares the fire room results of the three analysis methods with the data. These comparisons are made at 15 minutes into the fire, the length of the FDS simulation. Table 6.2 summarizes the results for key parameters of the fire room using the best results of each analysis method. The velocities shown in the table for the three analysis methods represent the layer averaged velocities.

Table 6.2: Steady State Fire Room Predictions for All T51.23 Analyses Compared to Data

\begin{tabular}{|c|r|r|r|r|}
\hline Quantity & \multicolumn{1}{|c|}{ Data } & Hand Calc. & \multicolumn{1}{c|}{ CFAST } & \multicolumn{1}{c|}{ FDS } \\
\hline Upper Temperature $\left({ }^{\circ} \mathrm{C}\right)$ & 730 & 834 & 870 & 808 \\
\hline Upper Velocity $(\mathrm{m} / \mathrm{s})$ & 4.5 & 3.3 & 1.2 & 2.8 \\
\hline Lower Velocity $(\mathrm{m} / \mathrm{s})$ & 2.3 & 0.4 & 0.0 & 1.1 \\
\hline Layer Height $(\mathrm{m})$ & 1.0 & 0.7 & 0.7 & 0.9 \\
\hline $\mathrm{O}_{2}$ Concentration $(\mathrm{v} / \mathrm{o})$ & 11.6 & N/A & 10.0 & 7.6 \\
\hline
\end{tabular}

The results shown in this table are somewhat surprising. The hand-calculation performs nearly as well as the other two methods. CFAST has the poorest temperature prediction while FDS has the poorest oxygen prediction. FDS does quite well though in predicting the layer height and the upper layer temperature. Velocity predictions cannot be directly compared to the data as the data consists of only two points from which a layer average cannot be determined. However, it is clear the CFAST's predictions are relatively poor considering the $0 \mathrm{~m} / \mathrm{s}$ prediction for the lower layer velocity.

\subsection{T52.14 SIMULATION RESULTS}

The results of the T52.14 oil pool fire test simulations are discussed in the following four sections. The sections individually describe the results of the three calculation methods applied to the T52.14 oil pool fire test as well as given an intercomparison of the three methods.

\subsubsection{T52.14 Hand Calculation Results}

Equations 7-9 were entered into Mathematica v3.0 ®. Before solving these equations a number of variables needed to be defined. The doorway loss coefficient $C_{d}$ was defined as $0.7^{1}$. The ambient temperature was defined as $300 \mathrm{~K}$. The upper layer wall surface area was calculated from the room geometry as $31.49 \mathrm{~m}^{2}$. The gas molar mass was taken to be that of air, 0.0288 $\mathrm{kg} / \mathrm{mol}$. The ambient pressure was assumed to be $101 \mathrm{kPa}$ (1 atm.) Lastly, the wall heat transfer coefficient was calculated from the wall heat conduction assuming steady-state heat transfer. For simplicity all the fire room walls were assumed to be $0.25 \mathrm{~m}$ of the Ytong firebrick. This results in $\mathrm{h}_{\mathrm{k}}=0.96 \mathrm{~W} / \mathrm{m}^{2} \cdot \mathrm{K}$. The following solutions were obtained by Mathematica ${ }^{\circledR}$ : 
Table 6.3: T52.14 Hand Calculation Results

\begin{tabular}{|l|r|}
\hline \multicolumn{1}{|c|}{ Variable } & Hand Calc \\
\hline $\mathrm{T}_{\mathrm{g}}\left({ }^{\circ} \mathrm{C}\right)$ & 1227 \\
\hline$\rho_{\mathrm{g}}\left(\mathrm{kg} / \mathrm{m}^{3}\right)$ & 0.2340 \\
\hline$\dot{m}_{\mathrm{g}}(\mathrm{kg} / \mathrm{s})$ & 2.1577 \\
\hline $\mathrm{H}_{\mathrm{N}}(\mathrm{m})$ & 1.0332 \\
\hline
\end{tabular}

Measured fire room temperatures for this test occurred in two planes located above the oil pool. These planes were at the $+27 \mathrm{~m}$ elevation, the middle of the fire room, and the $+28 \mathrm{~m}$ elevation, $0.55 \mathrm{~m}$ below the ceiling. If the data is averaged over the time period from 20 to 30 minutes, approximately the last ten minutes of the fire when the data indicates steady-state conditions exist, the measured temperatures range from $577^{\circ} \mathrm{C}$ to $1166^{\circ} \mathrm{C}$ with an average of $872{ }^{\circ} \mathrm{C}$. The hand calculation value of $1227^{\circ} \mathrm{C}$ lies $350^{\circ} \mathrm{C}$ above the average, $41 \%$ difference in temperature, and $100{ }^{\circ} \mathrm{C}$ above the upper bound of the measured values, a difference of $11 \%$ in absolute temperature. The average temperature for this prediction exceeds the recommended 15 $\%$ threshhold given in Table 2.1 .

The hand calculation in this case is not making as good a prediction as it did for T51.23. However, unlike T51.23, the boundary conditions outside the fire room are significantly different. The presence of the tremendous vertical flow through the maintenance shaft just outside the fire room is not a boundary condition typically encountered in fire experiments and, thus, is not one for which the hand calculation methods account and have been developed for. Thus, this presents a challenging test for such methods.

Table 6.4 gives the temperature profile in the fire room doorway averaged over the time period from 20 minutes to 30 minutes. Both the absolute sensor positions and the positions relative to the fire room floor are listed. This table indicates that the layer in the doorway is positioned about $1.5 \mathrm{~m}$ above the floor. Table 6.5 shows the doorway velocity profile. From this table the neutral plane is shown to be between $1.1 \mathrm{~m}$ and $1.6 \mathrm{~m}$ above the fire floor with the actual number closer to $1.6 \mathrm{~m}$. The hand calculation predicts a neutral plane location of $1.03 \mathrm{~m}$ or about $0.5 \mathrm{~m}$ below the measured value; this is an error of $30 \%$ which is acceptable according to Table 2.1.

Using the neutral plane location, mass flow rate, and the layer densities the average layer velocities can be calculated. This calculation yields an average upper layer velocity of $5.5 \mathrm{~m} / \mathrm{s}$ and an average lower layer velocity of $1.9 \mathrm{~m} / \mathrm{s}$. From this we see that the upper layer velocity is well predicted by the hand calculation. However, since the temperature is greatly overpredicted the mass flow rate is actually being underpredicted by $25 \%$. In essence, the hand calculation can not account for the jet pump like effect created by the upward flow in the maintenance shaft. This underprediction is acceptable, however. 
Table 6.4: T52.14 Measured Fire Room Doorway Average Temperatures (Average from $20 \mathrm{~min}$ to $30 \mathrm{~min}$ )

\begin{tabular}{|c|c|c|c|}
\hline Sensor & $\begin{array}{c}\text { Absolute Elevation } \\
(\mathrm{m})\end{array}$ & $\begin{array}{c}\text { Relative Elevation } \\
(\mathrm{m})\end{array}$ & $\begin{array}{c}\text { Temperature } \\
\left({ }^{\circ} \mathrm{C}\right)\end{array}$ \\
\hline CT9631 & 28.45 & 2.90 & 1180 \\
\hline CT9632 & 28.35 & 2.80 & 1154 \\
\hline CT9633 & 28.25 & 2.70 & 1128 \\
\hline CT9637 & 27.85 & 2.30 & 1170 \\
\hline CT9639 & 27.65 & 2.10 & 1147 \\
\hline CT9640 & 27.55 & 2.00 & 1156 \\
\hline CT9641 & 27.45 & 1.90 & 1107 \\
\hline CT9642 & 27.35 & 1.80 & 1147 \\
\hline CT9658 & 27.15 & 1.60 & 758 \\
\hline CT9657 & 26.90 & 1.35 & 455 \\
\hline CT9653 & 25.90 & 0.35 & 117 \\
\hline CT9651 & 25.60 & 0.05 & 80 \\
\hline
\end{tabular}

Table 6.5: T52.14 Measured Fire Room Doorway Average Velocities (Average from $20 \mathrm{~min}$ to $30 \mathrm{~min}$ )

\begin{tabular}{|c|c|c|c|}
\hline Sensor & $\begin{array}{c}\text { Absolute Elevation } \\
(\mathrm{m})\end{array}$ & $\begin{array}{c}\text { Relative Elevation } \\
(\mathrm{m})\end{array}$ & $\begin{array}{c}\text { Velocity } \\
(\mathrm{m} / \mathrm{s})\end{array}$ \\
\hline CV9600 & 28.25 & 2.70 & 7.89 \\
\hline CV9601 & 27.95 & 2.40 & 2.55 \\
\hline CV9602 & 27.55 & 2.00 & 4.86 \\
\hline CV9603 & 27.15 & 1.60 & 0.81 \\
\hline CV9604 & 26.65 & 1.10 & -1.64 \\
\hline CV9605 & 26.15 & 0.60 & -1.72 \\
\hline CV9606 & 25.65 & 0.10 & -1.28 \\
\hline
\end{tabular}

The following table, Table 6.6, shows the results of the Chen-Rodi and the Integral Analysis for the plume rising into the dome. The results are tabulated for the elevations of the two measurement grids in the dome at $+31 \mathrm{~m}$ and $+39 \mathrm{~m}$. The predicted neutral layer position, fire room temperature, and the mass flow rate were used as the initial plume conditions for both methods. It was assumed that a plume with the fire room temperature, doorway out-flowing velocity, and hydraulic diameter based on the neutral plane originated below the maintenance hatch at the elevation of the top of the doorway. 
Table 6.6: T52.14 Plume Hand Calculation Results

\begin{tabular}{|c|c|c|c|c|}
\hline \multirow{3}{*}{$\begin{array}{c}\text { Parameter at } \\
\text { Centerline }\end{array}$} & \multicolumn{4}{|c|}{ Location } \\
\cline { 2 - 5 } & \multicolumn{2}{|c|}{$+31 \mathrm{~m}$ grid } & \multicolumn{2}{c|}{$+39 \mathrm{~m}$ grid } \\
\cline { 2 - 5 } & Method & \multicolumn{2}{c|}{ Method } \\
\cline { 2 - 5 } & Chen-Rodi & Integral & Chen-Rodi & Integral \\
\hline Velocity $(\mathrm{m} / \mathrm{s})$ & 9 & 7 & 5 & 6 \\
\hline Temperature $\left({ }^{\circ} \mathrm{C}\right)$ & 959 & 229 & 55 & 66 \\
\hline Radius $(\mathrm{m})$ & N/A & 1 & N/A & 1 \\
\hline
\end{tabular}

Figures 6.23 and 6.24 show the measured temperatures for both grids averaged over the time period from 20 to 30 minutes, while figures 6.33 and 6.44 depict the velocities for the same time period. Due to the inability to resolve upward velocities at the $+31 \mathrm{~m}$ grid due to cross flow at the hatch affecting the velocity sensors, a contour plot for the velocity is not possible.

HDR DATA +31 m

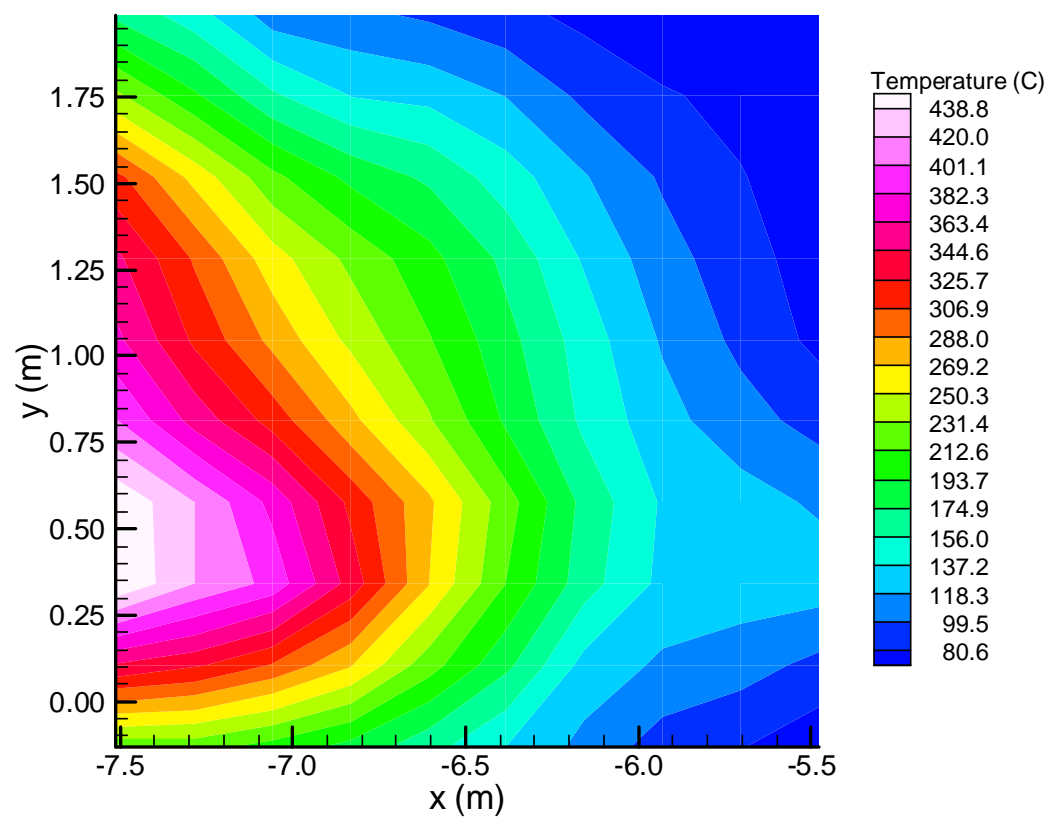

Figure 6.23: T52.14 +31 m Sensor Grid Average Temperatures (Average from $20 \mathrm{~min}$ to $30 \mathrm{~min}$ ) 


\section{HDR DATA +39 m}

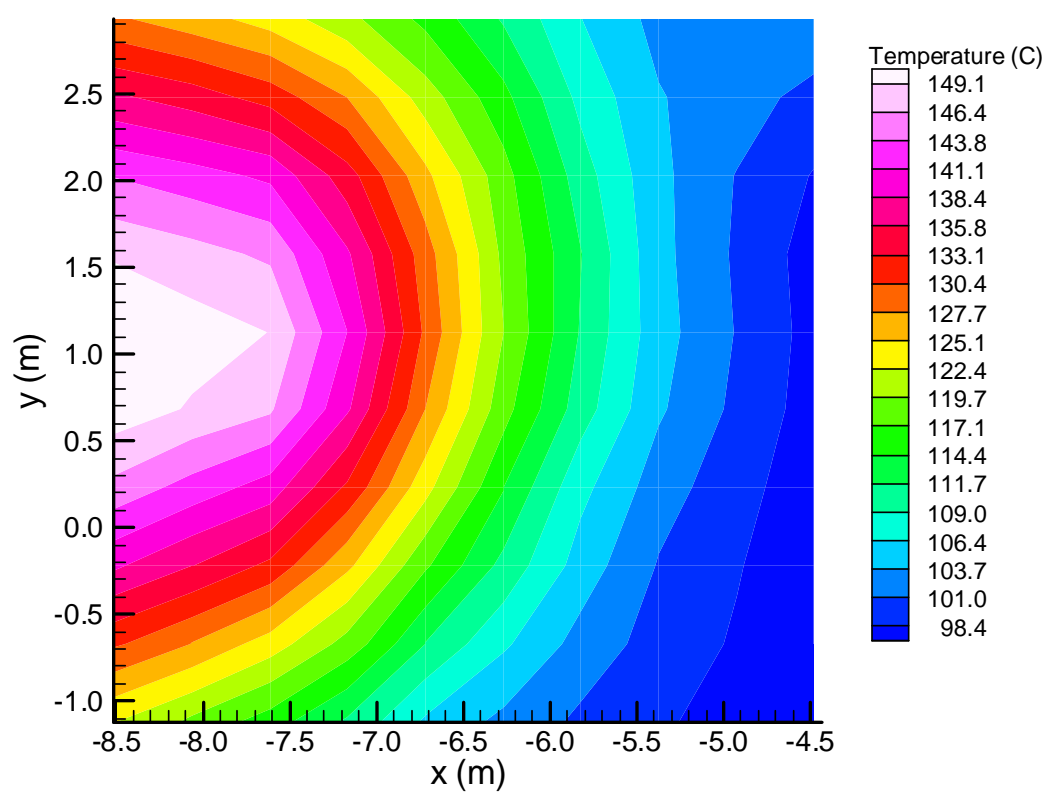

Figure 6.24: T52.14 +39 m Sensor Grid Average Temperatures (Average from $20 \mathrm{~min}$ to $30 \mathrm{~min}$ )

\section{HDR DATA +31 m}

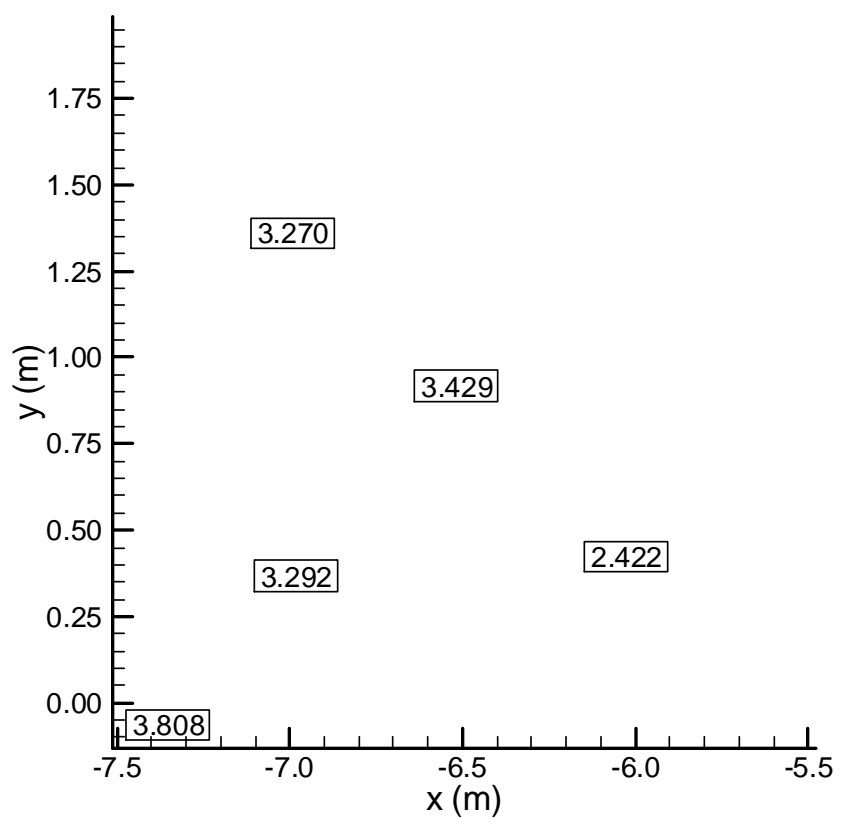

Figure 6.25: T52.14 +31 m Sensor Grid Average Velocities (Average from 20 min to $30 \mathrm{~min}$ ) 


\section{HDR DATA +39 m}

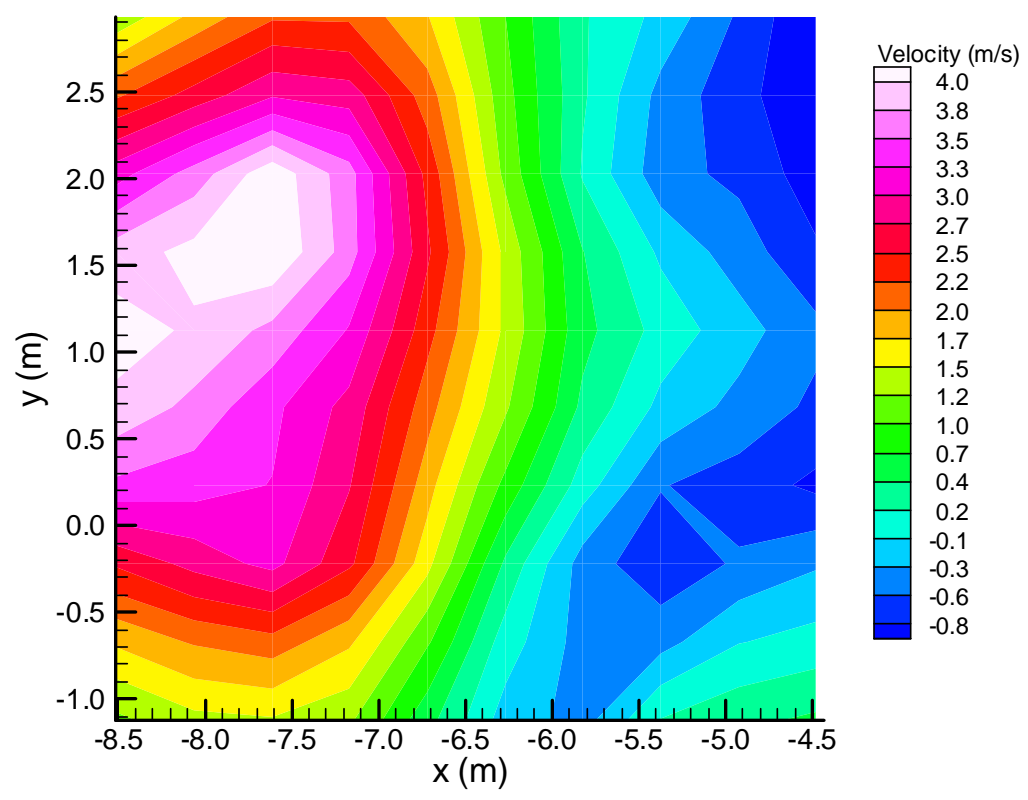

Figure 6.26: T52.14 +39 m Sensor Grid Average Velocities (Average from $20 \mathrm{~min}$ to $30 \mathrm{~min}$ )

The first pair of figures, Figures 6.23 and 6.24, indicate centerline temperatures of $440{ }^{\circ} \mathrm{C}$ and $150{ }^{\circ} \mathrm{C}$ respectively. At the $+31 \mathrm{~m}$ grid the Chen-Rodi correlation overpredicts the temperature by $520{ }^{\circ} \mathrm{C}$ and the integral method by $210{ }^{\circ} \mathrm{C}, 118 \%$ and $48 \%$ errors respectively. Both methods do not predict within the Table 2.1 guidelines. At the $+39 \mathrm{~m}$ grid the Chen-Rodi correlation underpredicts the temperature by $95^{\circ} \mathrm{C}$, a $63 \%$ error. The integral method underpredicts the temperature by $84^{\circ} \mathrm{C}$, a $56 \%$ temperature difference.

The upper grid predictions appear to show that both models are under-predicting the upper grid temperature. However, given that both methods underpredicted the $+31 \mathrm{~m}$ grid temperatures, it is expected that they would both underpredict the upper grid. A better test is the drop in temperature which is a function of the entrainment prediction. The relative drops in temperature for the T52.14 test, the Chen-Rodi, and the integral method are $66 \%, 94 \%$, and $71 \%$ respectively. With this comparison it is clear that in this case the Chen-Rodi correlation is overpredicting the entrainment whereas the integral method appears to have captured the entrainment quite well.

The second pair of figures, Figures 6.25 and 6.26, show plume centerline velocities of greater than $3.3 \mathrm{~m} / \mathrm{s}$ and $4.27 \mathrm{~m} / \mathrm{s}$ respectively. Due to the sparse information at the $+31 \mathrm{~m}$ grid, quantitative conclusions are not possible. Qualitatively, it is clear that the Chen-Rodi correlation at this location is greatly overpredicting the centerline velocity. The integral method is also over-predicting the velocity at this elevation. At the upper grid both methods overpredict the velocity by $26 \%$ and $35 \%$ respectively. 
The poor predictions made for the lower grid result from the fact that the plume at this location is a wall plume and, hence, lacks the total entrainment of the free plume assumed in the two models. Furthermore, the temperature profile in the data indicates a likelihood that some counter-current flow is occurring in the hatch. This would also act to reduce the entrainment of the plume. This reduction in entrainment results in a higher measured temperature than the model predicts. Neither plume analysis method is well suited to this particular location. In this far field location with a correlation method such as these, predictions closer to $30 \%$ should be possible.

In addition to temperature and velocity predictions, the integral method also calculates the plume radius. The integral method assumes a Gaussian plume shape. For the derivation used for this work, the radius referred to that location where the velocity was $1 \%$ of the centerline velocity. With a centerline velocity of $4.27 \mathrm{~m} / \mathrm{s}$, occurring at $\operatorname{HDR}(\mathrm{x}, \mathrm{y})$ coordinates of $(-7.61 \mathrm{~m}, 1.58 \mathrm{~m})$, the radius of the plume at the $+39 \mathrm{~m}$ grid would be at the location of an upward velocity of 0.04 $\mathrm{m} / \mathrm{s}$ which occurs at HDR $(\mathrm{x}, \mathrm{y})$ coordinates of $(-5.82 \mathrm{~m}, 0.23 \mathrm{~m})$. This is a radius of $2.25 \mathrm{~m}$, almost twice the predicted value.

The Gaussian functions for velocity, density, and radius function used in the integral plume method can also be used to determine the mass flow at a given elevation in the plume. This is done be integrating Equation 20 using the solutions obtained from the integral model. This integration was performed at the positions of the operating deck and at the plume's impingement point on the dome's hemispherical head. Knowledge of these values plus conservation of mass allows the calculation of the mass flows shown in the following table, Table 6.7.

Table 6.7: T52.14 Mass Flow Rates at Key Locations

\begin{tabular}{|c|c|c|c|}
\hline$\#$ & Location & $\begin{array}{c}\text { Mass Flow Rate } \\
(\mathrm{kg} / \mathrm{s})\end{array}$ & How Obtained \\
\hline 1 & Upper doorway & 2 & Hand-calc output \\
\hline 2 & Flow into dome & 7 & $\begin{array}{c}\text { Integrate at } \\
\text { operating deck }\end{array}$ \\
\hline 3 & Flow at plume top & 34 & $\begin{array}{c}\text { Integrate at steel } \\
\text { shell }\end{array}$ \\
\hline 4 & Dome Recirculation & 28 & $\# 3-\# 2$ \\
\hline 6 & Circulation loop & 7 & $\# 2$ \\
\hline
\end{tabular}

Assuming temperatures near the ambient in the main staircase maintenance hatch on the opposite side, the circulation loop mass flow rate can be used to calculate an average velocity through the circulation loop. A mass flow of $6.62 \mathrm{~kg} / \mathrm{s}$ at ambient temperature through the $4.54 \mathrm{~m}^{2}$ maintenance hatch yields an average velocity of $1.25 \mathrm{~m} / \mathrm{s}$ through the hatches. Table 6.8 below gives the measured velocities in the flow loop. For all locations the hand calculation has greatly overestimated the velocities through the flow loop. Three factors may account for a portion of this. First, it is already known that the mass flow rate at the measurement grid at the operating deck is overestimated since the hatch restricts flow and the analysis assumed a free plume.

Second, soot deposition on the paddlewheel flow sensors does degrade performance for low flow rates. Thirdly, a fraction of the mass flow seen at the hatch results from countercurrent flow of 
the containment atmosphere recirculating in the dome and descending the hatch near the fire room alongside the rising plume. Combined these effects, probably account for much of the error.

Table 6.8: T52.14 Velocities in Circulation Loop

\begin{tabular}{|c|c|c|}
\hline Sensor & Location & $\begin{array}{c}\text { Velocity } \\
(\mathrm{m} / \mathrm{s})\end{array}$ \\
\hline CF9301 & Main staircase 1.900 level & 0.005 \\
\hline CF7703 & Main staircase 1.700 level & 0.004 \\
\hline CF6602 & Main staircase 1.600 level & 0.043 \\
\hline CF7802 & Spiral staircase 1.700 level & 0.096 \\
\hline CF9205 & Spiral staircase 1.900 level & 0.662 \\
\hline
\end{tabular}

In the dome, if the ambient conditions outside the plume are considered to be near room temperature, the recirculation flow in the dome can be calculated. If $27.84 \mathrm{~kg} / \mathrm{s}$ of mass is being recirculated in the dome due to the plume entrainment, this corresponds to a turnover time of 200 seconds, i.e. 3.4 minutes. This implies that over the thirty minutes of the fire that the upper dome atmosphere was recirculated in the dome nine times. This is a tremendous air exchange given the $5000 \mathrm{~m}^{3}$ size of the dome and is most likely an overestimation by the model. However, since the model assumes a free plume and the dome is not an infinite volume, it is not surprising that this would be overpredicted. This does give insight, however, that a tremendous recirculation is occurring inside the dome.

\subsubsection{T52.14 CFAST Results}

The T52.14 CFAST results in this section are organized according to the predicted quantities, e.g. temperature, velocity, and gas concentrations

\subsubsection{T52.14 CFAST Temperature Results}

The first figures, Figure 6.27 shows the CFAST predicted upper and lower layer temperatures versus measured data in the fire room. The thermocouple locations for this test were all in the upper layer, so no direct comparisons can be made for the lower layer. Predictions are somewhat overpredicted during the peak of the fire but lie within the measured data for the steady-state portion of the fire. In the lower layer the model lies below the spectrum of data in the fire room. Given the absence of thermocouples at lower elevations in the fire room, the only conclusion that can be drawn is that for the model, CFAST is making a physically realistic computation.

However, for both layers the model results do not show as rapid a cooldown as indicated by the data, although it is fairly close. CFAST temperature predictions also follow the burning rate trend to a much larger degree than shown in the data. This indicates that CFAST is not fully capturing heat storage and release phenomena from the room surfaces. 


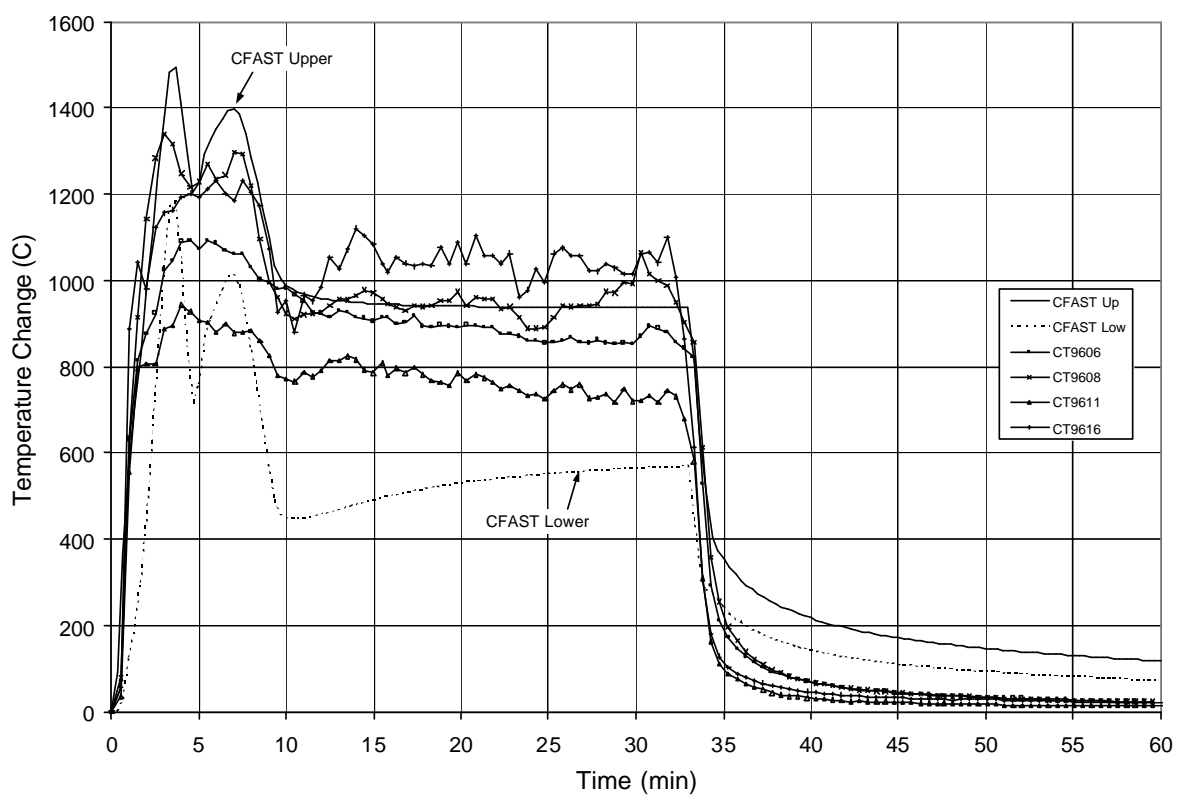

Figure 6.27: T52.14 Fire Room Temperatures, Measured vs. CFAST

The observations above have a number of factors that could be contributing to them. Since CFAST overpredicts the peak of the fire, it is possible that the pyrolysis curve supplied by the HDR facility overspecifies the peak of the fire leading to elevated temperature predictions. The cooldown errors seen also most likely result from mass flow prediction errors, with CFAST predicting too quick of a stop in the HDR model circulation after the fire.

The CFAST calculated layer heights for the fire room area and the hatch area are shown in Figure 6.28. The only location for which enough instrumentation is present to determine the layer height is in the doorway. Test data indicates that the layer interface is positioned near $+26.9 \mathrm{~m}$ in elevation or $1.35 \mathrm{~m}$ above the floor of the doorway. Since the fire room layer height calculated by CFAST is the average height over that entire region including the doorway, one would expect the CFAST prediction to be slightly lower than that measured in the doorway. Also, the layer in the hatch area is expected to by predicted higher than the fire room. This is indeed the case. The fire room layer height is predicted to be $0.5 \mathrm{~m}$ below that measured in the doorway, and the hatch area has a larger layer height than the fire room. CFAST predictions are excellent for this parameter. 


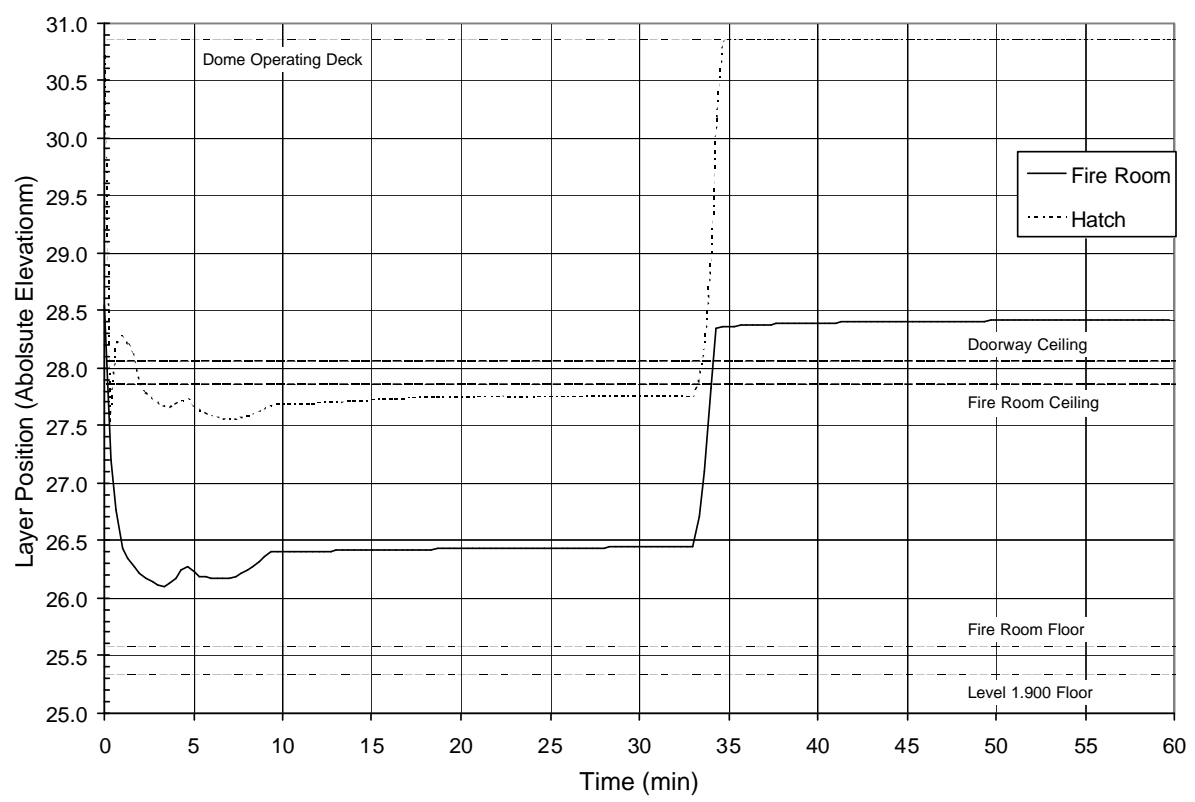

Figure 6.28: T52.14 CFAST Predicted Layer Heights

Figure 6.29 below shows the CFAST predicted temperatures in the compartment constructed below the maintenance hatch to the dome. The region within the compartment was not instrumented, however the inlet and exit hatches to this region were heavily instrumented. Therefore, the CFAST results for the upper layer are shown in comparison to the instrumentation grids located in the upper hatch. For the upper layer, it is important to realize that the flow field in this location consisted of a wall plume rising through the hatch corner nearest the fire room doorway. That is, the plume did not rise through the center of the hatch. For this situation it is difficult to define an upper layer temperature based on test data, as in this case an upper layer did not exist in a traditional sense. At best, for the upper layer CFAST can be expected to predict temperatures that lie within the range of temperatures seen in the plume, and indeed this is what occurs with CFAST results lying in the middle of the data's span. Except for during the cooldown, the model predicts the same temperature profiles seen in the data. 


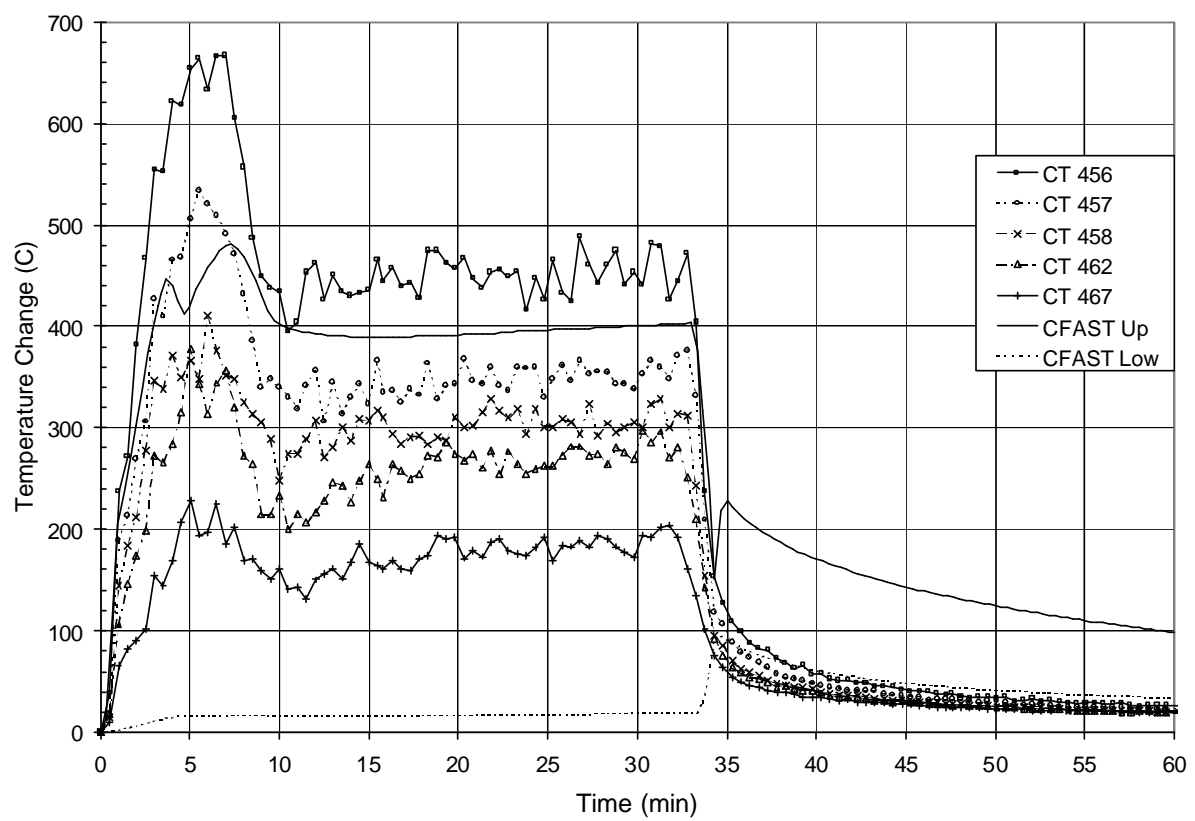

Figure 6.29: T52.14 Fire Level Hatch Upper Layer Temperatures, Measured vs. CFAST

Figure 6.30 shows CFAST predictions along with the corresponding measurements for the upper sensor grid. This locations represents the conditions of the atmosphere entering the upper region of the dome. Since the layer height in this regions quickly dropped to near zero, the lower layer is not meaningful for comparisons. The data shown represent the spread of temperatures seen in the plume entering the upper dome. Since CFAST results represent a volume averaged temperature for this region, one would anticipate CFAST to be predicting well below the highest measured temperatures as the plume only occupied a fraction of this region. The model predicts temperatures that lie near the highest measured temperatures at the upper sensor grid. CFAST is, therefore, over predicting the volume average temperature substantially in this region. The post fire cooldown is well predicted.

CFAST predictions compared with measured temperatures at the bottom of the global circulation loop are depicted in Figure 6.31. The temperatures shown are from a vertical rake located in the level 1.600 hallway connecting the main staircase side of the HDR with spiral staircase side. The data from the rake indicates that this region of the containment only saw a small temperature increase of a few degrees and that only during the early growth of the fire. During the fuel addition portion of the test, conditions were back to ambient. The CFAST model predicts both too large of a temperature increase during the test and do not cool back to ambient conditions during the fuel addition portion of the test. Furthermore, during the first five minutes of the fire the lower layer predictions exceed the upper layer predictions. After this point the predicted layer height decreases rapidly and the lower layer predictions lie nearly on top of the measured data; however, the layer height at this point lies below the measured data locations. It is clear that CFAST is not correctly predicting the flow circulating through the HDR. It is possible that further experimentation with flow connections between the two sides of the facility could 
improve predictions lower in the facility. However, there is little guidance to the code user on such issues.

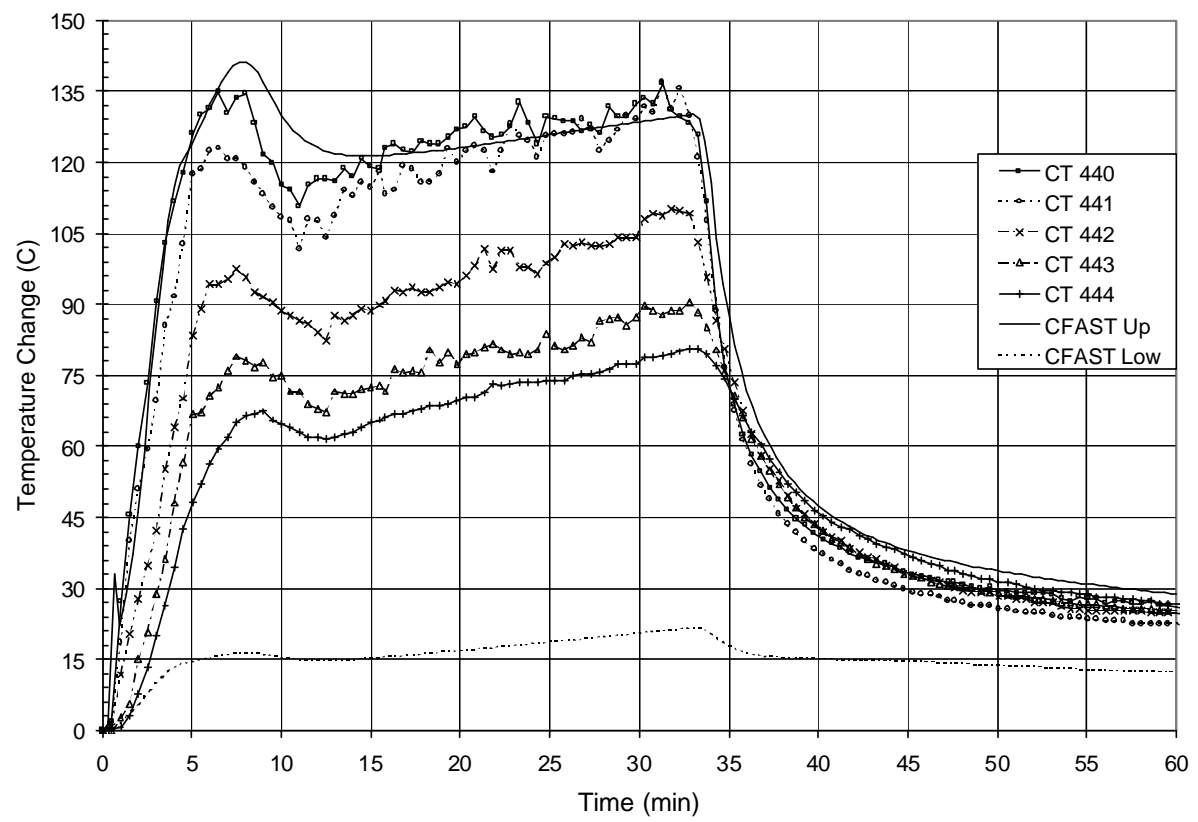

Figure 6.30: T52.14 Upper Sensor Grid Temperatures, Measured vs. CFAST

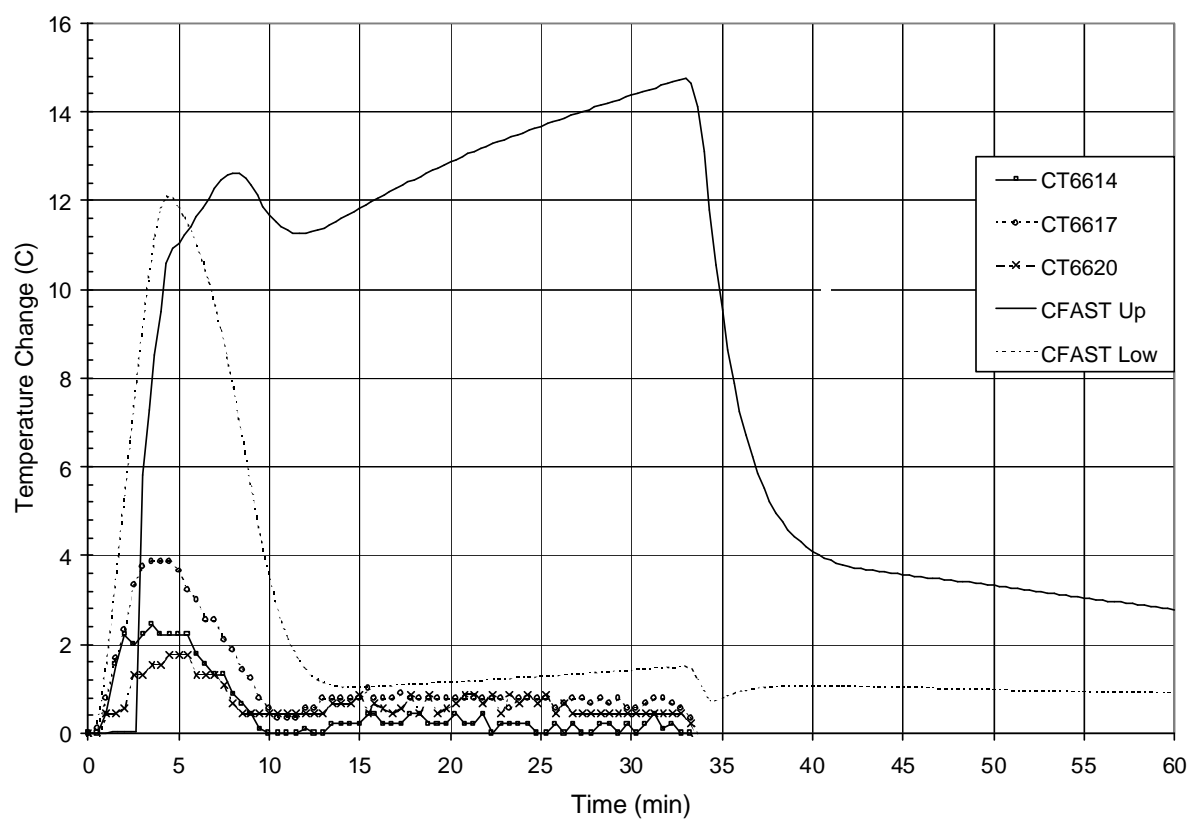

Figure 6.31: T52.14 Level 1.600 Temps Near Spiral Staircase, Measured vs. CFAST 


\subsubsection{T52.14 CFAST Velocity Results}

The first figure in this section, Figure 6.32, compares the CFAST predicted velocities to measured values for the upper layer and lower layer of the doorway. The measured values shown for the doorway are not the actual sensor readings, for all but the uppermost sensor, CV9600, the measured fluctuating data from the facility were smoothed greatly before being added to the electronic dataset.

In the upper layer, CFAST predictions lie near the average of the data during the fire. One cannot expect a better prediction from a zone model code. After the fire, however, the model shows a instantaneous drop to zero where the data clearly indicates that a small region of the upper doorway still has a substantial outward flow of $1 \mathrm{~m} / \mathrm{s}$ at 60 minutes.

In the lower layer, the model overpredicts the velocity by greater than $75 \%$. Also, during the post-fire cooldown the model predicts a small outward flow whereas the data indicates a small inward flow still exists in the lower layer. These results are somewhat puzzling. Since CFAST appears to be overpredicting the amount of cool air entering the fire room, one would expect the CFAST predicted temperatures in the fire room to tend towards underprediction. This was not the case as seen in Figure 6.27 which shows an overpredictiion of the fire room temperature. This would indicate that some aspect of the room heat transfer calculation is being underpredicted leading to the overprediction of temperature.

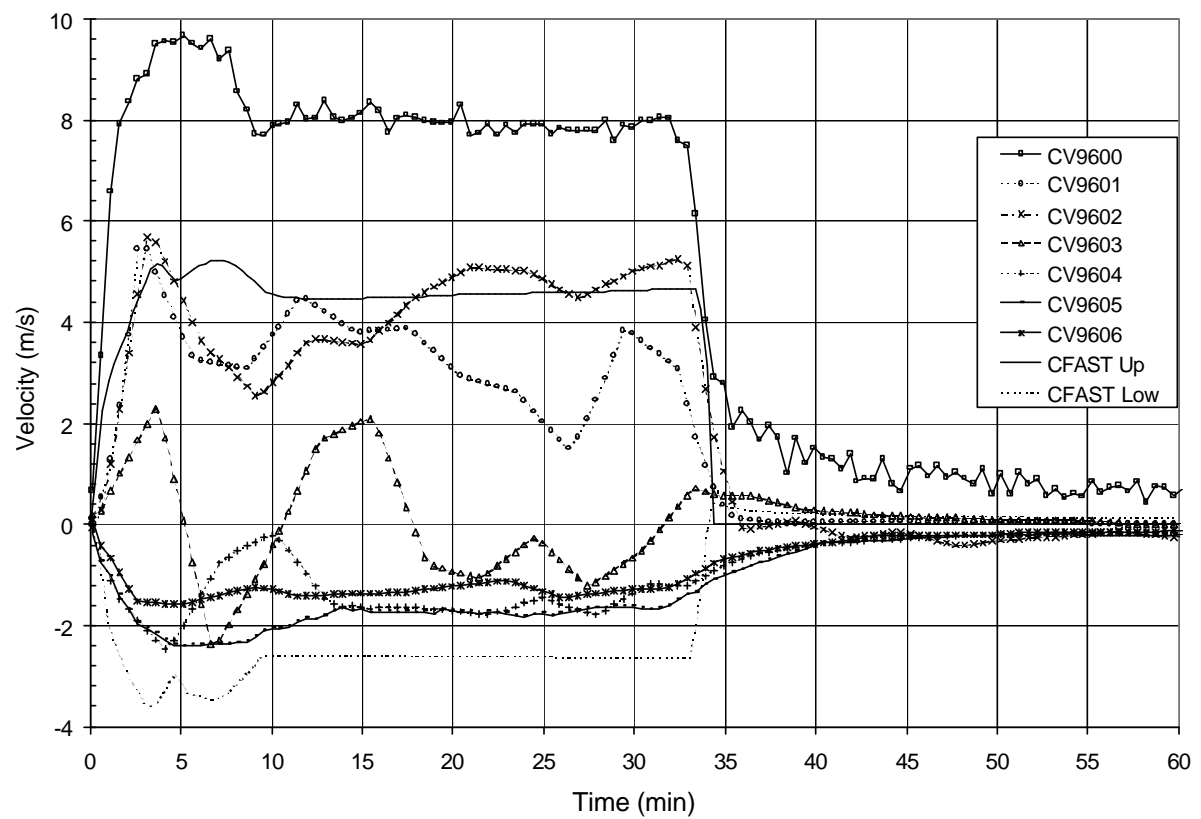

Figure 6.32: T52.14 Doorway Velocities, Measured vs. CFAST

The following figure, Figure 6.33, shows velocities leaving the fire room level and entering the dome through the maintenance hatch. The CFAST model results in velocity predictions which are about $50 \%$ below the measured velocities. However, since the upward flow did not actually 
occupy the whole hatch but rather $1 / 3$ to $1 / 2$ of the hatch, the CFAST predictions are correct in terms of mass flow. Unlike the T51.23 CFAST model, the first region of vertical flow after the fire room is very well predicted for T52.14. This is a tremendous accomplishment for a zone model code and after the results from the T51.23 simulations, a completely unexpected result.

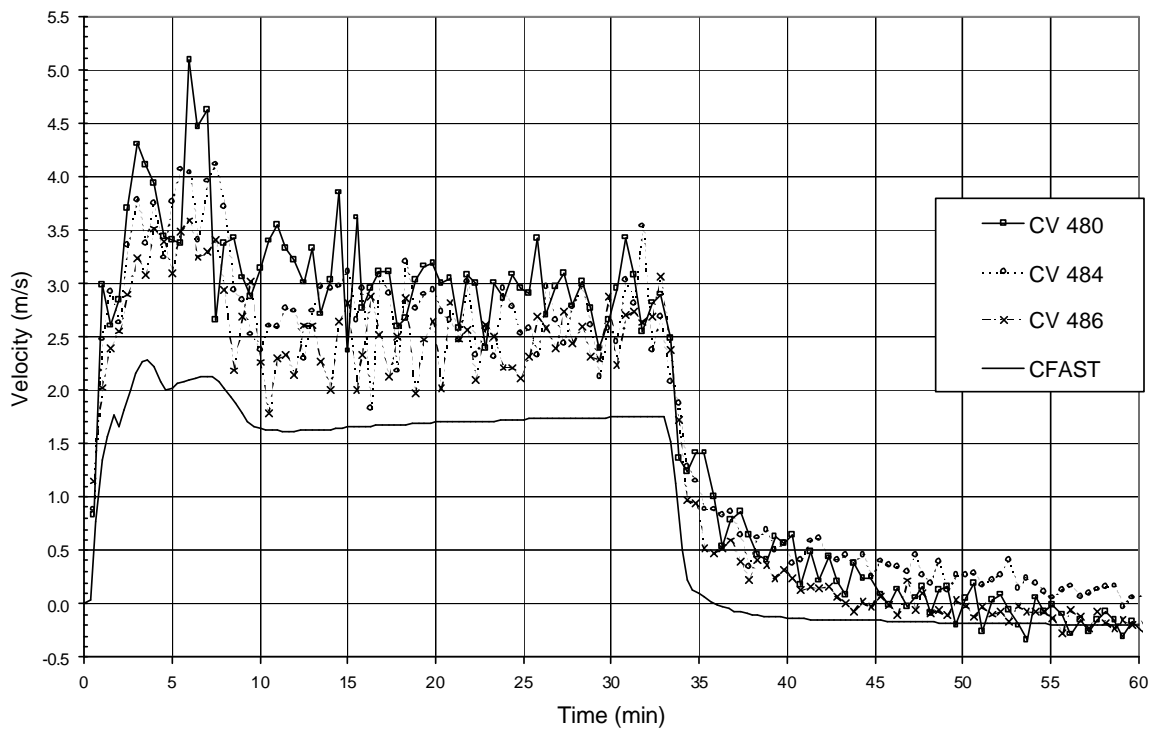

Figure 6.33: T52.14 Fire Level to Dome Velocities, Measured vs. CFAST

The last velocity figure, Figure 6.34, shows the velocity entering the downward flowpath on the main staircase side of the HDR. It is clear that CFAST models is greatly overpredicting the flow down the main staircase maintenance hatches. In all fairness, some of this is do to the model itself which does not contain a flowpath connecting the sides of the lower dome and, thus, forces more air down the main staircase. However, in prior work performed by the author ${ }^{45}$ in which a connection in the dome was made, the results were lower temperatures in the upper dome, higher temperatures in the main staircase side of the building, and the same magnitude of velocity prediction at this location. These results would indicate that CFAST may not be capable of calculating flows inside of large volumes. This is in contrast to work done by $\mathrm{Chow}^{55}$ which had success in using CFAST to model a large volume by subdividing that volume into smaller compartments. However, that work only subdivided the volume horizontally, not horizontally and vertically as was done by this author. CFAST's performance here is not surprising as CFAST was never designed with such flows in mind; however, this does question the ability to use CFAST for large atrium style spaces. Further work is warranted in examining the use of such subdivisions for modeling large volumes with CFAST.

\subsubsection{T52.14 CFAST Gas Concentration Results}

Figures 6.35, compares measured values for the oxygen, carbon dioxide, and carbon monoxide concentrations in the upper layer of the doorway with CFAST predictions. As discussed in the introductory sections, one of the greatest challenges for modeling a fire is the description of the combustion process, especially for underventilated fires. Unless an experiment exists for the exact geometry and test conditions being modeled, a CFAST user must make assumptions 
regarding the combustion product outcomes for a fire. These assumptions greatly impact its predictive capabilities. The following figures will illustrate aspects of this difficulty.

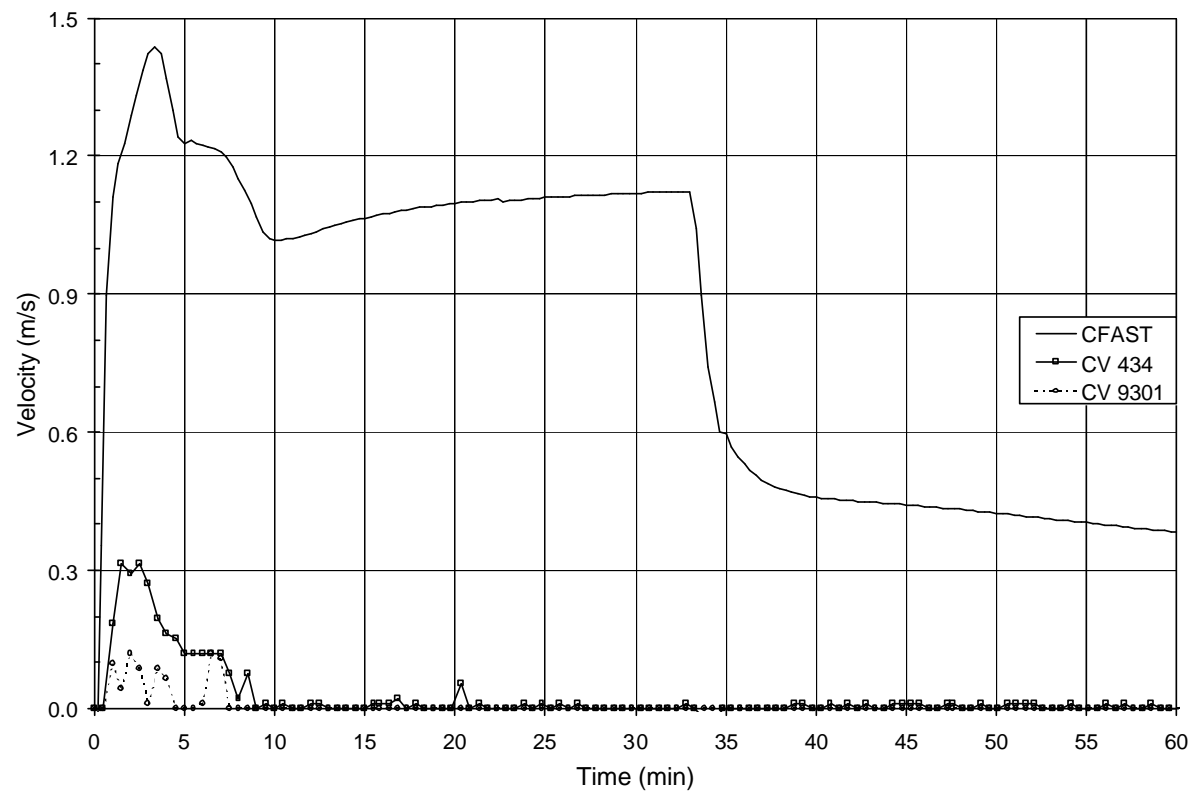

Figure 6.34: T52.14 Dome to Level 1.900 by Main Staircase Velocities, Measured vs. CFAST

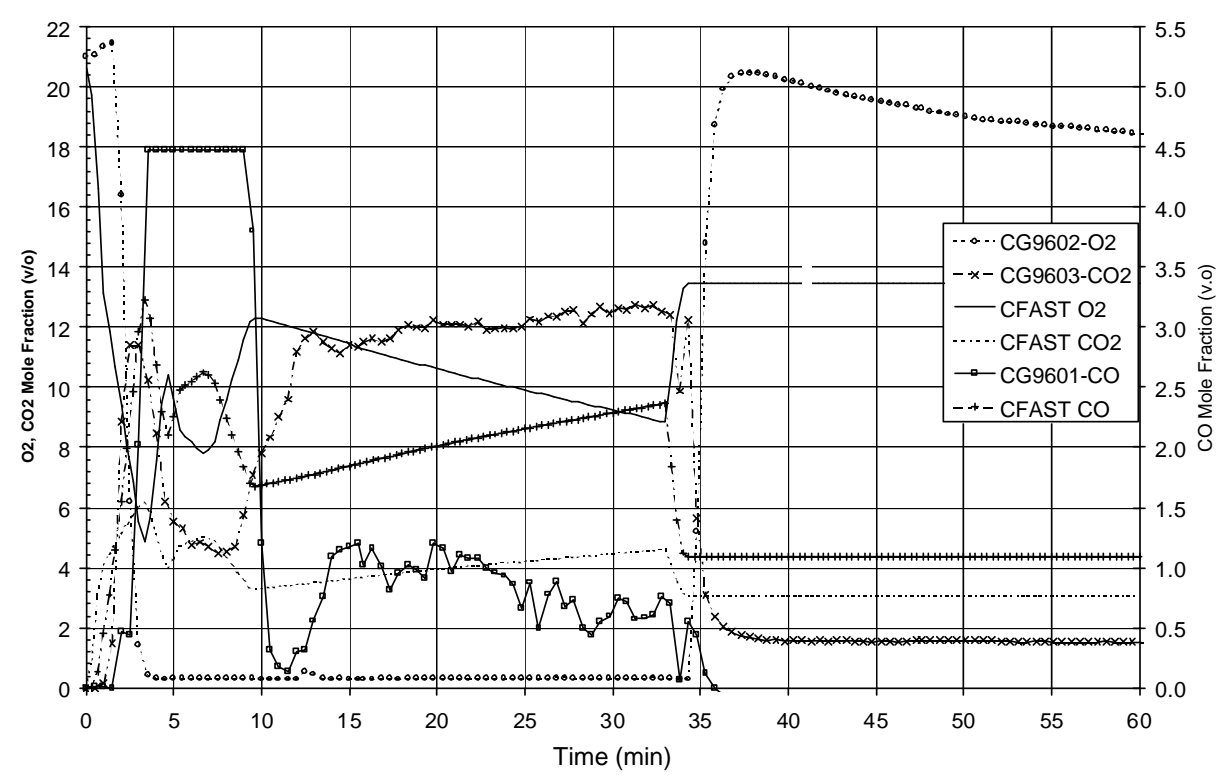

Figure 6.35: T52.14 Doorway Upper Layer $\mathrm{O}_{2}, \mathrm{CO}_{2}$, and $\mathrm{CO}$, Measured vs. CFAST

The CFAST prediction for oxygen, up until the peak of the fire near four minutes, lies ontop of the measured oxygen concentration. At this point in time the predictions and the data diverge. The CFAST prediction undergo an oscillation between 6 v/o and $10 \mathrm{v} / \mathrm{o}$ and then 6 v/o and 12 v/o as the fire's intensity dwindles before the fuel addition begins. After the fuel addition starts the CFAST prediction slowly decreases to 8 v/o. The measured concentration shows a markedly 
different behavior. After the peak of the fire, the data continues to decrease until the upper layer is completely depleted of oxygen. This condition remains until the end of the fire. CFAST does not successfully predict the oxygen concentration in the fire room during the fire. At the end of the fire the CFAST predicted concentrations do not fully recover to near ambient conditions. The data, however, show a quick recovery to the original concentration after the fire ends, followed by a slow decrease of 2 v/o as the global circulation loop continues to mix the oxygen-depleted atmosphere deposited in the dome throughout the facility.

Similar observations can be made for the $\mathrm{CO}_{2}$ concentration prediction. Again CFAST performance is excellent during the first two minutes of the fire, but afterwards the predictive quality worsens considerably. During the steady-state portion of the fire, the model underpredicts the $\mathrm{CO}_{2}$ concentration by 8 v/o, 4 v/o predicted versus 12 v/o measured, an error of $66 \%$ which is well outside acceptable limits. A portion of this may be due to combustion product specification in the input file, however, if the mass of $\mathrm{CO}$ and soot specified in the input file were zeroed out this would only increase the amount of $\mathrm{CO}_{2}$ by 2.5 times or from 4 v/o to 10 v/o. This would be a $16 \%$ error; however, since soot and $\mathrm{CO}$ are being produced, much of the error is not due to the input but rather the code computations. The code is not predicting the $\mathrm{CO}_{2}$ concentration well.

The CO predictions by CFAST do not ameliorate the situation. The beginning of the fire is rather well predicted, but the peak $\mathrm{CO}$ concentration is greatly underpredicted by at least $2 \mathrm{v} / \mathrm{o}$. The real extent of the underprediction is unknown due to a range selection error for the $\mathrm{CO}$ sensor (the sensor maxed out at $4.5 \mathrm{v} / \mathrm{o}$ ). During the steady-state portion of the fire, the CO predictions range from $1 \mathrm{v} / \mathrm{o}$ to $2 \mathrm{v} / \mathrm{o}$ above the measured values lying between $1 \mathrm{v} / \mathrm{o}$ and $1.5 \mathrm{v} / \mathrm{o}$. Since CO production is primarily specified by the user, the underprediction of the peak and the overprediction of the steady-state portion most likely result from a poor input specification. The failure of the $\mathrm{CO}_{2}$ prediction is further bolstered by the $\mathrm{CO}$ prediction. If all the $\mathrm{CO}$ that was overpredicted was $\mathrm{CO}_{2}$, the $\mathrm{CO}_{2}$ prediction would still be 6 v/o too low.

Figure 6.36 shows the CFAST predicted concentration of $\mathrm{CO}_{2}$ entering the upper dome. The measured values shown in the figure are from the uppermost measurement grid at $+39 \mathrm{~m}, 1 \mathrm{~m}$ below the start of the containment dome's hemispherical head. At this location CFAST matches the overall trend shown in the date, but is overpredicting the measured concentrations by $25 \%$. Since the measurement locations lie inside the plume and CFAST is predicting for the volume of the entire region beneath the measurement grid, one would expect CFASR predictions to be slightly less than the measured data. Thus, the $25 \%$ error is actually a lower bound on the error.

The final T52.14 CFAST figure, Figure 6.37, shows the measured versus predicted $\mathrm{CO}_{2}$ concentrations in the upward flow maintenance shaft. As with the dome CFAST predicts a similar transient behavior as seen in the data. However, CFAST predicts a drop in maximum concentration of $0.3 \mathrm{v} / \mathrm{o}$ from the dome whereas the data shows a drop of $0.7 \mathrm{v} / \mathrm{o}$. The end result is that CFAST is overpredicting the maximum concentration by $100 \%$. CFAST does correctly predict the fact that there is no concentration decrease at this location after the fire. This correct prediction of the end of the fire is not strictly a success for CFAST, however, given that for most 
other parameters and locations CFAST did not make good predictions for the cooldown phase of the fire.

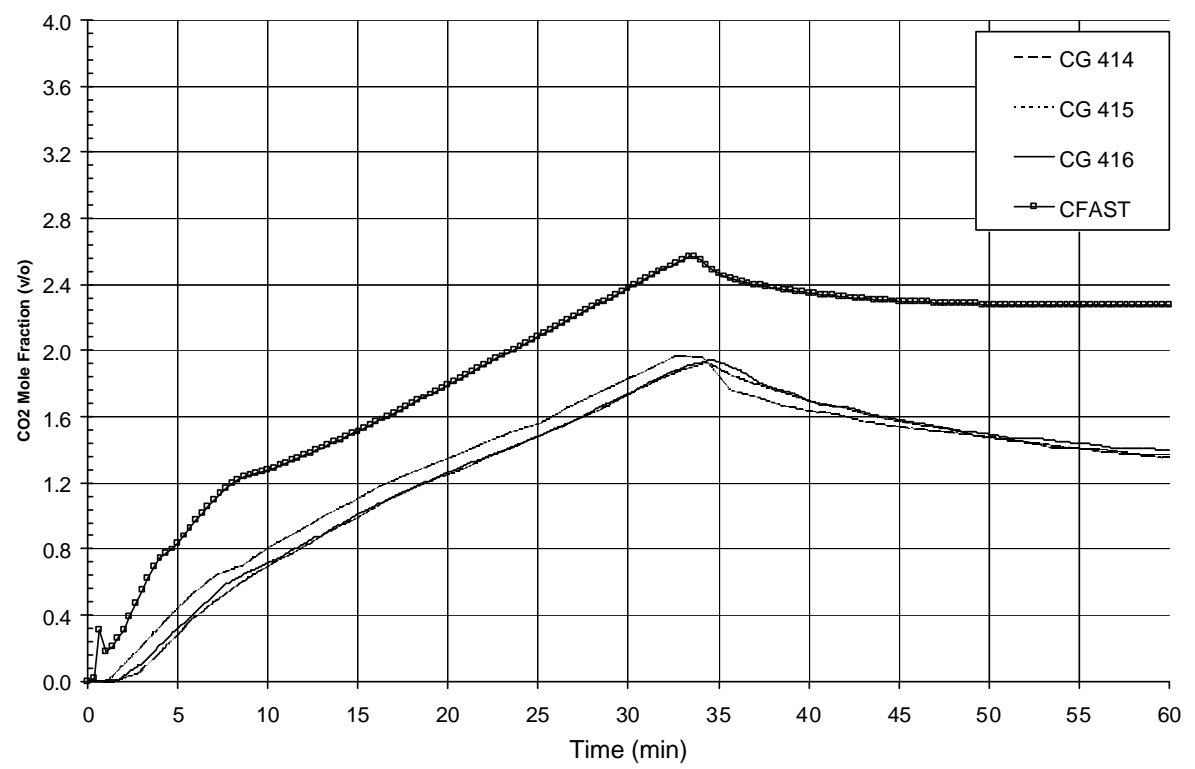

Figure 6.36: $\mathrm{T} 52.14 \mathrm{CO}_{2}$ Concentration at the Dome Hemispherical Head Over the Fire Room, Measured vs. CFAST

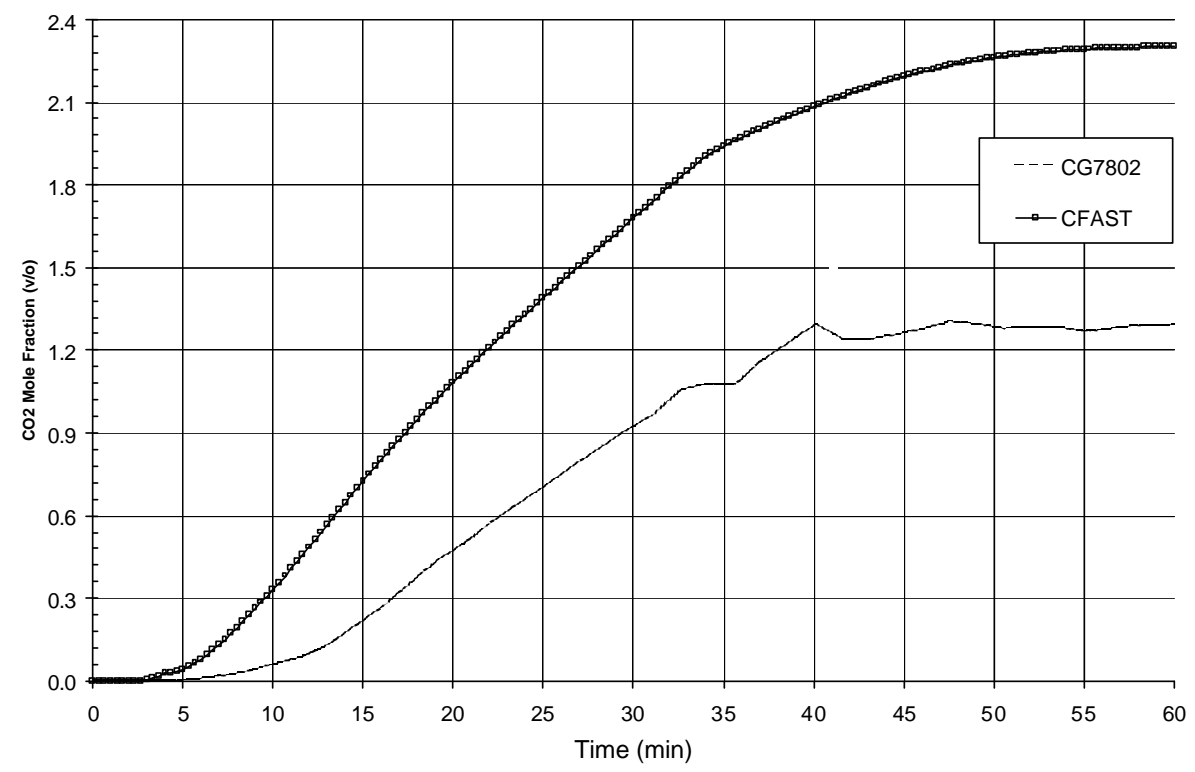

Figure 6.37: T52.14 $\mathrm{CO}_{2}$, in Upward Flow Path 1.700 Level, Measured vs. CFAST 


\subsubsection{T52.14 FDS Results}

The FDS results of this subsection are presented in groups based on the geometric divisions of the FDS model. The results are presented in terms of the fire room, the doorway, the hatch region, and the dome.

\subsubsection{Fire Room}

The first comparison, Figure 6.38, compares FDS predictions with the temperatures from a sensor is located in the corner of the fire room diagonally opposite the doorway. FDS v2.0 $\alpha$ again performs well in the fire room. At the peak of the fire, which occurred near $190 \mathrm{~s}$, FDS v2.0 $\alpha$ is predicting a temperature change $27 \%$ higher than measured as this location. There are a number of possiblities as to why the temperature is being overpredicted. A few are: not a high enough noding resolution, predictive errors in the radiation heat transfer, and the assumption of perfect combustion (e.g. not account for soot and $\mathrm{CO}$ production) which results in a higher effective heat of combustion inside the fire room.

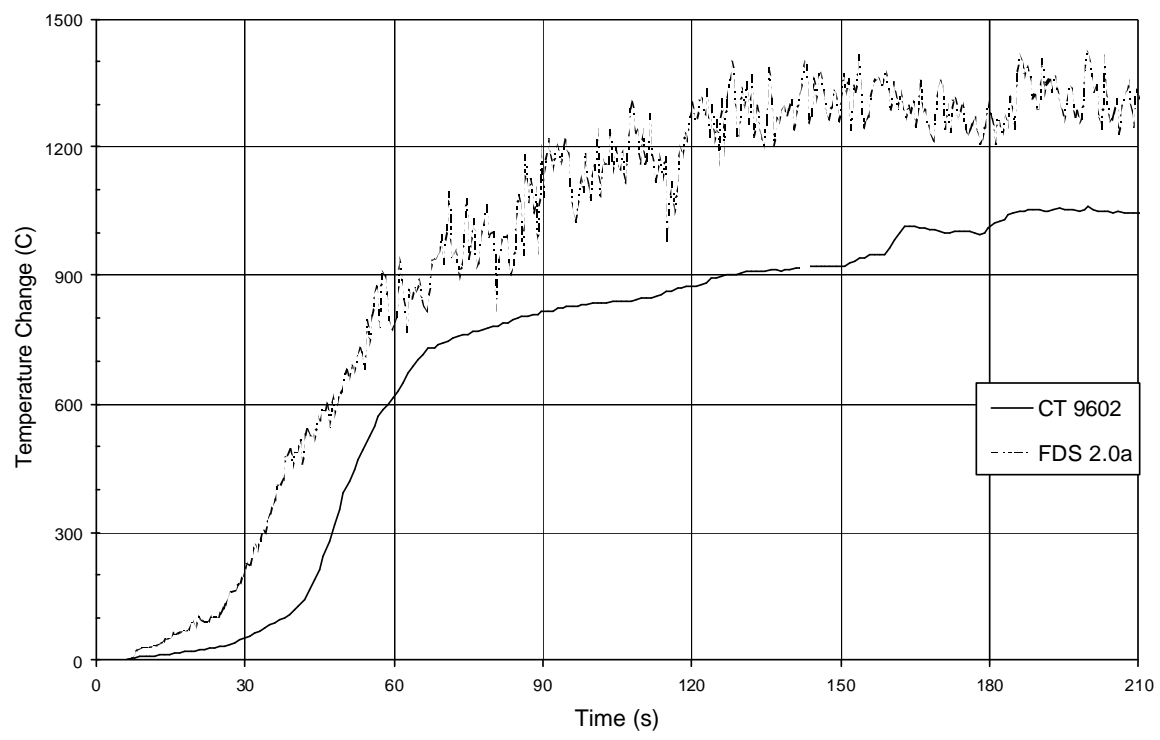

Figure 6.38: T52.14 FDS Results for CT9606

The table below, Table 6.9, shows the measured vs. predicted temperatures in the fire room during the peak of the fire. These were obtained by averaging the data and the predictions over the time span from 188 seconds to 211 seconds after the start of the fire. FDS v2.0 $\alpha$ averages a $19 \%$ overprediction inside the fire room, which is within the Table 2.1 criteria.. 
Table 6.9: T52.14 FDS Results for the Fire Room During Fire Peak

\begin{tabular}{|c|c|c|c|c|}
\hline Sensor & Type & HDR & FDS 2.0 $\alpha$ & Error \\
\hline CT9602 & ${ }^{\circ} \mathrm{C}$ & 989 & 1,249 & $23 \%$ \\
\hline CT9603 & ${ }^{\circ} \mathrm{C}$ & 1,199 & 1,313 & $7 \%$ \\
\hline CT9604 & ${ }^{\circ} \mathrm{C}$ & 1,209 & 1,381 & $13 \%$ \\
\hline CT9606 & ${ }^{\circ} \mathrm{C}$ & 1,052 & 1,319 & $24 \%$ \\
\hline CT9608 & ${ }^{\circ} \mathrm{C}$ & 1,339 & 1,331 & $2 \%$ \\
\hline CT9609 & ${ }^{\circ} \mathrm{C}$ & 1,165 & 1,192 & $9 \%$ \\
\hline CT9610 & ${ }^{\circ} \mathrm{C}$ & 892 & 1,034 & $15 \%$ \\
\hline CT9611 & ${ }^{\circ} \mathrm{C}$ & 910 & 1,121 & $23 \%$ \\
\hline CT9612 & ${ }^{\circ} \mathrm{C}$ & 974 & 996 & $2 \%$ \\
\hline CT9613 & ${ }^{\circ} \mathrm{C}$ & 728 & 1,178 & $62 \%$ \\
\hline CT9615 & ${ }^{\circ} \mathrm{C}$ & 955 & 1,237 & $30 \%$ \\
\hline CT9616 & ${ }^{\circ} \mathrm{C}$ & 1,194 & 1,099 & $8 \%$ \\
\hline CT9617 & ${ }^{\circ} \mathrm{C}$ & 917 & 1,144 & $25 \%$ \\
\hline CT9618 & ${ }^{\circ} \mathrm{C}$ & 1,222 & 1,255 & $3 \%$ \\
\hline CT9169 & ${ }^{\circ} \mathrm{C}$ & 905 & 1,354 & $50 \%$ \\
\hline CT9620 & ${ }^{\circ} \mathrm{C}$ & 1,244 & 1,269 & $2 \%$ \\
\hline CT9621 & ${ }^{\circ} \mathrm{C}$ & 888 & 1,441 & $62 \%$ \\
\hline CT9622 & ${ }^{\circ} \mathrm{C}$ & 1,267 & 1,312 & $4 \%$ \\
\hline
\end{tabular}

\subsubsection{Doorway}

The first two figures of this section, Figures 6.39 and 6.40 show the doorway temperature and velocity profiles during the peak of the fire. The measured data comes from a rake of thermocouples and pitot tubes at the centerline of the doorway. In Figure 6.39 it is observed that FDS v2.0 $\alpha$ is correctly predicting the temperature profile in the top of the doorway. FDS also predicts a velocity profile prediction for the lower region of the doorway which matches the profile seen in the data. In the upper portion of the doorway; however, FDS predicts a profile that decreases in velocity at the highest measurement location where the data shows a high velocity measurement. This discrepancy most likely results from a combination of the noding resolution in the upper doorway being too coarse and errors in the sensor due to the high temperatures and soot concentrations that occurred during the test. 


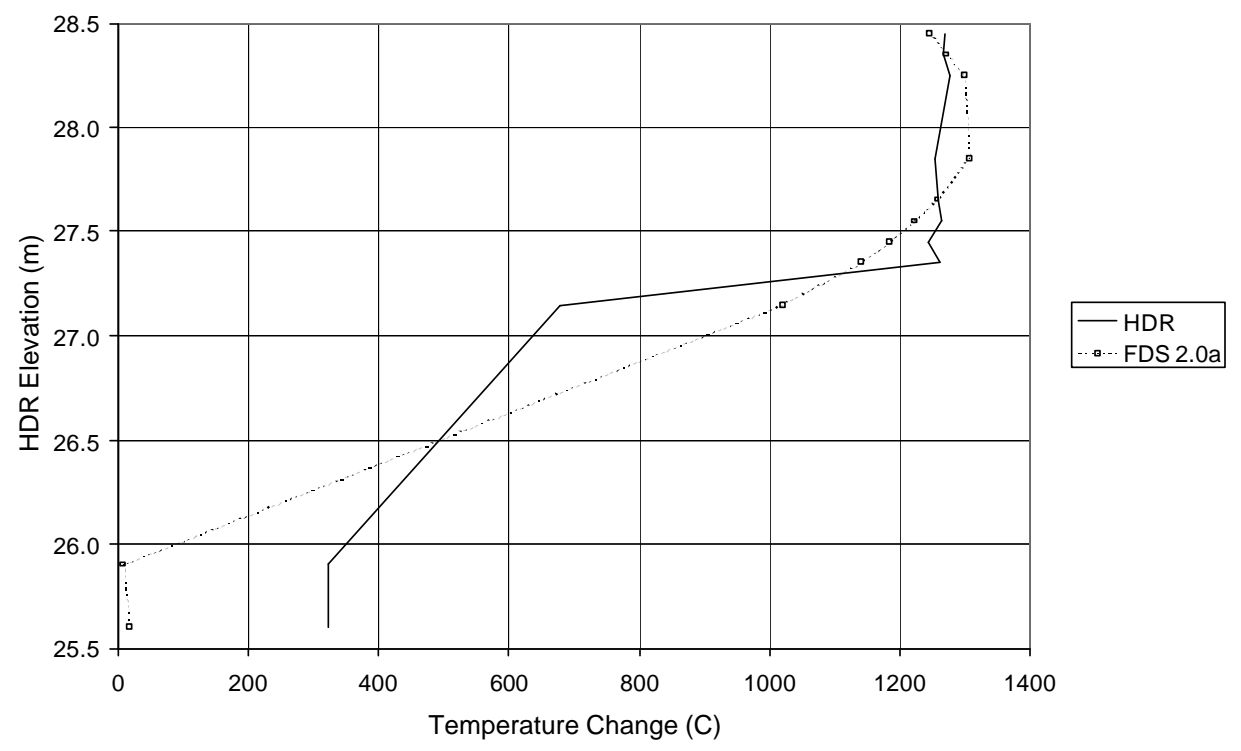

Figure 6.39 T52.14 FDS Results for Doorway Temperature Profile During Fire Peak

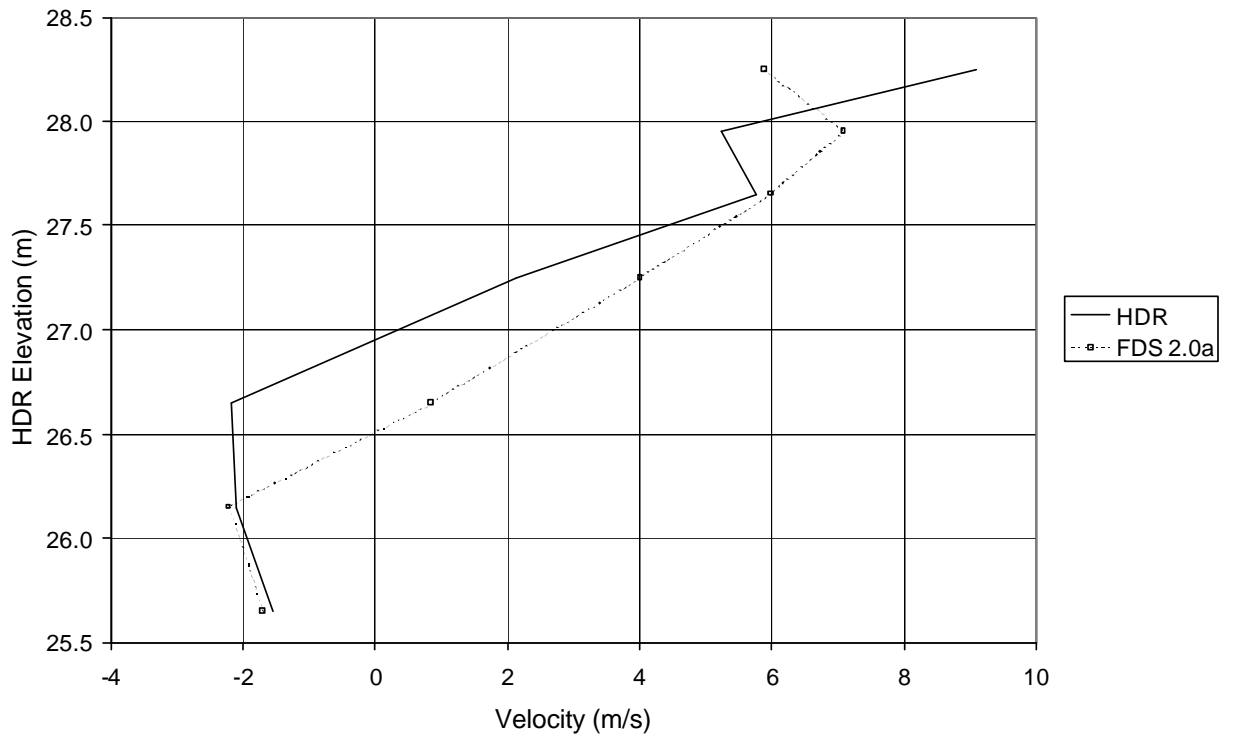

Figure 6.40 T52.14 FDS Results for Doorway Velocity Profile During Fire Peak

The following table, Table 6.11, shows measured vs. Predicted values for the sensors in the doorway during the peak of the fire. These values were obtained in the same manner as for Table 6.10. As with the fire room. FDS v2.0 $\alpha$ temperature predictions are excellent in the upper region of the doorway. The doorway lower level predictions are more difficult to assess due to thermocouple errors. It is also worth noting the FDS v2.0 $\alpha$ makes an improved prediction of the oxygen concentration in the upper doorway as compared to the T51.23 predictions as well as makes an adequate prediction of the carbon dioxide concentration in the upper doorway. 
Table 6.10: T5214 FDS Results for the Doorway During Fire Peak

\begin{tabular}{|c|c|c|c|c|}
\hline Sensor & Type & HDR & FDS 2.0 $\alpha$ & Error \\
\hline CT9631 & ${ }^{\circ} \mathrm{C}$ & 1,269 & 1,247 & $2 \%$ \\
\hline CT9632 & ${ }^{\circ} \mathrm{C}$ & 1,267 & 1,271 & $0 \%$ \\
\hline CT9633 & ${ }^{\circ} \mathrm{C}$ & 1,277 & 1,299 & $2 \%$ \\
\hline CT9637 & ${ }^{\circ} \mathrm{C}$ & 1,255 & 1,308 & $4 \%$ \\
\hline CT9639 & ${ }^{\circ} \mathrm{C}$ & 1,258 & 1,257 & $0 \%$ \\
\hline CT9640 & ${ }^{\circ} \mathrm{C}$ & 1,264 & 1,223 & $3 \%$ \\
\hline CT9641 & ${ }^{\circ} \mathrm{C}$ & 1,243 & 1,184 & $5 \%$ \\
\hline CT9642 & ${ }^{\circ} \mathrm{C}$ & 1,262 & 1,141 & $10 \%$ \\
\hline CT9651 & ${ }^{\circ} \mathrm{C}$ & 323 & 19 & $94 \%$ \\
\hline CT9653 & ${ }^{\circ} \mathrm{C}$ & 322 & 9 & $97 \%$ \\
\hline CT9657 & ${ }^{\circ} \mathrm{C}$ & 679 & 795 & $17 \%$ \\
\hline CT9658 & ${ }^{\circ} \mathrm{C}$ & 679 & 1,021 & $50 \%$ \\
\hline CV9600 & $\mathrm{m} / \mathrm{s}$ & 9.09 & 5.89 & $35 \%$ \\
\hline CV9601 & $\mathrm{m} / \mathrm{s}$ & 5.24 & 7.08 & $35 \%$ \\
\hline CV9602 & $\mathrm{m} / \mathrm{s}$ & 5.78 & 5.98 & $36 \%$ \\
\hline CV9603 & $\mathrm{m} / \mathrm{s}$ & 2.12 & 4.02 & $90 \%$ \\
\hline CV9604 & $\mathrm{m} / \mathrm{s}$ & -2.17 & 0.86 & $139 \%$ \\
\hline CV9605 & $\mathrm{m} / \mathrm{s}$ & -2.11 & -2.22 & $5 \%$ \\
\hline CV9606 & $\mathrm{m} / \mathrm{s}$ & -1.54 & -1.69 & $9 \%$ \\
\hline CG9602 & $\mathrm{v} / \mathrm{o} \mathrm{O}_{2}$ & 0.65 & 0.13 & $2 \%$ \\
\hline CG9603 & $\mathrm{v} / \mathrm{o} \mathrm{CO} 2$ & 10.8 & 12.4 & $14 \%$ \\
\hline
\end{tabular}

\subsubsection{Upper Hatch}

Table 6.11 shows the FDS predictions compared with the measured data for sensors located in the hatch leading to the dome from the fire room during the peak of the fire. Both versions make similar predictions in terms of predictive quality. The main reason for the large discrepancies in temperature is that FDS is predicting a somewhat more narrow plume in the hatch than indicated in the data. This could be the result of not enough grid points in the hatch region. Also this could result from model itself. In actuality the containment building shaft near the fire room acted like a jet pump, creating a large circulation loop inside the facility. This along with the recirculation the occurred in the dome are not being captured by FDS since the model did not include the entire facility. To have included the entire facility would have been impractical, however, due to the immense amount of nodes that would have been required. Velocity predictions are also poor in this location. 
Table 6.11: T52.14 FDS Results for the Upper Hatch During Fire Peak

\begin{tabular}{|c|c|c|c|c|}
\hline Sensor & Type & HDR & FDS 2.0 $\alpha$ & Error \\
\hline CT 455 & ${ }^{\circ} \mathrm{C}$ & 264 & 42 & $84 \%$ \\
\hline CT 457 & ${ }^{\circ} \mathrm{C}$ & 411 & 546 & $33 \%$ \\
\hline CT 459 & ${ }^{\circ} \mathrm{C}$ & 190 & 259 & $36 \%$ \\
\hline CT 461 & ${ }^{\circ} \mathrm{C}$ & 391 & 261 & $33 \%$ \\
\hline CT 463 & ${ }^{\circ} \mathrm{C}$ & 224 & 169 & $24 \%$ \\
\hline CT 465 & ${ }^{\circ} \mathrm{C}$ & 169 & 17 & $90 \%$ \\
\hline CT 467 & ${ }^{\circ} \mathrm{C}$ & 153 & 35 & $77 \%$ \\
\hline CT 469 & ${ }^{\circ} \mathrm{C}$ & 58 & 29 & $50 \%$ \\
\hline CT 471 & ${ }^{\circ} \mathrm{C}$ & 137 & 24 & $82 \%$ \\
\hline CT 473 & ${ }^{\circ} \mathrm{C}$ & 75 & 46 & $38 \%$ \\
\hline CT 475 & ${ }^{\circ} \mathrm{C}$ & 36 & 13 & $64 \%$ \\
\hline CT 477 & ${ }^{\circ} \mathrm{C}$ & 71 & 51 & $29 \%$ \\
\hline CT 479 & ${ }^{\circ} \mathrm{C}$ & 31 & 21 & $32 \%$ \\
\hline CV 480 & $\mathrm{m} / \mathrm{s}$ & 4.22 & -0.15 & $113 \%$ \\
\hline CV 484 & $\mathrm{m} / \mathrm{s}$ & 3.85 & 5.82 & $51 \%$ \\
\hline CV 486 & $\mathrm{m} / \mathrm{s}$ & 3.06 & 4.69 & $53 \%$ \\
\hline CV 488 & $\mathrm{m} / \mathrm{s}$ & 3.18 & 1.82 & $42 \%$ \\
\hline CV 490 & $\mathrm{m} / \mathrm{s}$ & 2.67 & 1.44 & $46 \%$ \\
\hline
\end{tabular}

\subsubsection{Lower Hatch}

Table 6.12 shows the FDS predictions compared with the measured data for sensors located in the hatch leading from the lower levels of the containment building to the fire room during the peak of the fire. As with the doorway, the thermocouples in this region could "see" flames in the fire room doorway. Thus, part of the temperature increase seen at these locations in the data results from radiation heat transfer to the thermocouples. A second factor is that the air entire the fire level through this hatch did slowly rise in temperature during the test as the heat from the fire was advected throughout the facility. FDS is not simulating those effects, although, it would be possible to modify FDS to contain a time dependent boundary condition for temperature at the lower boundary. FDS overpredicted the measured velocities by $1 \mathrm{~m} / \mathrm{s}$; however, it shows the same basic velocity profile as seen in the data with CF9202 and CF9205 being about equal and greater than CF9207. 
Table 6.12: T52.14 FDS Results for the Lower Hatch During Fire Peak

\begin{tabular}{|c|c|c|c|c|}
\hline Sensor & Type & HDR & FDS 2.0 $\alpha$ & Error \\
\hline CT9213 & ${ }^{\circ} \mathrm{C}$ & 62 & 0 & $100 \%$ \\
\hline CT9214 & ${ }^{\circ} \mathrm{C}$ & 50 & 0 & $100 \%$ \\
\hline CT9215 & ${ }^{\circ} \mathrm{C}$ & 22 & 0 & $100 \%$ \\
\hline CT9216 & ${ }^{\circ} \mathrm{C}$ & 68 & 0 & $100 \%$ \\
\hline CT9217 & ${ }^{\circ} \mathrm{C}$ & 90 & 0 & $100 \%$ \\
\hline CF9202 & $\mathrm{m} / \mathrm{s}$ & 1.09 & 2.11 & $93 \%$ \\
\hline CF9205 & $\mathrm{m} / \mathrm{s}$ & 1.18 & 2.16 & $84 \%$ \\
\hline CF9207 & $\mathrm{m} / \mathrm{s}$ & 0.12 & 1.31 & $958 \%$ \\
\hline
\end{tabular}

\subsubsection{Dome}

Table 6.13 shows the FDS predictions compared with the measured data for sensors located in the uppermost sensor grid during the peak of the fire. This grid was located at the transition to the dome's hemispherical head. Once again it is observed that FDS is predicting a somewhat more narrow of a plume than that seen in the data as well as a plume shifted in location from what is indicated in the data. This again is probably due to two factors, grid resolution, and including only a piece of the dome in the model

\subsubsection{Intercomparison of All Analysis Methods}

This section compares the fire room results of the three analysis methods with the data. These comparisons are made for steady-state portion of the fire test from 20 minutes to 30 minutes. Table 6.14 summarizes the results for key parameters of the fire room using the best results of each analysis method. The velocities shown in the table for the three analysis methods as well as the data represent the layer averaged velocities. 
Table 6.13: T5214 FDS Results for the Upper Sensor Grid During Fire Peak

\begin{tabular}{|c|c|c|c|c|}
\hline Sensor & Type & HDR & FDS 2.0 & Error \\
\hline CT 430 & ${ }^{\circ} \mathrm{C}$ & 67 & 39 & $41 \%$ \\
\hline CT 432 & ${ }^{\circ} \mathrm{C}$ & 42 & 38 & $8 \%$ \\
\hline CT 434 & ${ }^{\circ} \mathrm{C}$ & 24 & 8 & $66 \%$ \\
\hline CT 436 & ${ }^{\circ} \mathrm{C}$ & 71 & 75 & $6 \%$ \\
\hline CT 438 & ${ }^{\circ} \mathrm{C}$ & 34 & 30 & $13 \%$ \\
\hline CT 440 & ${ }^{\circ} \mathrm{C}$ & 99 & 42 & $57 \%$ \\
\hline CT 442 & ${ }^{\circ} \mathrm{C}$ & 49 & 30 & $40 \%$ \\
\hline CT 444 & ${ }^{\circ} \mathrm{C}$ & 34 & 6 & $76 \%$ \\
\hline CT 446 & ${ }^{\circ} \mathrm{C}$ & 69 & 11 & $84 \%$ \\
\hline CT 448 & ${ }^{\circ} \mathrm{C}$ & 30 & 8 & $75 \%$ \\
\hline CT 450 & ${ }^{\circ} \mathrm{C}$ & 70 & 1 & $98 \%$ \\
\hline CT 452 & ${ }^{\circ} \mathrm{C}$ & 70 & 1 & $98 \%$ \\
\hline CT 454 & ${ }^{\circ} \mathrm{C}$ & 23 & 0 & $100 \%$ \\
\hline CV 411 & $\mathrm{m} / \mathrm{s}$ & 1.27 & 3.12 & $145 \%$ \\
\hline CV 412 & $\mathrm{m} / \mathrm{s}$ & 0.38 & 3.76 & $889 \%$ \\
\hline CV 413 & $\mathrm{m} / \mathrm{s}$ & 0.06 & 0.67 & $1097 \%$ \\
\hline CV 416 & $\mathrm{m} / \mathrm{s}$ & 4.86 & 3.29 & $32 \%$ \\
\hline CV 417 & $\mathrm{~m} / \mathrm{s}$ & 1.25 & 2.87 & $129 \%$ \\
\hline CV 418 & $\mathrm{~m} / \mathrm{s}$ & -0.06 & 0.21 & $433 \%$ \\
\hline CV 421 & $\mathrm{m} / \mathrm{s}$ & 2.44 & -0.20 & $108 \%$ \\
\hline CV 422 & $\mathrm{m} / \mathrm{s}$ & -0.35 & -0.17 & $50 \%$ \\
\hline CV 423 & $\mathrm{m} / \mathrm{s}$ & 0.89 & -0.13 & $113 \%$ \\
\hline
\end{tabular}

Table 6.14: Steady State Fire Room Predictions for All T52.14 Analyses vs. Data

\begin{tabular}{|c|r|r|r|r|}
\hline Quantity & \multicolumn{1}{|c|}{ Data } & Hand Calc. & \multicolumn{1}{c|}{ CFAST } & \multicolumn{1}{c|}{ FDS } \\
\hline Upper Temperature $\left({ }^{\circ} \mathrm{C}\right)$ & 872 & 1,227 & 959 & 931 \\
\hline Upper Velocity $(\mathrm{m} / \mathrm{s})$ & 4 & 5 & 4 & 4 \\
\hline Lower Velocity $(\mathrm{m} / \mathrm{s})$ & 2 & 2 & 3 & 1 \\
\hline Layer Height $(\mathrm{m})$ & 2 & 1 & 1 & 1 \\
\hline $\mathrm{O}_{2}$ Concentration $(\mathrm{v} / \mathrm{o})$ & 0 & & 7 & 1 \\
\hline
\end{tabular}

The same observations that applied to the T51.23 comparisons apply here. The hand calculation performs quite well in comparison to the other two methods. Only the temperature is significantly different. As with the T51.23 results, even though FDS is overpredicting temperatures, it makes the same average layer prediction that CFAST makes. In fact FDS makes better predictions for lower layer velocity for the steady-state portion of the fire and nearly matches the data for the oxygen concentration, a parameter for which CFAST has an unacceptable error. 


\subsection{SUMMARY OF PERFORMANCES AND USABILITY}

This chapter summarizes the performances of the various computational methods whose results were presented in Chapter 7. The summary is given in three main sections. The first section will discuss the performance as related to the T51.23 test simulations. The second section will discuss the performance as related to the T52.14 test simulations. The final section discusses the performance of each methods from the perspective of ease of use, which while being subjective is nonetheless quite important if one or more of these methods is to see widespread use in a performance-based code system.

\subsection{SUMMARY OF T51.23 RESULTS}

Three methods were used to simulate the T51.23 test. These methods included a hand calculation, a CFAST model, and an FDS model. Each method had successes and failures when used to simulate the test.

\subsubsection{Hand Calculation}

The hand calculation performed for the T51.23 fire room was very successful. Fire room upper layer temperature, layer height, and the doorway upper layer mass flow were are all predicted within the criteria given in Table 2.1. The doorway lower layer mass flow was not predicted as well, but due to the sparseness of instrumentation in the doorway, it can not be concluded whether or not the hand calculation was deficient in calculating this quantity. When considering that hand calculation methods are designed primarily for speed and less so for accuracy, the performance in this case is outstanding.

\subsubsection{CFAST Calculations}

The CFAST calculations saw mixed results. The model made good predictions of near-field temperature and gas concentration. However, the model results showed a number of non-physical behaviors in the form of discontinuities in temperatures and gas-concentrations near the start and the end of the fire. As a steady-state combustion process, well supplied with oxygen, sudden sharp increases and decreases in these quantities are not occurring. The observed phenomena seems to be related to shifts in the layer height prediction which drives the temperature and mass flow solver. It may be worth revisiting CFAST's solution algortihm to see if jump conditions exist in the logic that could lead to the observed behavior or to see if relaxation is required in calculating one or more parameters.

In general, CFAST showed a wide variability in its predictive capabilities for the T51.23 test. Depending on the quantity of concern, CFAST may or may not be successful. Also no quantity was predicted with any consistent success. 


\subsubsection{FDS}

FDS v2.0 $\alpha$ performed well for this test. Temperatures in all regions of the fire level were well predicted as were the velocities. The only parameter that was poorly predicted was the oxygen concentration, however, a premixed fuel is not in the traditional domain of a mixture fraction approach.

\subsection{SUMMARY OF T52.14 RESULTS}

Three methods were used to simulate the T52.14 test. These methods included a two-part hand calculation, a CFAST model, and an FDS model. Each method had successes and failures when used to simulate the test.

\subsubsection{Hand Calculations}

The T51.24 test posed a much more difficult case for the hand calculation method. Fire room temperatures were greatly overpredicted by this method, although mass flows and the neutral plane height were reasonably predicted. A number of factors could be affecting this. The presence of a large vertical shaft just outside the fire room may be creating flow conditions that the hand calculation is not capable of resolving. Another, and likely quite important factor, is that the heat release rate is likely overspecified. While the pyrolysis rate is known reasonably well in the later stages of the T52.14 test, how much of that burned inside versus outside the fire room is not well known. This could be impacting the hand calculation results.

In the second part of the hand calculation, mixed results are observed. At the operating deck, where the plume is highly constrained, neither the Chen-Rodi nor the integral method give good predictions of velocity and temperature. At the upper grid, where the plume is closer to a free plume, both methods are again greatly underpredicting the temperatures. However, at this location the integral method is correctly predicting the drop in temperature and both methods are correctly predicting the velocity. As with the fire room, the plume analysis has difficulties in application to the flow conditions present in the HDR. However, the method is capable of yield basic insight of the fire's effect on the containment.

\subsubsection{CFAST Calculations}

Given the relatively poor results from the T51.23 simulations both in this work and in other work by the author ${ }^{45,53}$, it was anticipated that with an underventilated fire and the presence of the large dome near the fire room that CFAST would perform even worse for the T52.14 test. This was not the case, however. In general, gas concentrations, near-field and dome velocities, and dome temperatures were well predicted by CFAST models. Far-field temperatures and velocities were not well predicted, however, CFAST predictions in these regions were conservative.

The T52.14 CFAST predictions did show some disturbing attributes. In the far-field, temperature predictions showed unphysical behavior. For example, upper layer temperatures showed no increase for 8 minutes while the lower layer saw a $10{ }^{\circ} \mathrm{C}$. At 8 minutes the upper 
layer jumped instantly to the same temperature as the lower layer followed by a decrease in the lower layer temperature. Sudden discontinuities and oscillations are all indicative of either numerical instabilities in a code's algorithm or logic flaws in the algorithm's implementation.

\subsubsection{FDS Calculations}

Similar statements can be made for the v2.0 $\alpha$ T52.14 model as were made for the T51.23 model. Temperatures and velocity predictions inside the fire room and doorway were excellent as were the gas concentration predictions with FDS v $2.0 \alpha$ correctly predicting both the oxygen and the carbon dioxide levels. However, these success are tempered by the fact that there were poor predictions of velocities and temperatures in the hatches and the dome. This would seem to indicate that the ability to handle complex boundary conditions and choosing proper computation domains will be crucial to future use of FDS.

\subsection{METHOD USABILITY}

This section discusses the author's impressions on the ease of use of the three methods. These discussions include creating an input for the calculation, understanding how the calculation takes place, and being able to use the results of the calculation.

\subsubsection{Hand Calculations}

Hand calculations are by far the most transparent of the three methods used in this work. By their simplistic nature, hand calculations typically only involve a few equations grounded in basic principles. As these are the methods that tend to be used for problem solving in educational course work, explanatory material is easy to locate. The calculations themselves are straightforward requiring at most a spreadsheet and pencil and paper. Results from these methods are also easy to use as only a few quantities are solved for. While it may take a couple of hours to construct a template in a spreadsheet or other math toolkit for performing a hand calculation, the calculation itself takes almost no time.

\subsubsection{CFAST Calculations}

CFAST has been in existence for a number of years now. As such, one would expect that after many years of development and use of the code by a broad group of international users that its usability would be very high. This is not entirely the case, however.

CFAST has both a user's manual describing how to run the code and a theory manual describing the internal workings and theory behind the code. Both of these documents are well written, explaining the various code inputs and what the code does with them. What is missing, however, is guidance on creating an input model for a complex structure. For a simple structure with a few compartments and simple interconnections, the input descriptions in the manual suffice. However, for a large structure with many compartments, multiple levels, and complex interconnections no guidance is given on what should and should not be included in an input model and how to simplify groups of compartments into a single compartments or how to 
simplify multiple interconnections into single interconnections. This is a potential impediment to using CFAST for fires in large structures.

CFAST also possess a preprocessor. This program is a DOS-based program that uses character graphics to gain the look of a Windows ${ }^{\circledR}$ application. As a DOS based program with graphics it must be run in full-screen mode. In this mode a user is unable to cut and paste parameters from a spreadsheet or other document into the preprocessor. This makes generating an input file prone to transcription errors when typing in values that could be cut and pasted. Ideally this preprocessor should be migrated towards a pure Windows $₫$ environment. The preprocessor also writes input files that are overly difficult to read. For example, room dimensions are written to the input file with a precision of $10^{-5} \mathrm{~m}$. This is somewhat absurd since compartment dimensions in either a model facility or a prototype facility are not known to this level of precision. Other parameters are also written in a similar manner. This excessive number of digits degrades the readability of an input file.

The CFAST code output is written into a single, proprietary format, binary output file. As such one can not directly read the output file into common graphics applications. CFAST is distributed with a DOS based post-processor that allows a user to extract subsets of the data file to a spreadsheet compatible, ASCII format. However, for a large model these subsets (temperatures, mass flows, gas concentrations, etc.) can become unwieldy. Improvements to this could be had by either providing more control in the post-processor in deciding what data to extract from the output file, or by perhaps generating separate files for the various quantities in a standard binary format. It should be noted that conservation of hard disk space is not the issue it was a decade ago when CFAST was first released.

In addition to the above mentioned deficiencies, the author has observed some problems with executing CFAST. In the cast of T51.23, CFAST would not initialize the pressure solver without a small leakage connection to the outside. While this would not impact a user making a calculation for a residential dwelling, this does impact users modeling facilities such as containment buildings which have very little leakage. It has also been observed that in some model configurations CFAST will have time steps on the order of nanoseconds, which of course makes for a prohibitively long computation. However, by making very small changes to compartment dimensions and/or compartment connections, the code will progress with millisecond time steps resulting in a feasible computation time. This fact combined with the behavior observed in the model results, indicates possible stability problems with CFAST.

\subsubsection{FDS Calculations}

FDS has only recently been released as version 1.0. For the time period during which this work was done, FDS was very much a developmental code. As such, one anticipates a certain degree of user unfriendliness since code user/code developer interactions tend to act quickly to improve usability in first release.

As with CFAST, FDS is distributed with both a theory manual and a user's manual. The theory manual is very well written, containing detailed descriptions of the equations used in FDS, how 
they are discretized, and how the code algorithm proceeds. The user's manual is also well written. It contains a number of sample input files for a wide variety of fire types and structures. It also contains a detailed description of each input file and the various input options. However, as with the CFAST manuals, it could use more guidance on constructing input models such as recommended node sizes, initial timestep, modeling non-orthogonal surfaces, etc.

FDS currently lacks an input preprocessor. For a very simple fire, this is not a major drawback; however, for simulations such as the ones performed in this work it becomes somewhat tedious to generate the geometric descriptions. A GUI preprocessor would greatly improve FDS's ability to be used widely.

Where FDS really shines is in its post-processing capabilities. A separate, multi-platform, program called Smokeview has been written that allows the user to visualize all the various outputs created by FDS. With this program contour plots, (x,y) plots, and transient animations can be rendered. This program uses a graphical interface and allows the user to rotate and walkthrough the input geometry while visualizing the data. Furthermore, FDS writes its output into a number of separate data files written in either an ASCII format or a standard binary format. This allows easy use of other graphics packages for analyzing code output. Furthermore, the output file formats are fully specified in the user's manual which allows users to write their own post-processing routines. 


\subsection{CONCLUSIONS}

A performance-based code system must have access to appropriate computational tools in order for credible statements of performance to be made. These computational tools may take different forms: hand calculations, lumped parameter methods, computational fluid dynamics, etc.; however, they must all share certain characteristics. They must possess a certain degree of user friendliness if they are to see widespread use in a regulatory regime not traditionally associated with computer modeling, and they must predict the consequences of a fire with a reasonable degree of accuracy. Since criteria for neither characteristic has been established, this work examined two potential tools and evaluated their performance in relation to a proposed set of performance criteria, Table 2.1. The usability of the tools was also discussed. Basic conclusions of each method will be discussed.

\subsection{Hand Calculations}

The first tool examined was the application of simple hand calculations to the two fire tests. Hand calculations, as they omit or greatly simplify the various phenomena related to a fire, cannot be expected to yield precise information on a fire's consequences. However, one can expect that a hand calculation yields sufficient information regarding a fire to determine whether or not a more detailed analysis is warranted.

The results obtained in this work showed that hand calculations are capable of yielding useable information regarding the basic parameters of a compartment fire. However, as the results for T52.14 demonstrated, care must be taken when applying hand calculations. Due to their simplicity, they should not be applied indiscriminately to any given fire, but rather the underlying assumptions of the method should be compared with the fire to be modeled to ensure applicability. This was observed in the inability of the two plume models to yield accurate results at the level of the operating deck, see Section 7.2.1.

\section{$8.2 \quad$ CFAST}

Since CFAST is already a familiar tool to many in the fire protection arena, it is important that its limitations in terms of modeling large structures be understood. This work has clearly shown that CFAST is in need of significant improvements if it is to be used in a performanced-based code regime for analyzing entire structures. Far-field mass flows, temperature changes, and propagation of gas species are not well predicted by CFAST. Even near-field predictions of temperatures and mass flows can be in substantial error. Furthermore, observed behaviors such as higher lower layer temperatures in regions with only horizontal flow could could cause acceptance problems as such results act to degrade confidence in the overall performance.

It is obvious that predicting the near-field accurately is important as this is the region where the fire is most likely to cause physical damage to equipment and structures. In the far-field, one may be inclined to discount large errors as the net changes in temperatures and gas concentrations tend to be smaller and risk of thermal damage becomes small. However, these parameters must still be predicted accurately. Survival of personnel in the far-field is largely 
dependent on exposure to small concentrations of toxic gasses. Also, ventilation systems and equipment cooling fans can become clogged with soot and fail to function leading to other modes of failure.

Prior work performed by this author with CFAST noted many of these same problems. In addition it was observed that CFAST had numerous problems associated with fuels containing oxygen $^{52}$ and with ventilation system induced flows ${ }^{44}$.

What is clear, however, is that some model such as CFAST will be required in a performance-based code system. Hand calculations are not going to have the precision to analyze an entire structure, and CFD methods are currently computationally too expensive to model multiple fire scenarios in large structures for long periods of time or to model very large, complex, structures in their entirety. Because of this, it can be concluded that CFAST should undergo further development and validation directed toward the goal of using it in a performance-based code system.

Specifically the following recommendations for CFAST development are given:

1. Migrate the code away from a DOS environment to a pure Windows environment. This will accrue a number of usability benefits. As a Windows program, operations such as cut and paste will be available. Furthermore the look and feel of the program will be identical to other Windows software resulting in an immediate sense of familiarity. Lastly, as a Windows program, the code can make use of the Windows built-in, helpfile applets to aid the user when creating an input file. Lastly, Microsoft has stated that it wishes to remove support for DOS applications from future versions of Windows. While this may not happen in the very near future, it should be prepared for.

2. Examine the code's numerics for gas concentration calculations. It is possible that the calculations need to be relaxed when the solution calls for rapid concentration changes.

3. Develop an improved combustion model. First, in its current implementation it is entirely up to the user to specify the combustion products. That is the quality of output is highly dependent on quantities that the user cannot know ahead of time for a blind computation. Second, prior work has shown that CFAST is not capable of correctly tracking combustion products if an oxygen containing fuel is specified.

4. Create another document to be distributed with CFAST that discusses how to approach modeling of large structures or odd-sized rooms such as atrium, shafts, or very long hallways.

5. Further improvements are needed in the determination of mass flows between compartments, especially far-field vertical flows. 
6. Further benchmarking of the code for fires in complex structures, especially one's with operating ventilation systems is needed.

\section{$8.3 \quad$ FDS}

FDS, as well as other CFD methods in general, is a relative newcomer to fire protection. CFD models such as FDS are not easy to use. Furthermore, their computational requirements greatly limit their applicability. One is not going to use a CFD model to analyze hundreds of possible scenarios in a large structure. CFD models, rather, are going to be used to analyze very specific scenarios which require the precision that only CFD can provide. For example, whereas a zone model can predict the average heat flux seen at some distance from a fire, it cannot predict the spatial distribution of the heat flux at that distance. A zone model cannot determine that one object is perhaps shielded by another object from the effects of a fire. A CFD model can be capable of yielding such information. Although they are computationally expensive and time consuming, CFD methods are the only available method when one needs highly localized information of on fires' effects.

The work herein examined one CFD model, FDS. It has been observed that FDS v1.0 was not capable of modeling fires which are large with respect to their compartments, or fires which are greatly underventilated. The results presented in Chapter 6 indicate, however, that the current sub-models being implemented for release as FDS v2.0 should greatly improve FDS's predictive capabilities. In addition to improvements already in the works for v2.0 the following developments are recommended for FDS to improve its usability and accuracy:

1. Create a GUI front end for generating input files in a manner that ensures cross-platform consistency, such as using OpenGL (like with Smokeview).

2. Provide further guidance in the user's manual on node sizes and how to specify compartments with complex internal blockages or non-orthoganal surfaces. 


\subsection{WORKS CITED}

1. Karlsson, B. And J. Quintiere. Enclosure Fire Dynamics. Boca Raton, FL: CRC Press, 2000. Abramovich, G.N. The Theory of Turbulent Jets. Cambridge, MA: MIT Press, 1963.

2. Floyd, J. "Evaluation of the Predictive Capabilities of Current Computational Methods for Fire Simulation Using the HDR T51 and T52 Tests With a Focus on Performance-Based Codes." Ph.D. Dissertation. College Park, MD: University of Maryland, 2000.

3. Peacock, R. D., et al. "CFAST, the Consolidated Model of Fire Growth and Smoke Transport." NIST Technical Note 1299. Gaithersburg, MD: National Institute of Standards and Technology, 1993.

4. McGrattan, K.B., et al. "Fire Dynamics Simulator: Technical Reference Guide." NISTIR 6467. Gaithersburg, MD: National Institute of Standards and Technology, 2000.

5. Nowlen, S.P. "A Summary of the Fire Testing Program at the German HDR Test Facility." NUREG/CR-6173. Washington, DC: US Nuclear Regulatory Commission, 1995.

6. Mowrer, F.W. and D.W. Stroup. "Features, Limitations and Uncertianties in Enclosure Fire Hazard Analyses - Preliminary Review." NISTIR 6152. Gaithersburg, MD: National Institute of Standards and Technology, 1998.

7. Drysdale, D. An Introduction to Fire Dynamics. New York, NY: John Wiley and Sons, 1985.

8. Lattimer, B.Y. and U. Vandsburger. "The Transport of High Concentrations of Carbon Monoxide to Locations Remote from the Burning Compartment." NIST-GCR-97-713. Gaithersburg, MD: National Institute of Standards and Technology, 1997.

9. Lee, A. and J. Lee. "Effect of Lateral Confinement on Initial Dilution of Vertical Round Buoyant Jet." Journal of Hydraulic Engineering. 124:3 (1998), 263-279.

10. Badre, A. and D. Grand. "Summary Report On Development of an Integral Model of a Radioactive Jet." European Applied Research Reports - Nuclear Science and Technology Section. 5:1 (1983) 1-120.

11. Bukowski, R.W. "Predicting the Fire Performance of Buildings: Establishing Appropriate Calculation Methods for Regulatory Applications." ASIAFLAM'95. International Conference on Fire Science and Engineering, 1st. Proceedings. Kowloon, Hong Kong: Interscience Communications Ltd., (1995), 9-18.

12. Brenig, H.W., et al. "First Evaluation of the Fire Computer Codes Applied to the Analysis of the HDR Fire Experiments (In German)." PHDR Working Report 5.093/86. Karlsruhe, Germany: Project HDR, Nuclear Center Karlsruhe, 1989. 
13. Chen, J. C. and W. Rodi. Vertical Turbulent Jets, A Review of Experimental Data. New York, NY: Pergamon Press, 1980.

14. Wolf, L., K. Mun and J. Floyd. "HDR Hydrogen Mixing Evaluation for Containment Safety Evaluations: Phase 1 Final Report for DOE Project Order Number: DE-AP07-951D81401." College Park, MD: University of Maryland, 1995.

15. Papanicolaou, P. and J. List. "Investigations of Round Turbulent Buoyant Jets." Journal of Fluid Mechanics. 195 (1988), 341-391.

16. Potter, M.C. and J.F Foss. Fluid Mechanics. Okemos, MI: Great Lakes Press Inc., 1982.

17. Sneck, H.J. and D.H. Brown. "Plume Rise From Large Thermal Sources Such as Dry Cooling Towers." ASME Journal of Heat Transfer. 233 (1974), 232-238.

18. Henderson-Sellers, B. Modeling of Plume Rise and Dispersion - The University of Salford Model: U.S.P.R. New York, NY: Springer-Verlag, 1987.

19. McGrattan, K.B. and G.P. Forney. "Fire Dynamics Simulator: User's Guide." NISTIR 6469. Gaithersburg, MD: National Institute of Standards and Technology, 2000.

20. Floyd, J., H. Baum, and K. McGrattan. "A Mixture Fraction Based Combustion Model for Fire Simulation Using CFD.” San Francisco, CA: Proceedings of the International Conference on Engineered Fire Protection Design, 2001.

21. Floyd, J., C. Wieczorek, and U. Vandsburger. "Simulation of the Virginia Tech Fire Research Laboratory Using Large Eddy-Simulation with Mixture Fraction Chemistry and Finite Volume Radiative Heat Transfer.” Interflam 2001 Proceedings. Endinburgh, Scotland: Interscience Communications, 2001.

22. Mahalingam, S., et al., "Analysis and Numerical Simulation of a Nonpremixed Flame in a Corner." Combustion and Flame. 118 (1999), 221-232.

23. Raithby, G. and Chui, E. "A Finite-Volume Method for Predicting Radiant Heat Transfer in Enclosures with Participating Media.” Journal of Heat Transfer. 112 (1990), 415-423.

24. Rehm, R. G. and H. R. Baum. "The Equations of Motion for Thermally Driven, Buoyant Flows." Journal of Research of the National Bureau of Standards. 83:3 (1978), 297-308.

25. Hirsch, C. Numerical Computation of Internal and External Flows, Volume 1: Fundamentals of Numerical Discretization. New York, NY: John Wiley and Sons, 1988.

26. Smagorinski, J. "General Circulation Experiments with the Primitive Equations. I. The Basic Experiment." Monthly Weather Review. 91 (1963), 99-164. 
27. Ferziger, J.H. "Subgrid Scale Modelling." Large Eddy Simulation of Complex Engineering and Geophysical Flows. Galperin, B. and S.A. Orsag editors. New York, NY: Cambridge University Press, 1993.

28. Baum, H.R., K.B. McGrattan, and R.G. Rehm. "Three Dimensional Simulations of Fire Plume Dynamics." Fire Safety Science - Proceedings of the Fifth International Symposium. Hasemi, Y. editor. Melbourne, Australia. 1997. 511-522.

29. Forney. G.P. And K.B. McGrattan. "User's Guide for Smokeview Version 1.0: A Tool for Visualizing Fire Dynamics Simulation Data.” NISTIR 6513. Gaithersburg, MD: National Institute of Standards and Technology. 2000.

30. Baum, H.R. and B.J. McCaffrey. "Fire Induced Flow Field - Theory and Experiment." Fire Safety Science - Proceedings of the Second International Symposium. Hasemi, Y., et al. editor. Tokyo, Japan. 1989. 29-148.

31. Fleischmann, C.M. and K.B. McGrattan. "Numerical and Experimental Gravity Currents Related to Backdrafts." Fire Safety Journal. 33 (1999) 21-34.

32. Davis, W.D., K.A. Notarianni, and K.B. McGrattan. "Comparison of Fire Model Predictions with Experiments Conducted in a Hangar with a 15 Meter Ceiling." NISTIR 5927. Gaithersburg, Maryland: National Institute of Standards and Technology, 1996.

33. Spearpoint, M., F. Mowrer, and K. McGrattan. "Simulation of a Compartment Flashover Fire Using Hand Calculations, Zone Models, and a Field Model." ICFRE 3 Proceedings. Boston, MA: Society of Fire Protection Engineers, 1999.

34. Baum, H.R. and K.B. McGrattan. "Simulation of Oil Tank Fires." Proceedings of Interflam'99, Volume 2. London, England: Interscience Communications Ltd. 1999. 1117-1128.

35. McGrattan, K.B., H.R. Baum, and A. Hamins. Thermal Radiation from Large Pool Fires. NISTIR-6546. Gaithersburg, MD: National Institute of Standards and Technology, 2000.

36. McGrattan, K.B., A. Hamins, and D. Stroup. Sprinkler, Smoke \& Heat Vent, Draft Curtain Interaction - Large Scale Experiments and Model Development. NISTIR 6196-1. Gaithersburg, Maryland: National Institute of Standards and Technology, 1998.

37. Peacock, R. D., et al. "A User's Guide for FAST: Engineering Tools for Estimating Fire Growth and Smoke Transport." Special Publication 921. Gaithersburg, MD: National Institute of Standards and Technology, 1997.

38. Cooper, L.Y. "Calculation of Flow Through a Horizontal Ceiling/Floor Vent." NISTIR 89-4052. Gaithersburg, Maryland: National Institute of Standards and Technology, 1989. 
39. Siegel, R. and J.R. Howell. Thermal Radiation Heat Transfer 2nd Edition. New York, NY: Hemisphere Publishing Corp., 1981.

40. Bailey, J.L., et al., "Development of an Algorithm to Predict Vertical Heat Transfer Through Ceiling/Floor Conduction,” Fire Technology, Vol. 34, 1998, 139-155.

41. Matsutama, K., T. Wakamatsu, and K. Harada. "Systematic Experiments of Room and Corridor Smoke Filling for use in Calibration of Zone and CFD Fire Models." Proceedings of the 15th Meeting of the UJNR Panel on Fire Research and Safety. 2 (2000), 321-327.

42. Schall, M. and Valencia, L. "Data Compilation of the HDR Containment for Input Data Processing for Pre-Test Calculations (English Translation)." PHDR Working Report 3.143/79. Karlsruhe, Germany: Project HDR Nuclear Center, January 1982.

43. Floyd, J., L. Wolf, and J. Krawiec. "Evaluation of the HDR Fire Test Data and Accompanying Computational Activities With Conclusions From Present Code Capabilities, Volume 1: Test Series Description for T51 Gas Fire Test Series." NIST GCR 97-727. Gaithersburg, MD: National Institute of Standards and Technology, 1997.

44. Floyd, J. and L. Wolf. "Evaluation of the HDR Fire Test Data and Accompanying Computational Activities With Conclusions From Present Code Capabilities, Volume 3: Test Series Description and CFAST Validation for T51 Wood Crib Fire Test Series." NIST GCR 99-778. Gaithersburg, MD: National Institute of Standards and Technology, 1999.

45. Floyd, J., K. Mun, B. Rauch, and L. Wolf. "Evaluation of the HDR Fire Test Data and Accompanying Computational Activities With Conclusions From Present Code Capabilities, Volume 4: Test Series Description and CFAST Validation for T52 Oil Pool Fire Test Series." College Park, MD: University of Maryland, 2000.

46. Müller, K. and R. Dobbernack. "Evaluation of Fire Behavior in Compartment Networks in a Closed Containment, Design Report, Test Group BRA-E, Exploratory Experiments T51.1 (In German)." PHDR Working Report 5.025/84. Karlsruhe, Germany: Project HDR, Nuclear Center Karlsruhe, 1984.

47. Dobbernack, R.K. Müller, and H. Valencia. "Fire Experiments in a Closed Containment Natural Ventilated Hydrocarbon Fires in Dome Area, Quick Look Report, Test Group BRA, Experiments T52.11-14 (In German)." PHDR Technical Report 79-90. Karlsruhe, Germany: Project HDR, Nuclear Center Karlsruhe, 1990.

48. Rautenberg, J., K. Müller, R. Volk, U. Max, and R. Dobbernack. "Hydrocarbon Fire Experiments in the Dome Region of a Reactor Containment, Final Evaluation Report, Test Group BRA, Experiments T52.1-14 (In German)." PHDR Working Report 89-90. Karlsruhe, Germany: Project HDR, Nuclear Center Karlsruhe, 1991. 
49. Müller, K. and R. Dobbernack. "Fire Experiments in the HDR Containment, Test Group BRA, T51.2 Experiments (In German)." PHDR Working Report 5.069/86. Karlsruhe, Germany: Project HDR, Nuclear Center Karlsruhe, 1986.

50. Shell Chemicals of Norway. http://www.shell.no/op/hmschess/chess/html/grp_1/00001193.htm (In Norwegian). A/S Sola, Norway: Norske Shell, October 1999.

51. Travis, J.R., et al. "GASFLOW: A Computational Model to Analyze Combustion Events in Nuclear Containment and Facility Buildings." Proceedings of 3rd International Seminar on Fire Safety of Nuclear Power Plants. Müller, K. editor. Karlsruhe, Germany: HDR Nuclear Center, 1993. 211-262.

52. Floyd, J., L. Wolf, and J. Krawiec. "Evaluation of the HDR Fire Test Data and Accompanying Computational Activities With Conclusions From Present Code Capabilities, Volume 2: CFAST Validation for T51 Gas Fire Test Series." NIST GCR 97-731. Gaithersburg, MD: National Institute of Standards and Technology, 1997.

53. Floyd, J. and L. Wolf. "Large Eddy Simulations with Fire Dynamics Simulator of the HDR T52.14 Oil Fire Test." ICONE-8486. Proceedings of the Eighth International Conference on Nuclear Engineering. Angahie, S. editor. Baltimore, MD. 2000.

54. Floyd, J., L. Wolf., and B. Rauch "Zone Model Simulations with CFAST of HDR T52.11 Oil Fire Experiment in the Containment." ICONE-8487. Proceedings of the Eighth International Conference on Nuclear Engineering. Angahie, S. editor. Baltimore, MD. 2000.

55. Chow, W.K. "Multi-Cell Concept for Simulating Fires in Big Enclosures Using a Zone Model." Journal of Fire Science. 14 (1996), 186-198. 


\subsection{ADDITIONAL REFERENCES}

1. Beyler, C., "Major Species Production by Diffusion Flames in a Two-layer Environment." Fire Safety Journal. 10 (1986), 47-56.

2. Buchannan, A.H. "Implementation of Performance-based Fire Codes." Fire Safety Journal. 32 (1999) 377-383.

3. Bukowski, R.W. and T. Tanaka. "Toward the Goal of a Performance Fire Code." Fire and Materials. 15 (1991), 175-180.

4. Chu,V.H. and W.D. Baines. "Entrainment by Buoyant Jet Between Confined Walls." Journal of Hydraulic Engineering. 115:4 (1989), 475-492.

5. Chua, L.P. and A.C. Lua. "Measurements of a Confined Jet." Physics of Fluids. 21:12 (1998), 3137-3144.

6. Derr, M. "A Computer to Outsmart a Raging Fire." New York Times on the Web. http://www.nytimes.com/library/national/science/030700sci-fire-research.html. (2000)

7. Dey, M., et al. "Technical Review of Risk-Informed Performance-Based Methods for Nuclear Power Plant Fire Protection Analyses." NUREG-1521 (Draft). Rockville, MD: U.S. Nuclear Regulatory Commission, 1998.

8. Dey, M.K. "A Conceptual Framework for Formulating a Focused and Cost-Effective Fire Protection Program Based on Analyses of Risk and the Dynamics of Fire Effects." Nuclear Engineering and Design. 193 (1999) 185-196.

9. Epstein, M. and M.A. Kenton. "Combined Natural Convection and Forced Flow Through Small Openings in a Horizontal Partition, With Special Reference to Flows in Multicompartment Enclosures." Journal of Heat Transfer. 111 (1989) 980-987.

10. George, T., et. al. "GOTHIC Containment Analysis Package Technical Manual, Version 3.4e, Volume 1: Technical Manual." EPRI RP3408-1. Richland, Washington: Numerical Applications Inc., 1991.

11. Gifford, F.A. "The Rise of Strongly Radioactive Plumes." Journal of Applied Meteorology. 6 (1967), 644-649.

12. Hirschler, M.M. "Fire Hazard Assessment: Roadblock or Opportunity?" Fire Technology. 34:2 (1998), 177-187.

13. Holman, J.P. Heat Transfer, 7th Edition. New York, NY: McGraw-Hill Inc., 1990. 
14. IAEA. "Evaluation of Fire Hazard Analyses for Nuclear Power Plants." Safety Series No. 50-P-9. Vienna, Austria: International Atomic Energy Agency, 1995.

15. Jansen and Bader. "Evaluation of the Behavior of Compartment Networks During a Large Hydrocarbon Fire in a Closed Containment, Supplemental Data Report, Experiments E41.1-4 (In German)." PHDR Working Report 40.002/88. Karlsruhe, Germany: Project HDR Nuclear Center, 1989.

16. Koffel, W.E. "Life Safety Code Update." NFPA Journal. 92:2 (1998), 24.

17. Marshall, N.R. "Air Entrainment into Smoke and Hot Gases in Open Shafts." Fire Safety Journal. 10 (1986), 37-46.

18. Meacham, B.J. "Fire Safety in Nuclear Power Plants: A Performance-Based Approach." Proceedings of 3rd International Seminar on Fire Safety of Nuclear Power Plants. Müller, K. editor. Karlsruhe, Germany: Project HDR, Nuclear Center Karlsruhe, 1993. 7-15.

19. Meacham, B.J. "Assessment of the Technological Requirements for the Realization of Performance-Based Fire Safety Design in the United States." NIST-GCR-98-763. Gaithersburg, MD: National Institute of Standards and Technology, 1998a.

20. Meacham, B.J. "The Evolution of Performance-Based Codes and Fire Safety Design Methods." NIST-GCR-98-761. Gaithersburg, MD: National Institute of Standards and Technology, 1998b.

21. McGrattan, K.B., H.R. Baum, and R.G. Rehm. "Large Eddy Simulations of Smoke Movement." Fire Safety Journal. 30:2 (1998), 161-178.

22. Mowrer, F.W., R.B. Williamson, and F.L. Fisher. "Analysis of the Early Fire Development at the MGM Grand Hotel." Proceedings of the Second International Conference on Fire Research and Engineering. Almand, K.H. editor. Gaithersburg, Maryland. 1997. 49-60.

23. NFPA. "Fire Protection for Light Water Nuclear Power Plants." ANSI/NFPA 803. Quincy, MA: National Fire Protection Association, 1993.

24. Peterson J. and Y. Bayazitoglu. "Measurements of Velocity and Turbulence in Vertical and Axisymmetric Isothermal and Buoyant Jets." Journal of Heat Transfer. 114 (1992), 135-142.

25. Reese, S. "Performance-Based Design 101." NFPA Journal. 93:4 (1999), 82-85.

26. Stroup, D.W. "Using Fire Models to Establish Performance Requirements for the Design of Buildings." Report of the 13th Joint Panel Meeting of the U.S./Japan Government

Cooperative Program on Natural Resources. Beall, K.A. editor. Gaithersburg, MD: National Institute of Standards and Technology, 1996. 
27. Wigley, T.M.L. "A Numerical Analysis of the Effect of Condensation on Plume Rise." Journal of Applied Meteorology. 14 (1975), 1105-1109.

28. Wilkinson, D. "Avoidance of Seawater Intrusion into Ports of Ocean Outfalls." Journal of Hydraulic Engineering. 114:2 (1988), 218-228.

29. Bader and Jansen. "Experiments with Hydrocarbon Fire in the Dome Region of the HDR Under Natural Ventilation Conditions, Supplemental Data Report, Test Group BRA, Experiments T52.1-4 (In German)." PHDR Working Report 5.115/87. Karlsruhe, Germany: Project HDR Nuclear Center, 1987.

30. Grimm, R. "Evaluation of Fire Behavior in a Compartment Network in a Closed Containment, Supplemental Design Report, Test Group BRA, Test Group T51.21-T51.24 (In German)." PHDR Working Report 5.078/86. Karlsruhe, Germany: Project HDR Nuclear Center, May 1986.

31. Karwat, H., K. Müller, and U. Max. "CEC Standard Problem: Prediction of Effects Caused by a Cable Fire Experiment Within the HDR Containment, Task Specification.” EUR. 1992.

32. Karwat, H., K. Müller, and U. Max. "CEC Standard Problem: Prediction of Effects Caused by a Cable Fire Experiment Within the HDR Containment, Final Comparison Report." EUR 15648 EN. 1993.

33. Max, U., K. Müller, et al. "Behavior of Oil Fires in a Closed Subsystem With Ventilation Connected and Variable Door Opening, Quick Look Report, Experiments E41.5-10 (In German)." PHDR Technical Report 122-93. Karlsruhe, Germany: Project HDR Nuclear Center, 1993.

34. Müller, K.,H. Wegener, and R. Dobbernack. "Evaluation of Fire Behavior in a Compartment Network in a Closed Containment, Supplemental Design Report, Test Group BRA, Experiments T51.2." PHDR Working Report 5.069/86. Karlsruhe, Germany: Project HDR Nuclear Center, 1986.

35. Müller, K. and L. Valencia. "Experiments with Hydrocarbon Fire in the Dome Region of the HDR Under Natural Ventilation Conditions, Design Report, Test Group BRA, Experiments T52.1/T52.2 (In German).” PHDR Working Report 5.075/86. Karlsruhe, Germany: Project HDR Nuclear Center, 1987.

36. Müller, K., et al. "Evaluation of the Behavior of Compartment Networks During a Large Hydrocarbon Fire in a Closed Containment, Design Report, Test Group: Large Hydrocarbon Fire, Experiments E41.1-5 (In German).” PHDR Working Report 40.002/88. Karlsruhe, Germany: Project HDR Nuclear Center, 1988. 
37. Müller, K. and R. Volk. "Behavior of Oil Fires in a Closed Subsystem With Ventilation Connected and Variable Door Opening, Design Report, Experiments E41.5-10 (In German)." PHDR Working Report 40.024/90. Karlsruhe, Germany: Project HDR Nuclear Center, 1990.

38. Müller, K., H. Wegener, L. and Löhr. "Cable Fire in an Enclosed Multi-Compartment Arrangement in the Containment, Design Report, Experiments E42 (In German)." PHDR Working Report 40.03/91. Karlsruhe, Germany: Project HDR Nuclear Center, 1992.

39. Rautenberg, J., R. Dobbernack, K. Müller, and R. Volk. "Evaluation of Fire Behavior in a Compartment Network in a Closed Containment, Final Evaluation Report, Test Group BRA, Experiments T51.1; T51.2 (In German)". PHDR Working Report 82-91. Karlsruhe, Germany: Project HDR Nuclear Center, 1991.

40. Rautenberg, J., R. Dobbernack, K. Müller, and R. Volk. "Evaluation of the Behavior of Compartment Networks During a Large Hydrocarbon Fire in a Closed Containment, Final Evaluation Report, Experiments E41.1-4 (In German).” PHDR Technical Report 103-92. Karlsruhe, Germany: Project HDR Nuclear Center, 1992.

41. Rautenberg, J., U. Max, K. Müller, and J. Hans. "Cable Fire in an Enclosed Multi-Compartment Arrangement in the Containment, Final Evaluation Report, Experiments E42 (In German).” PHDR Technical Report 123-94. Karlsruhe, Germany: Project HDR Nuclear Center, 1994.

42. Rockett, J. "HDR Reactor Containment Fire Modeling with BR12.” VTT Publication 113. Finland: Fire Technology Laboratory. Technical Research Centre of Finland (VTT), 1992.

43. Tenhumberg. "Evaluation of Fire Behavior in Compartment Networks inc a Closed Containment, Data Report, Test Group BRA-E, Experiments T51.11-T51.15, Test Period 01/24 - 02/01/1985 (In German).” PHDR Working Report 5.43/85. . Karlsruhe, Germany: Project HDR Nuclear Center, 1985.

44. Tenhumberg. "Evaluation of Fire Behavior in Compartment Networks in a Closed Containment, Data Report, Test Group BRA-E, Experiments T51.16-T51.19, Test Period 06/25 - 07/01/85 (In German).” PHDR Working Report 5.055/85. Karlsruhe, Germany: Project HDR Nuclear Center, 1985.

45. Wenzel, H., L. Grimm, and L. Löhr. "Evaluation of the Behavior of Compartment Networks During a Large Hydrocarbon Fire in a Closed Containment, Data Report, Experiments E41.1-4 (In German).” PHDR Working Report 40.008/89. Karlsruhe, Germany: Project HDR Nuclear Center, 1989.

46. Wenzel, H., L. Grimm. and L. Löhr. "Behavior of Oil Fires in a Closed Subsystem With Ventilation Connected and Variable Door Opening, Data Report, Experiments E41.5-10 (In German).” PHDR Working Report 40.026/90. Vol. 1 and 2. Karlsruhe, Germany: Project HDR Nuclear Center, 1990. 
47. Wenzel, H. and L. Löhr. "Cable Fire in an Enclosed Multi-Compartment Arrangement in the Containment, Data Report, Experiments E42, Time Period 01/21-02/18/92 (In German)."

PHDR Working Report 40.042/91. Karlsruhe, Germany: Project HDR Nuclear Center, 1992. 